NATIONAL LABORATORY

MANAGED BY UT-BATTELLE

FOR THE DEPARTMENT OF ENERGY

\title{
Analysis of the IFA-432, IFA-597, and IFA-597mox Fuel Performance Experiments by FRAPCON-3.4
}

\section{July 2012}

Prepared by Aaron M. Phillippe Larry Ott Kevin Clarno Jim Banfield

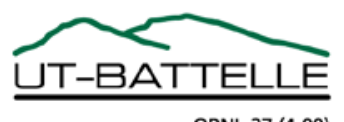

ORNL-27 (4-00) 


\section{DOCUMENT AVAILABILITY}

Reports produced after January 1, 1996, are generally available free via the U.S. Department of Energy (DOE) Information Bridge.

Web site http://www.osti.gov/bridge

Reports produced before January 1, 1996, may be purchased by members of the public from the following source.

National Technical Information Service

5285 Port Royal Road

Springfield, VA 22161

Telephone 703-605-6000 (1-800-553-6847)

TDD 703-487-4639

Fax 703-605-6900

E-mail info@ntis.gov

Web site http://www.ntis.gov/support/ordernowabout.htm

Reports are available to DOE employees, DOE contractors, Energy Technology Data Exchange (ETDE) representatives, and International Nuclear Information System (INIS) representatives from the following source.

Office of Scientific and Technical Information

P.O. Box 62

Oak Ridge, TN 37831

Telephone 865-576-8401

Fax 865-576-5728

E-mail reports@osti.gov

Web site http://www.osti.gov/contact.html

This report was prepared as an account of work sponsored by an agency of the United States Government. Neither the United States Government nor any agency thereof, nor any of their employees, makes any warranty, express or implied, or assumes any legal liability or responsibility for the accuracy, completeness, or usefulness of any information, apparatus, product, or process disclosed, or represents that its use would not infringe privately owned rights. Reference herein to any specific commercial product, process, or service by trade name, trademark, manufacturer, or otherwise, does not necessarily constitute or imply its endorsement, recommendation, or favoring by the United States Government or any agency thereof. The views and opinions of authors expressed herein do not necessarily state or reflect those of the United States Government or any agency thereof. 
Reactor and Nuclear Systems Division

\title{
ANALYSIS OF THE IFA-432, IFA-597, AND IFA-597mox FUEL PERFORMANCE EXPERIMENTS BY FRAPCON-3.4
}

\author{
Aaron M. Phillippe* \\ Larry Ott \\ Kevin Clarno \\ Jim Banfield
}

\footnotetext{
*Master's degree student, Department of Nuclear Engineering, University of Tennessee-Knoxville
}

Date Published: July 2012

\author{
Prepared by \\ OAK RIDGE NATIONAL LABORATORY \\ P.O. Box 2008 \\ Oak Ridge, Tennessee 37831-6285 \\ managed by \\ UT-BATTELLE, LLC \\ for the \\ U.S. DEPARTMENT OF ENERGY \\ under contract DE-AC05-00OR22725
}





\section{CONTENTS}

Page

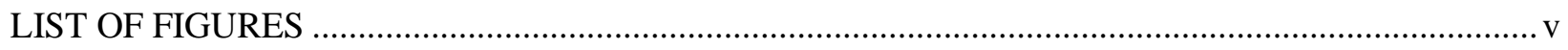

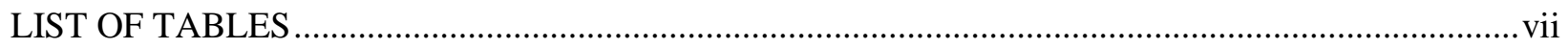

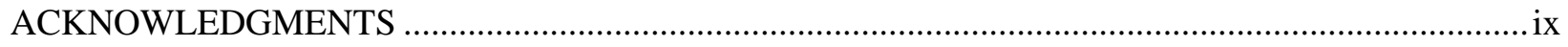

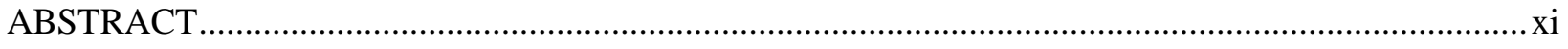

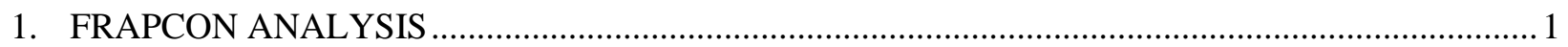

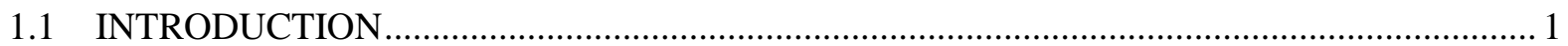

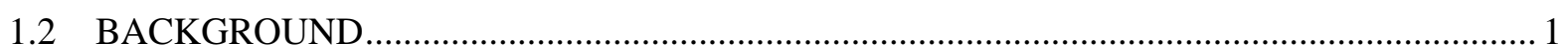

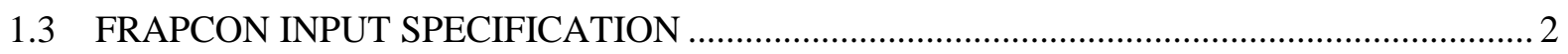

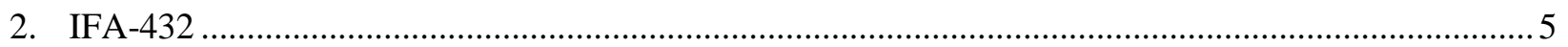

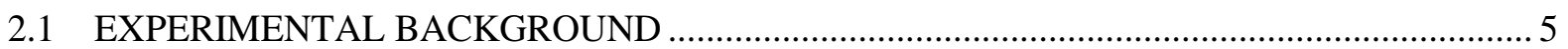

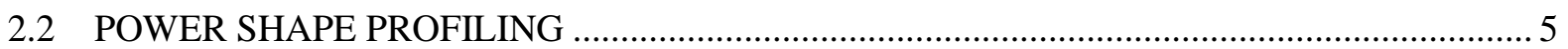

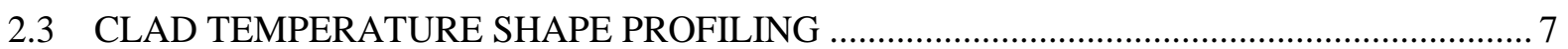

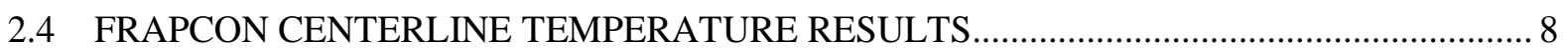

2.5 FRAPCON AXIAL CLAD ELONGATION ................................................................... 9

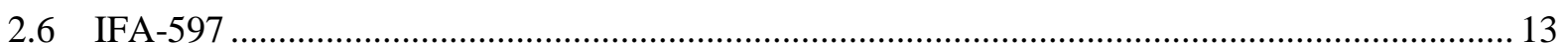

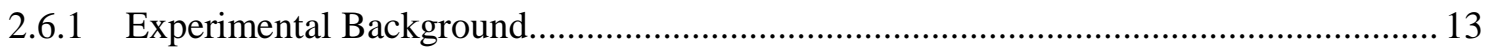

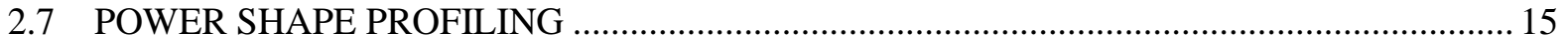

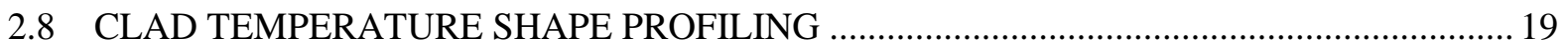

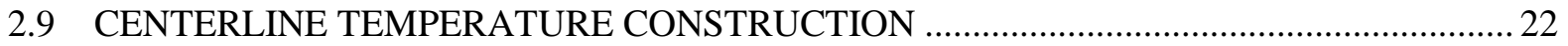

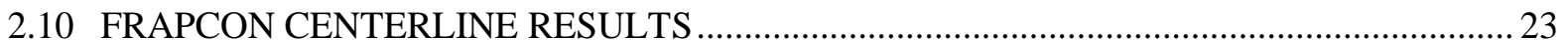

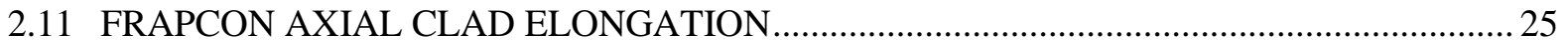

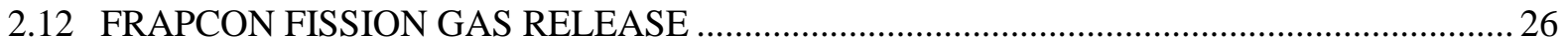

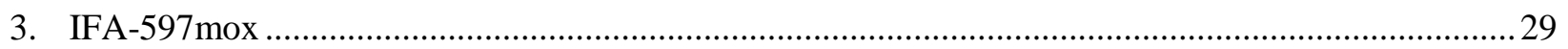

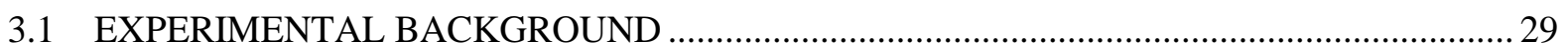

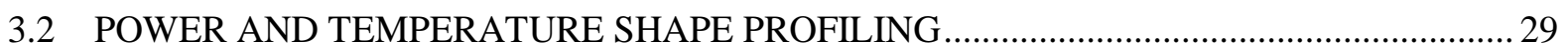

3.3 FRAPCON CENTERLINE TEMPERATURE RESULTS ..................................................... 31

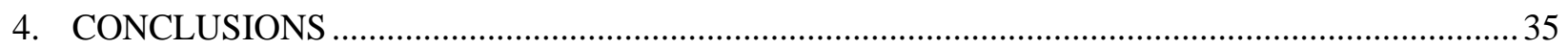

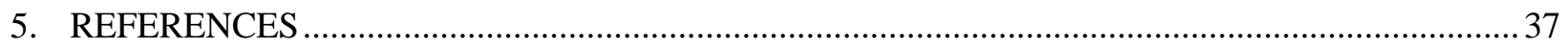

APPENDIX A : FRAPCON INPUT PARAMETERS …….................................................................

APPENDIX B : FRAPCON RESULTS FOR IFA-432 ….......................................................... B-1

APPENDIX C : FRAPCON RESULTS FOR IFA-597mox................................................................ 



\section{LIST OF FIGURES}

Page

Fig. 1. Upper and lower region power peaking factors for IFA-432 Rod 1...................................... 6

Fig. 2. Sorted PPFs for fitting IFA-432 Rod 1 power profile. ...................................................... 7

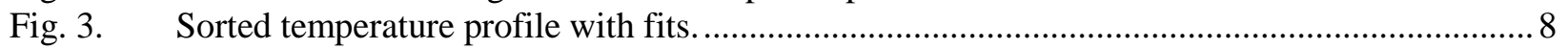

Fig. 4. Example fits of Legendre fit coefficients. ...................................................................... 16

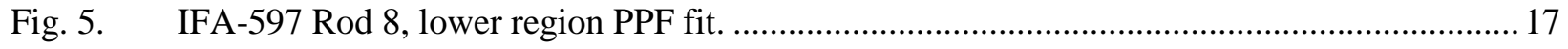

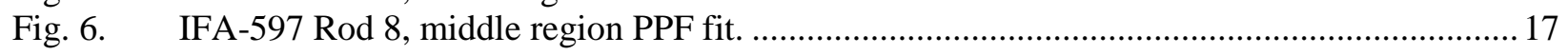

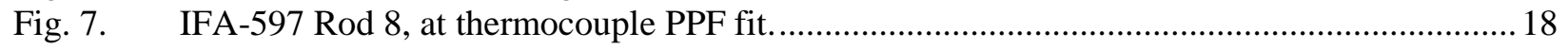

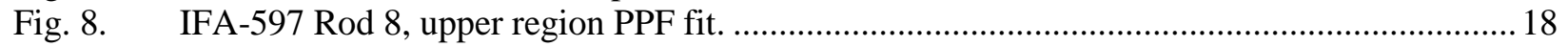

Fig. 9. IFA-597 Rod 8 axial power peaking profiles. ................................................................... 19

Fig. 10. IFA-597 Rod 8, lower region surface temperature fit.................................................... 20

Fig. 11. IFA-597 Rod 8, middle region surface temperature fit. ..................................................... 20

Fig. 12. IFA-597 Rod 8, at thermocouple surface temperature fit...................................................... 21

Fig. 13. IFA-597 Rod 8, upper region surface temperature fit.......................................................... 21

Fig. 14. IFA-597 Rod 8, axial surface temperature profiles. .............................................................. 22

Fig. 15. IFA-597 Rod 8 centerline temperature as a function of LHGR and BU. .............................. 23

Fig. 16. IFA-597 Rod 8 centerline temperature comparison with constant surface temperature............24

Fig. 17. IFA-597 Rod 8 centerline temperature comparison with specified surface temperature........... 24

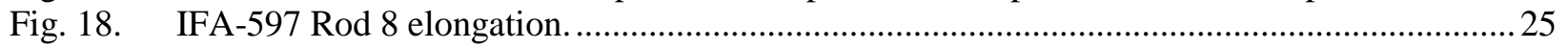

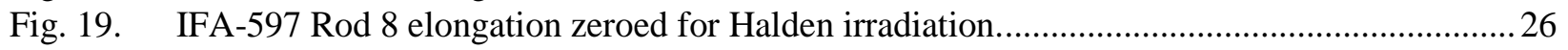

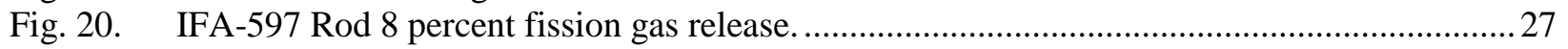

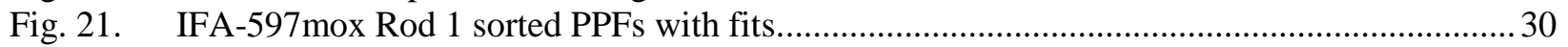

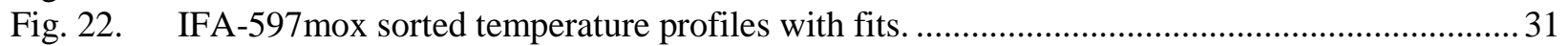

Fig. 23. IFA-597mox Rod 1 centerline temperature comparison (PowerOnly)................................... 32

Fig. 24. IFA-597mox Rod 2 centerline temperature comparison (PowerTemp) .................................. 32

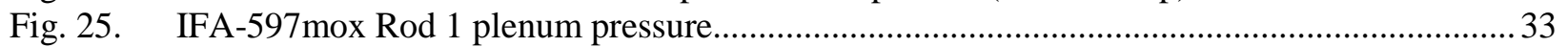

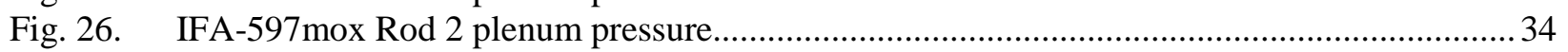

Fig. B.1. IFA-432 Rod 1 FRAPCON centerline temperature results. .............................................. B-1

Fig. B.2. IFA-432 Rod 1 FRAPCON centerline temperature error....................................................... B-1

Fig. B.3. IFA-432 Rod 2 FRAPCON centerline temperature results. ............................................... B-2

Fig. B.4. IFA-432 Rod 2 FRAPCON centerline temperature error..................................................

Fig. B.5. IFA-432 Rod 3 FRAPCON centerline temperature results. ...............................................

Fig. B.6. IFA-432 Rod 3 FRAPCON centerline temperature error......................................................

Fig. B.7. IFA-432 Rod 5 FRAPCON centerline temperature results. ............................................... B-4

Fig. B.8. IFA-432 Rod 5 FRAPCON centerline temperature error.....................................................

Fig. B.9. IFA-432 Rod 6 FRAPCON centerline temperature results. ..............................................

Fig. B.10. IFA-432 Rod 6 FRAPCON centerline temperature results.................................................. B-5

Fig. C.1. IFA-597mox Rod 1 centerline temperature comparison using Halden

Fig. C.2. IFA-597mox Rod 2 centerline temperature comparison using Halden correlation

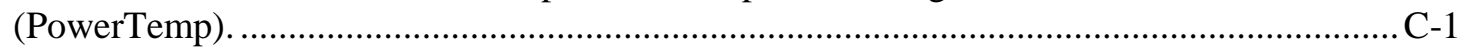

Fig. C.3. IFA-597mox Rod 1 plenum pressure comparison using Halden correlation............................2

Fig. C.4. IFA-597mox Rod 2 plenum pressure comparison using Halden correlation.......................... C-2

Fig. C.5. Differences between experimental and predicted centerline temperatures for IFA-597mox,

Rods 1 and 2, given two different conductivity models. ....................................................... -3 



\section{LIST OF TABLES}

Page

Table 1. IFA-432 experiment pellet specifications ........................................................................ 5

Table 2. Comparison of results when modeling annular and solid pellets, and specifying a temperature profile 9

Table 3. BU ranges for clad elongation data given in experimental database.................................... 13

Table 4. IFA-597 pellet and clad geometry specifications for Rod 8................................................. 14

Table 5. IFA-579MOX pellet and clad geometry specifications........................................................29

Table A.1. FRAPCON input parameters for IFA-432 Rods 1 and 2 ....................................................

Table A.2. FRAPCON input parameters for IFA-432 Rods 3 and 5....................................................

Table A.3. FRAPCON input parameters for IFA-432 Rod 6 ............................................................

Table A.4. FRAPCON input parameters for IFA-597 Rod 8 ...............................................................5

Table A.5. FRAPCON input parameters for IFA-597mox Rods 1 and 2 …........................................6 



\section{ACKNOWLEDGMENTS}

The authors wish to acknowledge Ivan Maldonado for his support of this work. The careful reviews of Jeff Powers and Dean Wang are also gratefully acknowledged. This work was funded by the Nuclear Energy Advanced Modeling and Simulation (NEAMS) program of the US Department of Energy, Office of Nuclear Energy. 



\begin{abstract}
Validation of advanced nuclear fuel modeling tools requires careful comparison with reliable experimental benchmark data. A comparison to industry-accepted codes, that are well characterized, and regulatory codes is also a useful evaluation tool. In this report, an independent validation of the FRAPCON-3.4 fuel performance code is conducted with respect to three experimental benchmarks, IFA432, IFA-597, and IFA-597mox. FRAPCON was found to most accurately model the mox rods, to within $2 \%$ of the experimental data, depending on the simulation parameters. The IFA-432 and IFA-597 rods were modeled with FRAPCON predicting centerline temperatures different, on average, by 21 percent.
\end{abstract}





\section{FRAPCON ANALYSIS}

\subsection{INTRODUCTION}

This report was developed to document an independent validation of the FRAPCON fuel performance code for three leading experimental benchmarks as a baseline analysis for the future validation, and codeto-code comparison, of advanced nuclear fuel modeling and simulation tools. Analysis of the Halden irradiation experiments ${ }^{1}$ IFA $^{*}-432$, IFA-597, and IFA-597mox was conducted using FRAPCON-3.4 (here after referred to as FRAPCON). ${ }^{2}$ Each experiment was chosen for a specific purpose:

- IFA-432: nominal operating conditions with traditional uranium oxide $\left(\mathrm{UO}_{2}\right)$ fuel and cladding with various gap thicknesses to measure gap heat transfer and pellet-clad interaction

- IFA-597: nominal operating conditions and power ramps with traditional fuel and cladding irradiated to a high burnup (BU), to measure effects of high-BU fuel

- IFA-597mox: nominal operating conditions and power ramps with mixed oxide (MOX) fuel and $\mathrm{Zr}-4$ cladding to measure the performance of MOX fuel

\subsection{BACKGROUND}

FRAPCON is a nuclear fuel performance code developed for the US Nuclear Regulatory Commission by Pacific Northwest National Laboratory for calculating steady-state fuel behavior up to a high BU of $62 \mathrm{GWd} / \mathrm{MTU}$ (gigawatt-days per metric tonne of initial uranium). The code uses a single-channel coolant enthalpy rise model, a one dimensional (1-D) finite-difference heat conduction model, and variable radial mesh spacing to accommodate the power peaking at the pellet edge at high $\mathrm{BU} .^{3}$

Analysis of the Halden irradiation experiments IFA-432, IFA-597, and IFA-597mox was conducted using FRAPCON. This version of FRAPCON has been validated for Boiling Water Reactors (BWRs), Pressurized Water Reactors (PWRs), and Heavy Water Boiling Reactors (HBWRs). The fuel types that have been validated with the code include $\mathrm{UO}_{2}$, $\mathrm{MOX}$, urania-gadolinia $\left(\mathrm{UO}_{2}+\mathrm{Gd}_{2} \mathrm{O}_{3}\right)$, and $\mathrm{UO}_{2}$ with Integral Fuel Burnable Absorber (IFBA) coatings of zirconia-borate $\left(\mathrm{ZrB}_{2}\right)$. The cladding types include Zircaloy-2, Zircaloy-4, M5 ${ }^{\odot}$, and ZIRLO ${ }^{\odot}$. FRAPCON can predict axial and radial temperature distributions in the fuel and cladding, rod internal pressure, fission gas released from the fuel, cladding axial and hoop strain, and corrosion and hydriding of the cladding. ${ }^{3}$

As a steady-state analysis code, FRAPCON is applicable to situations in which problem boundary conditions and source terms (power) change at a "sufficiently slow rate.” The following are the other major limitations of the code (acknowledged by the developers): ${ }^{3}$

1. "The current code is limited to modeling fuel consisting of $\mathrm{UO}_{2}$ pellets in zirconium alloy cladding with a gas gap under light and heavy water reactor conditions. Input parameters for other fuel forms (such as metal fuels) and other reactor coolants (such as liquid sodium) are not available, and model changes may be required to accommodate them. The code has been validated up to a rod-average burnup of $62 \mathrm{GWd} / \mathrm{MTU}$, although the code should give reasonable predictions for burnup beyond this level. Also, the code is not validated beyond the fuel or cladding melting temperature. If melting of the fuel or the cladding occurs, the code will stop” (page 1.2).

\footnotetext{
*Instrumented Fuel Assembly.
} 
2. "The thermal models of the code are based on steady-state conditions and equations, and calculate only radial heat flow. This assumption is valid for modeling a typical fuel rod (i.e., with a large length-to-diameter ratio). Similarly, the gas release models are based on steady-state and slow power ramp data and do not reflect release rates expected for rapid power changes. Therefore, time steps should be no less than 0.1 day but no greater than 50 days" (page 1.2). Additionally, "changes in local LHGR of greater than $1.5 \mathrm{~kW} / \mathrm{ft}$ per time step are not recommended” (page A.10).

3. “Only small cladding deformations ( $<5$ percent strain) are meaningfully calculated by FRAPCON-3. All of the thermal and mechanics modeling assumes an axisymmetric fuel rod with no axial constraints. These assumptions are reasonable for modeling an LWR fuel rod," under normal operation, but cannot be used for rod or assembly bowing analysis (page 1.2).

4. “The code's ability to predict cladding strains resulting from pellet-cladding mechanical interaction has been assessed against power ramp data. FRAPCON-3 has been found to slightly over predict cladding strain up to a burnup of about $45 \mathrm{GWd} / \mathrm{MTU}$. The limited high burnup data suggests that FRAPCON-3 may under predict the cladding strain during power ramps at high burnup (i.e., $>55 \mathrm{GWd} / \mathrm{MTU}$ ) for hold times greater than 30 minutes” (page 1.2).

Fuel pellet and cladding deformations in FRAPCON are modeled with the following assumptions:

1. incremental theory of plasticity

2. Prandtl-Reuss flow rule

3. isotropic work-hardening

4. thin-wall cladding

5. no slippage between clad and fuel interface when fuel and clad are in contact

6. bending strains and stresses are negligible

7. axisymmetric loading and deformation of cladding

8. thermal expansion, swelling, and densification are the only sources for fuel deformation

9. no resistance to expansion of fuel

10. no creep deformation of fuel

11. isotropic fuel properties

(Page 2.33) ${ }^{3}$

In general, when the pellets are in contact with the cladding, then the axial extension of the pellets is directly transferred to the clad, due to the assumption of no slippage. Otherwise, clad axial extension is dependent on temperature changes, creep, and irradiation-induced creep.

\subsection{FRAPCON INPUT SPECIFICATION}

The input parameters to model an experiment in FRAPCON include specifics on the rod design and fabrication, in-core operational characteristics, and modeling approximations. The specifics of the rod design and operational characteristics are unique for each experiment, but many of the inputs, such as modeling approximations, are identical for all simulations.

A listing of the variables and an explanation of their values are presented as follows. Only the variables that were not defaults in the models of the experiments are described. 


\begin{tabular}{|c|c|}
\hline $\begin{array}{lr}\text { Rod and Reactor Design } \\
\text { iplant } \\
\text { pitch } \\
\text { dco } \\
\text { thkcld } \\
\text { reactor type index } \\
\text { thkgap } \\
\text { totl } \\
\text { cpl } & \text { rod pitch (in.) } \\
\text { dspg } & \text { cladding thickness (in.) } \\
\text { dspgw } & \text { pellet-clad radial gap (in.) } \\
\text { vs } & \text { total active fuel length (ft.) } \\
\text { hplt } & \text { cold plenum length (in.) } \\
\text { rc } & \text { plenum spring outer diameter (in.) } \\
\text { hdish } & \text { spring wire diameter (in.) } \\
\text { dishsd } & \text { \# of spring turns } \\
& \text { pellet height (in.) } \\
& \text { inner pellet radius (in.) } \\
& \text { depth of pellet dish (in.) } \\
\text { pellet end-dish shoulder width } \\
\text { pellet OR minus dish radius (in.) }\end{array}$ & $\begin{array}{lr}\text { Dynamic Reactor Operating Conditions } \\
\text { p2 } & \text { coolant pressure (psia) } \\
\text { tw } & \text { coolant inlet temp. }\left({ }^{\circ} \mathrm{F}\right) \\
\text { go } & \text { mass flux of coolant }\left(\mathrm{lb} / \mathrm{hr}-\mathrm{ft}^{2}\right) \\
\text { flux } & \text { reactor flux } \\
& \text { (neutrons } / \mathrm{m}^{2} \text {-s-(W/g of fuel)) } \\
\text { im } & \text { number of time steps } \\
\text { Problem Time } & \text { cumulative time after step } \\
\text { qmpy } & \text { (days) } \\
\text { iq } & \text { linear heat generation rate (kW/ft.) } \\
\text { x } & \text { index for power shape } \\
\text { qf } & \text { power shape axial locations (in.) } \\
\text { jst } & \text { LHGR pwr. peak profile } \\
\text { ifixedtsurf } & \text { index for axial temp. distribution } \\
\text { xt } & \text { temp. shape axial locations } \\
\text { cladt } & \text { temp profile }\left({ }^{\circ} \mathrm{F}\right) \\
\text { jstsurftemp } & \text { temp prof. \# per time step }\end{array}$ \\
\hline $\begin{array}{lr}\text { Modeling Approximations } \\
\text { nr } \\
\text { ngasr } \\
\text { na } & \text { \# radial bounds in pellet } \\
\text { nunits } & \text { \# rings in pellet for gas calc. } \\
\text { icor } & \text { units flag } \\
\text { im } & \text { crud model flag } \\
\text { nsp } & \text { number of time steps } \\
\text { jn } & \text { system time dep. Index } \\
\text { jnsurftemp } & \text { \# of axial power shapes } \\
\text { crdt } & \text { \# of clad temperature shapes } \\
\end{array}$ & $\begin{array}{lr}\text { Pellet Composition } & \\
\text { enrch } & \text { U-235 enrichment } \\
\text { imox } & \text { fuel type flag } \\
\text { moxtype } & \text { MOX grade flag } \\
\text { comp } & \text { wt. \% of Pu in fuel } \\
\text { enrpu39 } & \text { wt. \% of Pu-239 of Pu } \\
\text { enrpu40 } & \text { wt. \% of Pu-240 of Pu } \\
\text { enrpu41 } & \text { wt. \% of Pu-241 of Pu } \\
\text { enrpu42 } & \text { wt. \% of Pu-242 of Pu } \\
\text { fotmtl } & \text { atomic ratio of O to U }\end{array}$ \\
\hline $\begin{array}{l}\text { Cladding Fabrication } \\
\text { roughc } \\
\begin{array}{r}\text { clad surface mean } \\
\text { roughness (in.) }\end{array}\end{array}$ & $\begin{array}{lc}\text { Fill Gas Composition } & \\
\text { fgpav } & \text { initial fill gas pressure } \\
\text { idxgas } & \text { fill gas type index } \\
\end{array}$ \\
\hline $\begin{array}{lr}\text { Pellet Fabrication } \\
\text { den } \\
\begin{array}{r}\text { as fabricated Fuel density } \\
\text { (\% Theoretical Density) }\end{array} \\
\text { roughf } \\
\text { rsntr } \\
\\
\text { tsint } & \text { pellet surface mean roughness (in.) } \\
& \text { density increase }\left(\mathrm{kg} / \mathrm{m}^{3}\right)\end{array}$ & $\begin{array}{lr}\text { Cladding Composition } & \\
& \\
\text { icm } & \text { cladding type flag } \\
\text { zr2vintage } & \mathrm{Zr}-2 \text { age flag }\end{array}$ \\
\hline
\end{tabular}

There are certain limits built into FRAPCON that restrict how much information can be provided. The most significant limitations related to this study are for controlling the number of time steps $(\mathrm{im} \leq 400)$ and the number of temperature and power distributions $(\leq 20)$. The limitation on the number of axial regions $(\mathrm{na} \leq 40)$ restricts the level of refinement possible for specification of the source-terms and boundary conditions (jn and insurftemp, respectively). Because the Halden reactor is a HBWR, it is 
proper in FRAPCON for these particular experiments to provide the clad (oxide) surface temperature axially, rather than compute the axial coolant temperature profile and convective heat transfer based on the coolant mass flux and inlet temperature. 


\section{IFA-432}

\subsection{EXPERIMENTAL BACKGROUND}

The Nuclear Energy Agency (NEA) database includes data for five rods from the IFA-432 experiments. Rods 1 and 6 were in the Halden reactor ${ }^{4}$ from December 1975 to June 1982 and irradiated to an average $\mathrm{BU}$ of $34 \mathrm{GWd} / \mathrm{MT}\left(\mathrm{UO}_{2}\right.$ ) (gigawatt-days per metric tonne of uranium oxide). ${ }^{*}$ Rods 2, 3, and 5 were in the reactor from December 1975 to May 1984 to an average BU of $44 \mathrm{GWd} / \mathrm{MT}\left(\mathrm{UO}_{2}\right)$. Online temperature measurements were taken via centerline thermocouples in each rod. Plenum pressure data was obtained via pressure transducers for the majority of the rod irradiation periods. Additionally, rod elongation measurements were also obtained throughout the irradiation. The NEA database did not contain the information for Rod 4 with the other rods, so no analysis was done for it.

The specific data provided in the NEA database for this experiment include (throughout the irradiation) rod-average power, clad temperature, and linear heat generation rate (LHGR) at three locations on the rods, and the lower thermocouple temperature measurements. For transient analysis, the database contains thermocouple data for Rods 1, 3, and 5 after two reactor scrams (rapid shutdown). In addition, the database contains several collections of processed data, including (1) the thermocouple measurements as a function of BU at given values of LHGR, (2) thermocouple measurements as a function of LHGR at given values of BU, and clad elongation for Rods 2, 3, and 6 as a function of (3) power and (4) BU. The generic pellet and clad information for the experiments is given in Table 1 . Specific experimental inputs for each rod are given in Appendix A.

Table 1. IFA-432 experiment pellet specifications ${ }^{5}$

\begin{tabular}{lccccc}
\hline & \multicolumn{7}{c}{ Rod } \\
\cline { 2 - 6 } \multicolumn{1}{c}{ Dimension } & $\mathbf{1}$ & $\mathbf{2}$ & $\mathbf{3}$ & $\mathbf{5}$ & $\mathbf{6}$ \\
\hline Pellet Density, g/cc & 10.42 & 10.42 & 10.42 & 10.09 & 10.42 \\
Pellet Length, mm & 13.00 & 13.00 & 13.00 & 13.00 & 13.00 \\
Pellet Outer Diameter, mm & 10.67 & 10.52 & 10.85 & 10.67 & 10.67 \\
Clad ID, mm & 10.9 & 10.9 & 10.9 & 10.9 & 10.9 \\
Clad OD, mm & 12.78 & 12.78 & 12.78 & 12.78 & 12.78 \\
Gap Diameter, mm & 0.23 & 0.38 & 0.08 & 0.23 & 0.23 \\
Fuel Height, mm & 577.9 & 571.0 & 570.2 & 578.7 & 576.2 \\
\hline
\end{tabular}

Note: Pellets 1, 2, and 3 were stable pellets with grain sizes between 2-70 microns. Pellet 5 was a stable pellet with grain sizes between 5-20 microns. Pellet 6 was an unstable pellet with a grain size of 2-10 microns. Unstable pellet was taken to mean that in some way, via the pellet manufacturing process, the pellet behaves in an atypical fashion. This behavior could be in fission gas release, swelling, etc.

\subsection{POWER SHAPE PROFILING}

The experimental results contain estimates of the power (in LHGR) at three axial locations (top thermocouple, middle, and bottom thermocouple) for each of $~ 250$ time steps, for which thermocouple readings were taken. This database of power as a function of time is used to define the source terms in the FRAPCON simulation for all 250 time steps. However (as noted previously), FRAPCON is limited to

${ }^{*} M T U=238 / 270 * M T\left(U O_{2}\right)$ 
specifying no more than 20 axial power shapes during a simulation. Therefore, a fit was required to group similar profiles together into 20 approximate shapes such that the 250 time steps could be assigned to one of them. FRAPCON separates the power profile into two data arrays - one containing the average LHGR for a given time step and the other containing the axial power peaking factors for a given time step. This allows for the ability to group power profiles independent of their magnitude.

The methodology used in this project to group the datasets into approximate shapes is described as follows.

First, all time steps in which the average LHGR was zero were removed from the database. The power peaking factors (PPFs) were calculated at the top, middle, and bottom of the rods based on the provided LHGR in the databases, following Equation (1), where " $i$ " is the axial node and ALHGR is the average LHGR for the rod. It was found that the middle PPF was $1.000 \pm 0.004$ for all five rods, thus approximately linear, rather than quadratic (as expected from three points).

$$
P P F_{i}=\frac{L H G R_{i}}{A L H G R}
$$

Figure 1 shows an example plot of the top and bottom PPFs for Rod 1. The PPFs were sorted by the value of the bottom PPF, and then by the top PPF. This resulted in two curves that could be given a visual fit, as shown in

Fig. 2. Twenty steps were applied in combination to the top and bottom PPFs, whereby short sections of the curve were given a single value for the top PPF and the bottom PPF. The curve was divided based on its steepness, where a steeper slope meant a smaller set of points given a single value. The single value was assigned as the average value of the set. Once a set of 20 unique profiles was created, the data was resorted by time step, as required for input to FRAPCON.

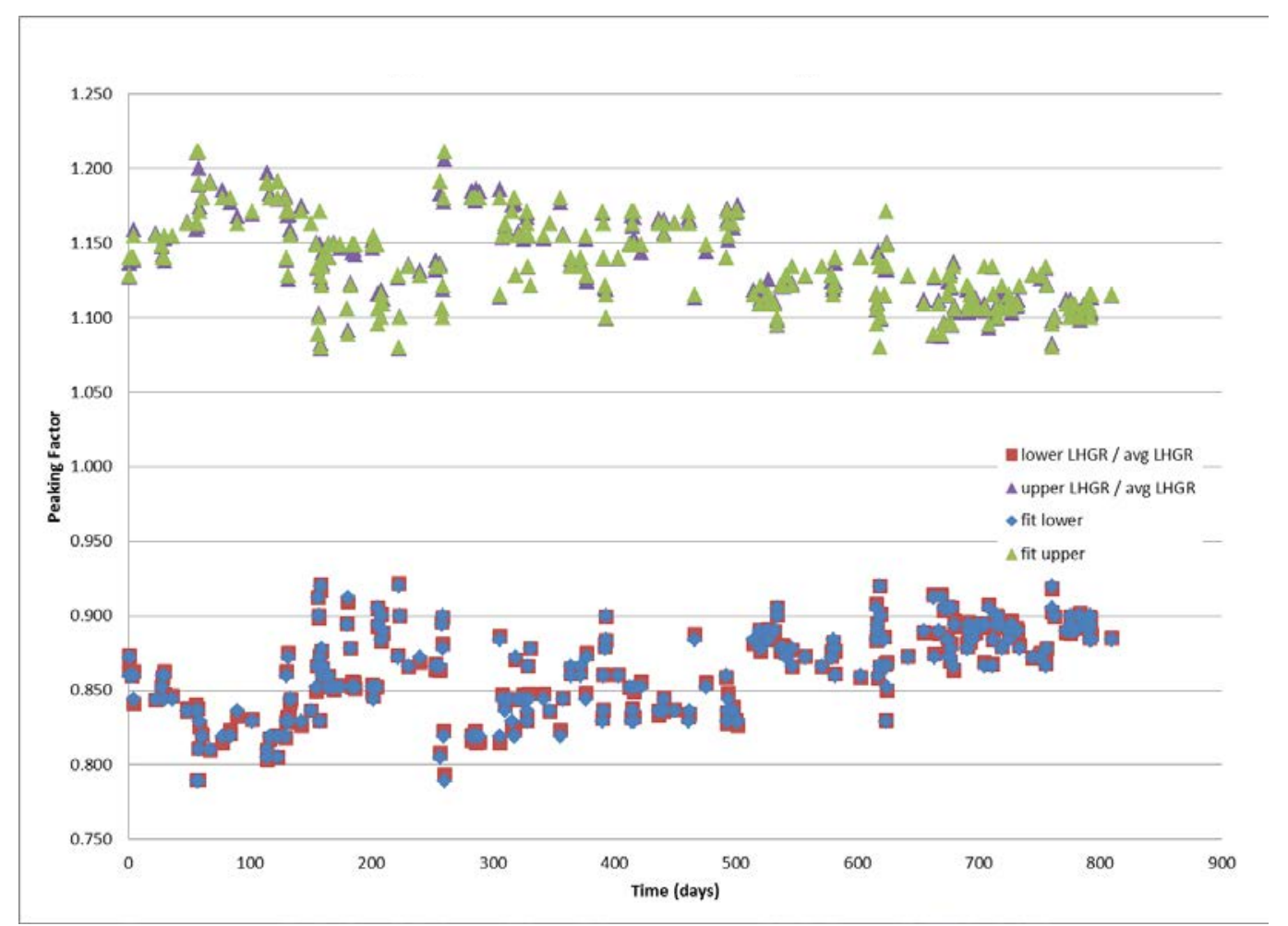

Fig. 1. Upper and lower region power peaking factors for IFA-432 Rod 1. 


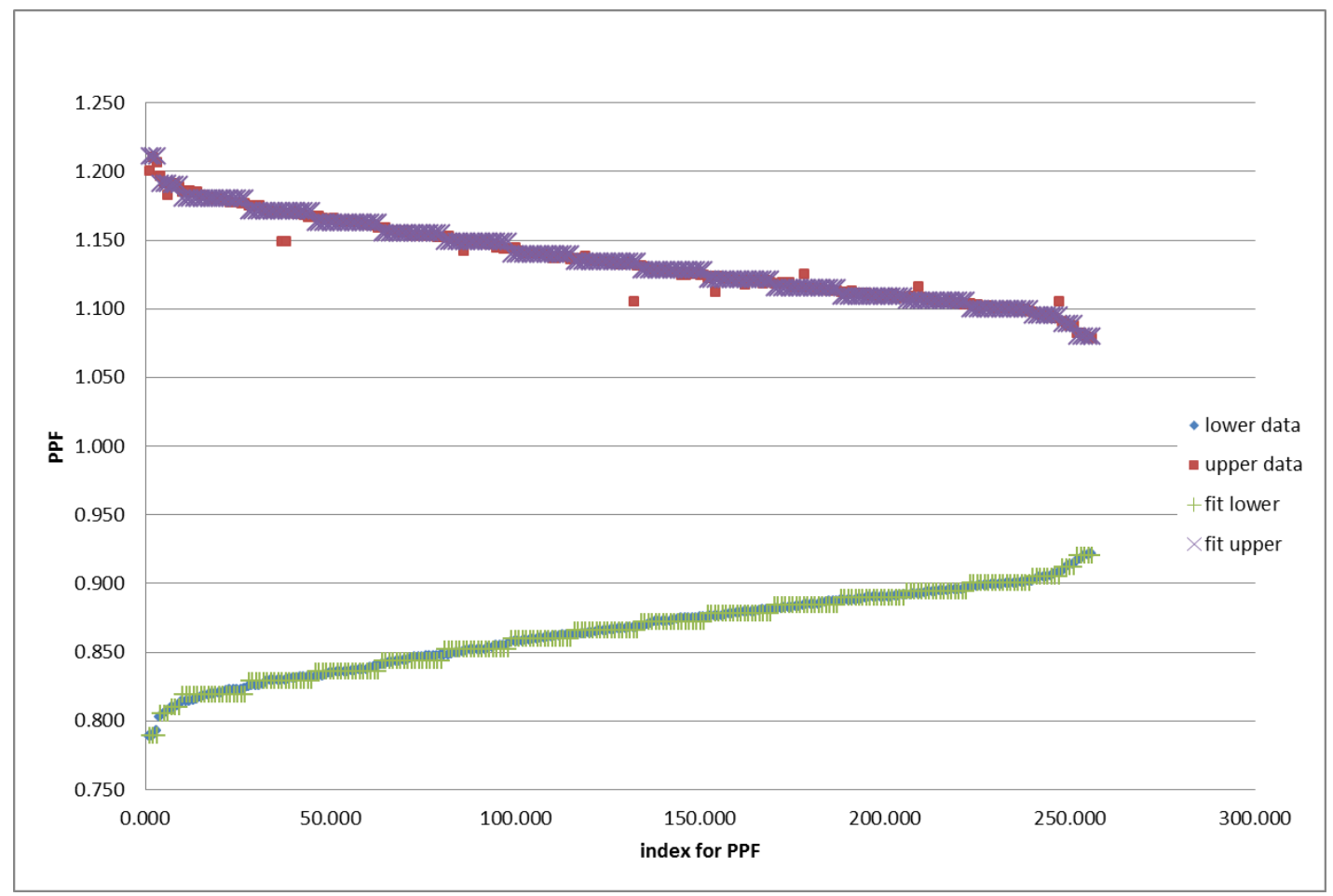

Fig. 2. Sorted PPFs for fitting IFA-432 Rod 1 power profile.

FRAPCON requires a power profile to be defined with elevations that include each end of the rod; therefore, linear interpolation and extrapolation were used to obtain the end-of-rod PPFs. (The thermocouple locations were approximately $7 \mathrm{~cm}$ from the rod ends.) Because of the linearity of power profiles for the IFA-432 experiments, FRAPCON's interpolation does not produce any unusual power shapes.

\subsection{CLAD TEMPERATURE SHAPE PROFILING}

Clad surface temperatures are also provided with the experimental database at the same point locations ( $7 \mathrm{~cm}$ from the ends and the middle) as the LHGRs. These values can be input into the FRAPCON model for thermal boundary conditions. The same limitation on the number of profiles exists for inputting the axial temperature profile, and the same general procedure is used to generate the 20 temperature profiles. However, the actual temperatures are used in the temperature profiles.

Again, a linear temperature profile is assumed, because there is no additional information provided from the experiment. This allows the cladding (oxide) outer surface temperature to be extrapolated to each end of the fuel rod. As can be seen in Fig. 3, the temperatures at the top portion of the rod are relatively accurate but not as well behaved as the power profile. It should be noted that the clad surface temperatures have a $10^{\circ} \mathrm{C}$ range, from 246 to $256^{\circ} \mathrm{C}$. The surface temperature data was generated with the use of the JENS-LOTTES Correlation. ${ }^{6}$ 


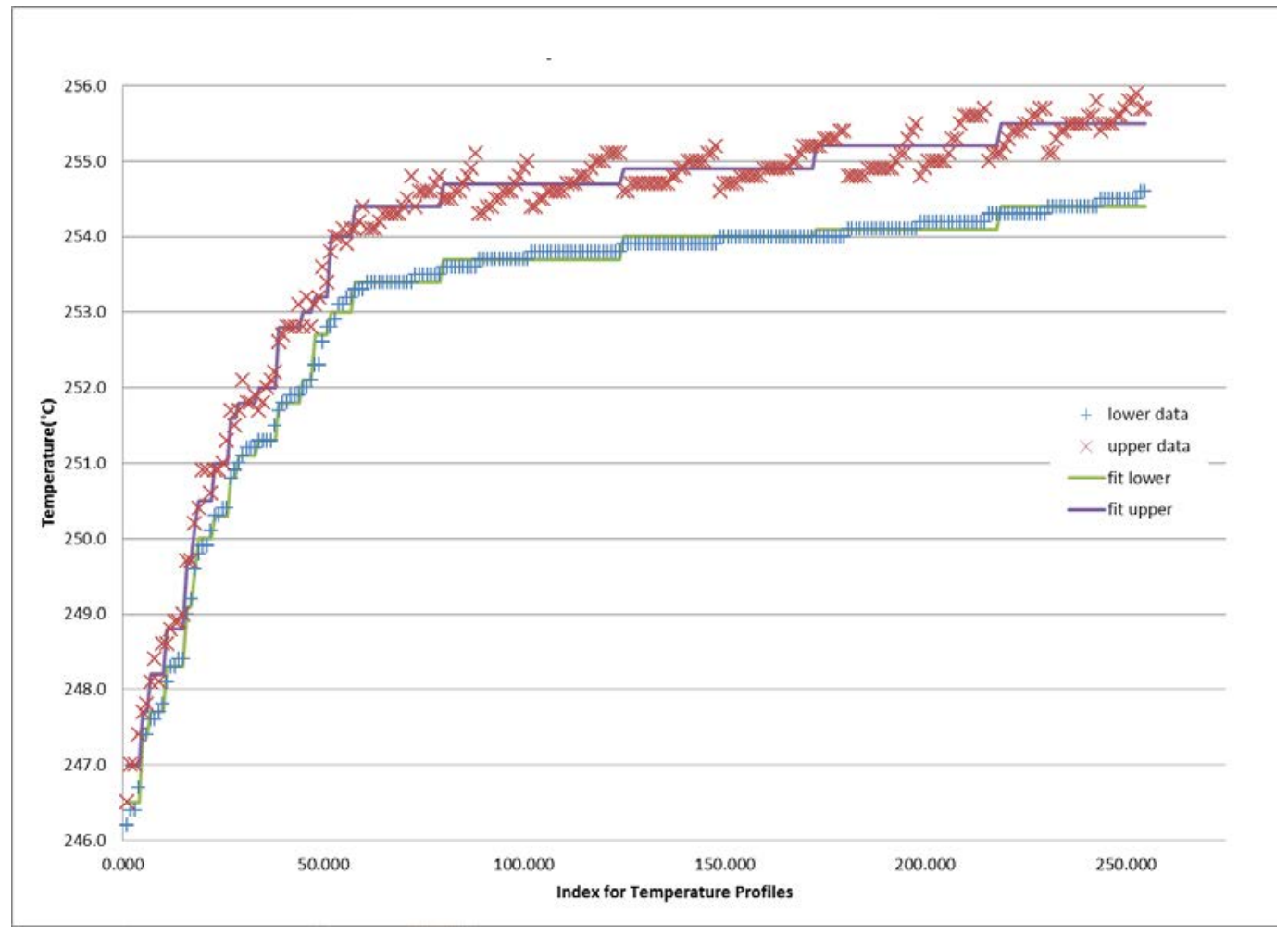

Fig. 3. Sorted temperature profile with fits.

\subsection{FRAPCON CENTERLINE TEMPERATURE RESULTS}

The following sections detail the outcome of the FRAPCON simulations for Rods 1, 2, 3, 5, and 6 of the IFA-432 experiments.

The experimental setup contained solid $\mathrm{UO}_{2}$ pellets in the rod centers, with annular pellets at each end (top and bottom $7 \mathrm{~cm}$ ) to allow for the insertion of thermocouples. However, FRAPCON limits the user to the specification of only one type of fuel pellet—annular or solid. Therefore, four analyses were performed on each rod.

1. all solid fuel using the power profile, but a fixed (axially) outer clad surface temperature

2. all annular fuel using the power profile, but a fixed (axially) outer clad surface temperature

3. all solid pellet-filled rod with power and temperature profile specified

4. all annular pellet-filled rod with power and temperature profile specified

The results are compiled in Appendix B, which contains the centerline temperature, calculated at the elevation of the bottom thermocouple, for each of the 20 cases.

Table 2 shows the root mean square (RMS) error, defined in Eq. (2), of each case with the experimental data. In general, the error was relatively comparable for all four cases of each experiment and the prediction is relatively insensitive to the specific choice of geometry and boundary condition approximation. 


$$
R M S E=\sqrt{\frac{\sum_{i=1}^{n}\left(x_{i}-F_{i}\right)^{2}}{n}}
$$

where

$F_{i}$ value from experiment

$x_{i}$ value from FRAPCON.

Table 2. Comparison of results when modeling annular and solid pellets, and specifying a temperature profile

\begin{tabular}{lcccc}
\hline \multicolumn{5}{c}{ RMS Error } \\
\hline & PowerOnly & PowerOnly_annular & PowerAndTemp & PowerAndTemp_annular \\
\hline Rod 1 & 72.02 & 65.90 & 72.32 & 65.12 \\
Rod 2 & 126.15 & 139.89 & 125.51 & 137.86 \\
Rod 3 & 92.35 & 77.99 & 96.46 & 75.71 \\
Rod 5 & 121.17 & 126.59 & 121.02 & 125.61 \\
Rod 6 & 61.02 & 78.67 & 59.11 & 75.69 \\
\hline
\end{tabular}

In general, FRAPCON is found to over predict the centerline temperature at the thermocouple elevation. This over prediction is generally within $200 \mathrm{~K}$. There were two exceptions; Rod 2 had an average error closer to $500 \mathrm{~K}$, while Rod 6 had an average error of $75 \mathrm{~K}$. Rod 2 had a large initial pellet-clad gap (380 $\mu \mathrm{m})$, leading to the assumption that the gap conductance model is a weak link in the code. The only significant differences between Rods 1 and 6 are the grain size of the pellets and the stability of the pellets.

\subsection{FRAPCON AXIAL CLAD ELONGATION}

Rods 2, 3, and 6 had different initial pellet-clad gap distances (380, 50, and $230 \mu \mathrm{m}$, respectively), and the experimental database contains data for the axial elongation (integrated axial strain times the initial length) of each of these rods. This data was compiled as a function of average LHGR at certain intervals of BU (rather than time); thus, several interpolations were required to compare the experimental data with the FRAPCON results.

For this analysis, the experimental elongation measurements at various BU intervals are mapped to the timescale. For each irradiation step, there is a defined average power (ALHGR) and time-step length $(\Delta t)$, and the BU is an integral of the power over the irradiation history. Therefore, it is straightforward to back out the actual time from the BU, when the irradiation history is known. However, as shown in Figs. 4, 5, and 6, the experimental data does not cover the entire time range of the irradiation.

The experimental and simulation elongation results are plotted as a function of LHGR for each of the four ranges of BU given in the database. A sixth-order polynomial fit was then performed. This can be observed in the plots of Fig. 7. This functionalized the elongation data for LHGR on discrete ranges of BU. For a given time step, both ALHGR and BU are now known. Each fit for a particular BU range was evaluated at the ALHGR for a value of elongation (Fig. 8). Then, a third-order Legendre fit (least-squares fit) was produced from the four elongation data points. This functional fit was then evaluated at the BU value of the time step. Because of the nature of the fitting process, the elongation was only evaluated in 
the range between the smallest BU in the bottom range and the largest BU in the top range. Therefore, the beginning and end of the rod histories are not evaluated for elongation.

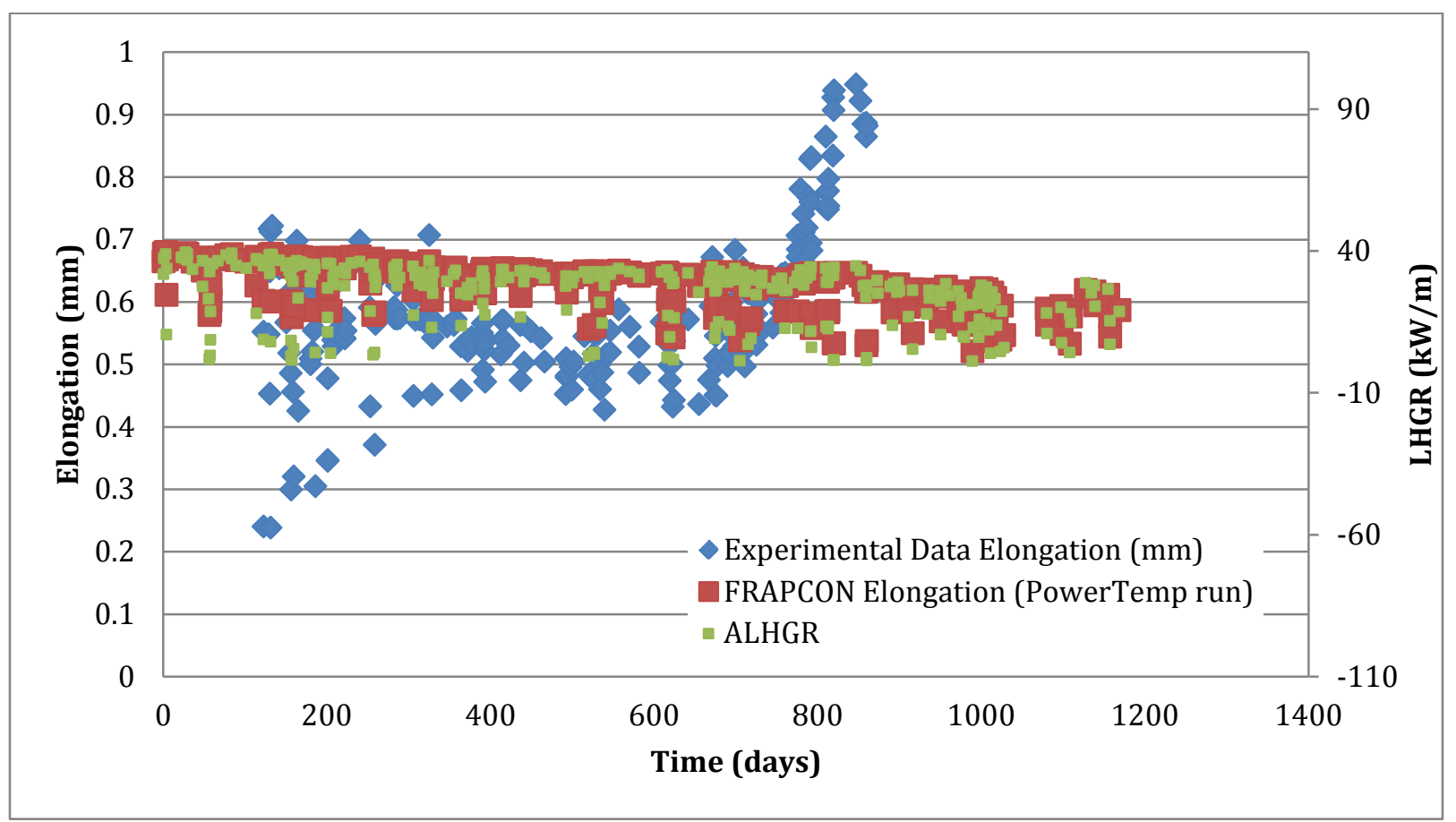

Fig. 4. Axial elongation for Rod 2 of IFA-432. 


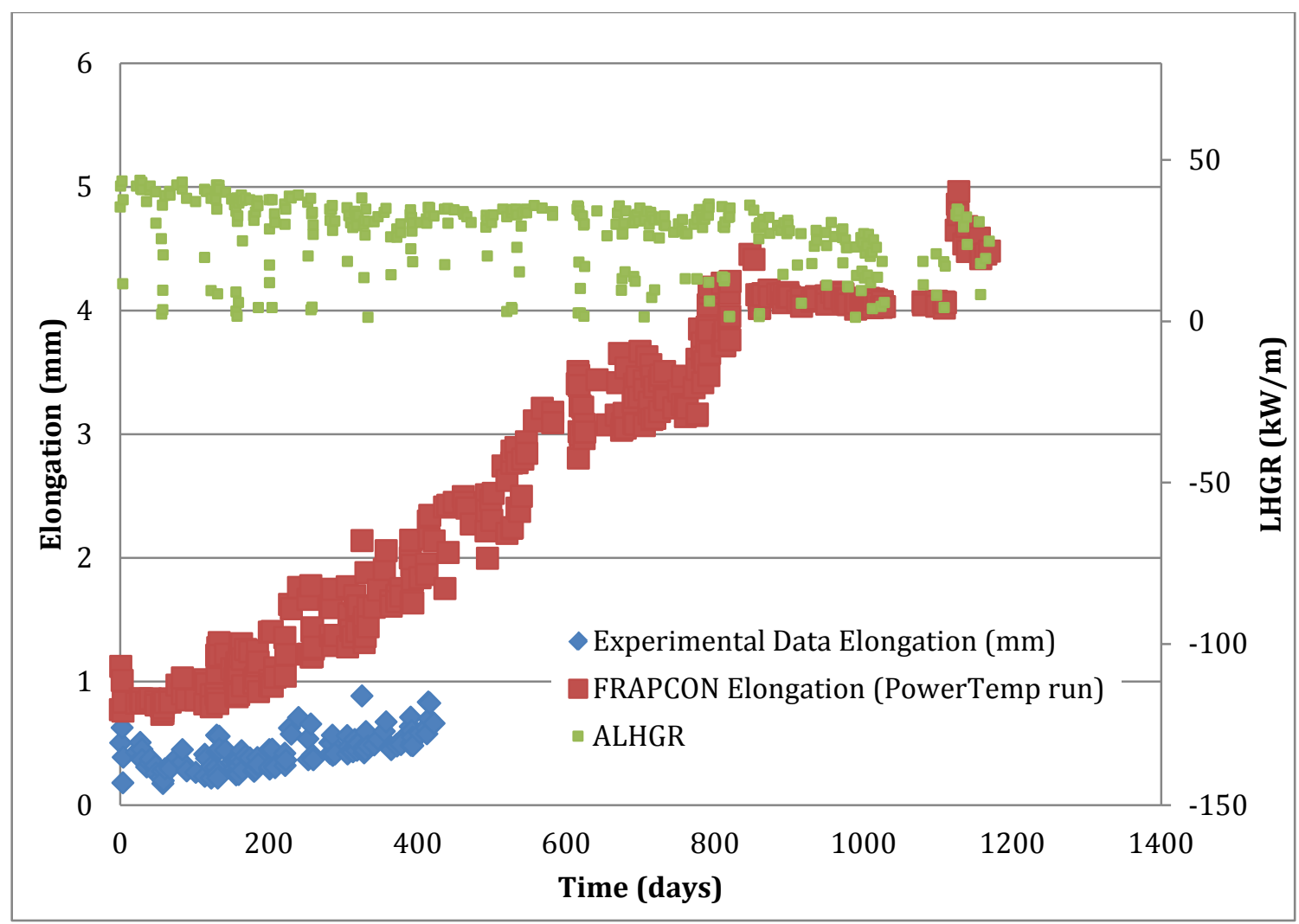

Fig. 5. Axial elongation for Rod 3 of IFA-432.

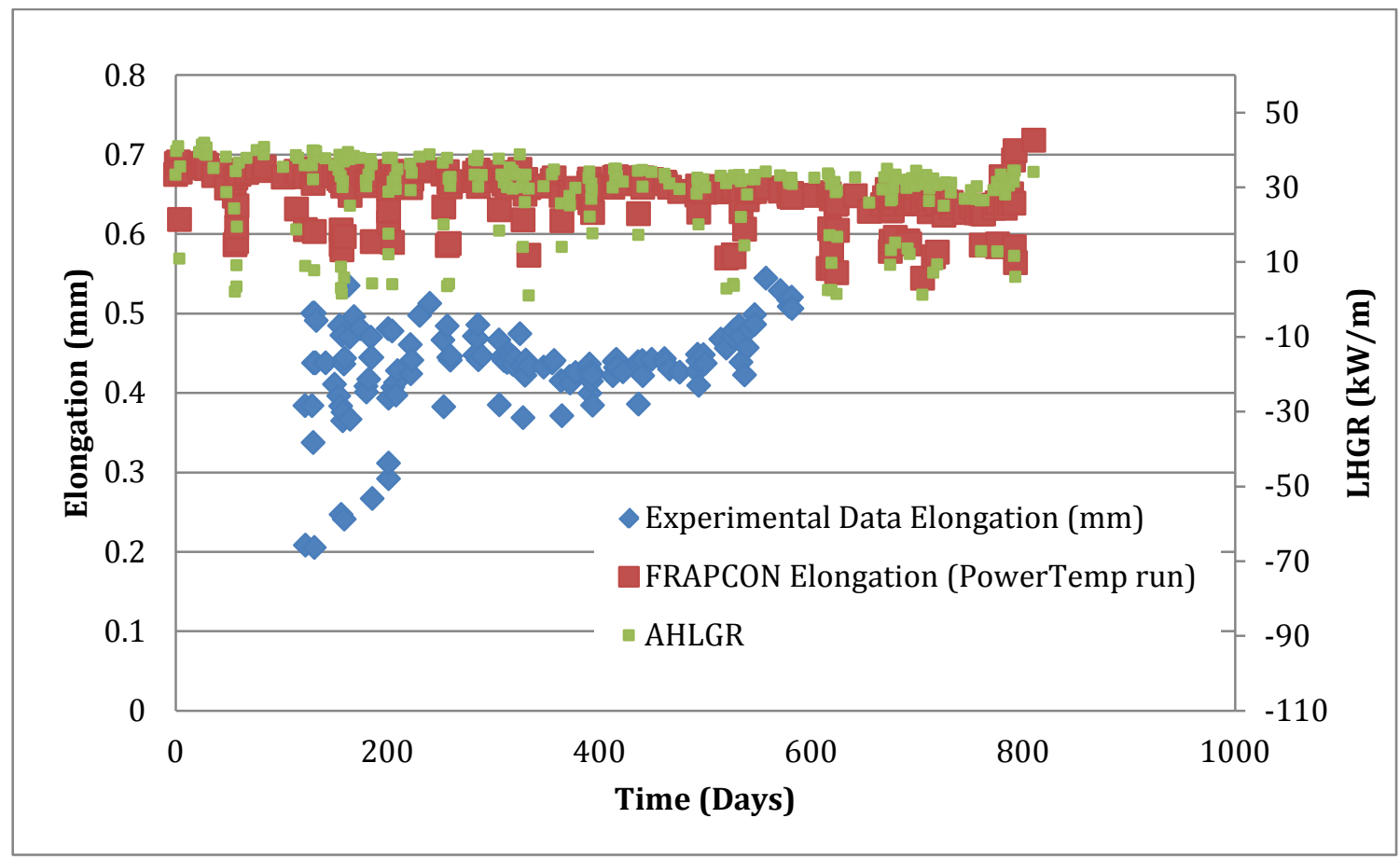

Fig. 6. Axial elongation for Rod 6 of IFA-432. 


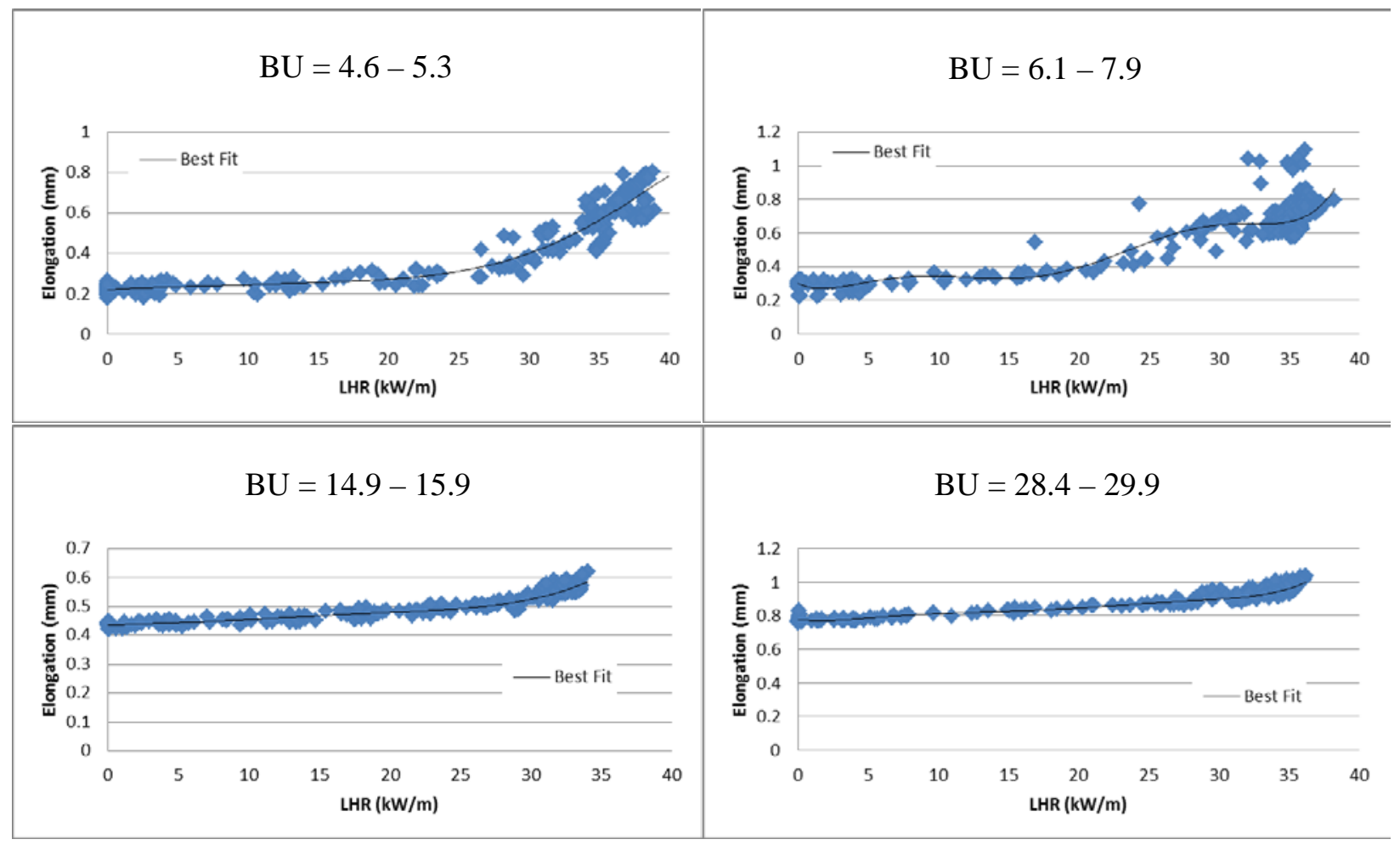

Fig. 7. Fits for elongation vs. LHGR for given ranges of BU.

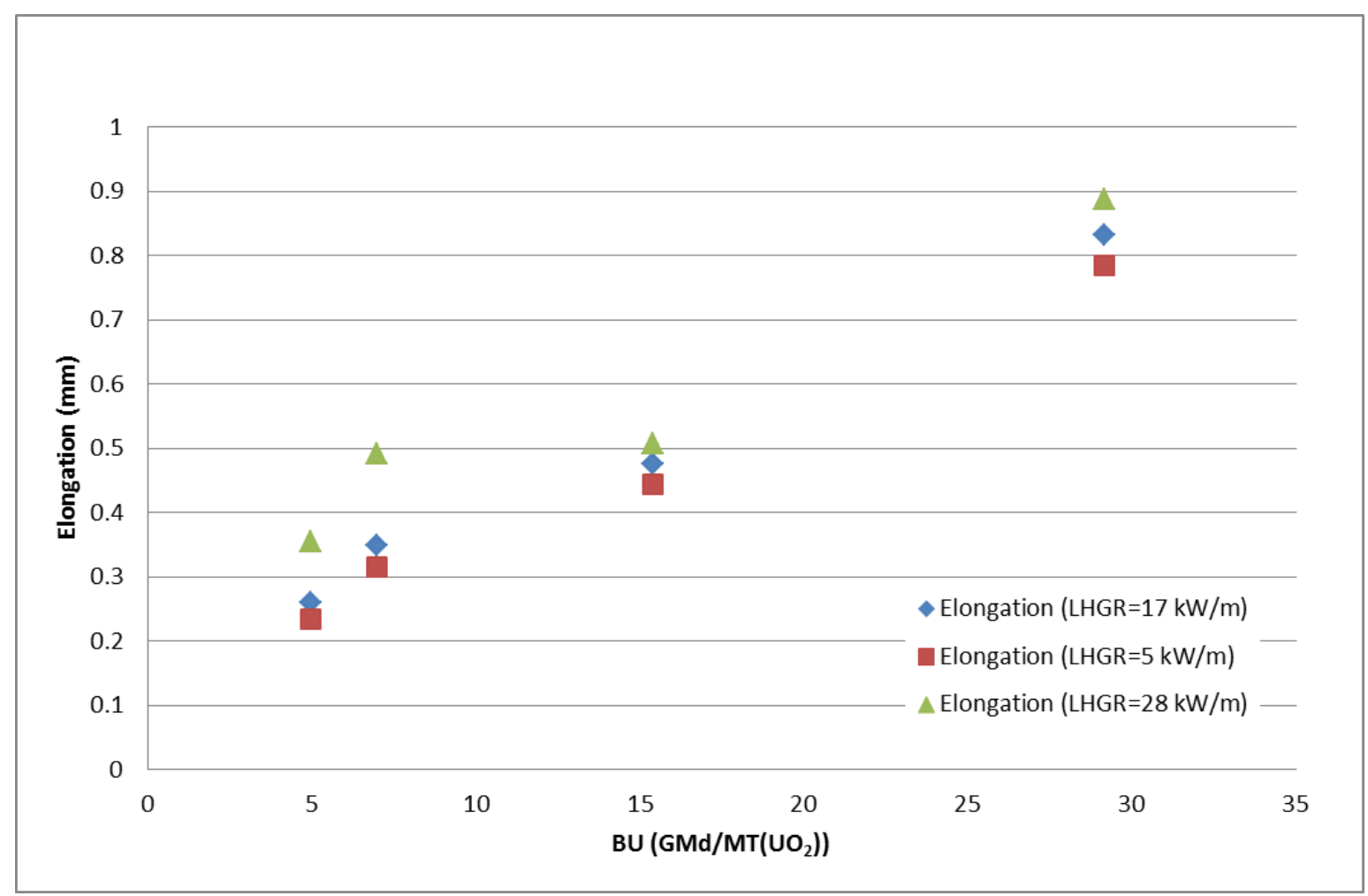

Fig. 8. Fits for elongation as a function of BU given a LHGR value. 
Table 3 shows the ranges of BU for which elongation data was provided.

Table 3. BU ranges for clad elongation data given in experimental database

\begin{tabular}{ccccc}
\hline & \multicolumn{4}{c}{ BU ranges given [GWd/MT(UO) } \\
& \multicolumn{1}{c}{$\mathbf{1}$} & $\mathbf{2}$ & $\mathbf{3}$ & $\mathbf{4}$ \\
\hline Rod 2 & $4.6-4.95$ & $6.1-7.9$ & $14.9-15.9$ & $28.4-29.9$ \\
Rod 3 & $0.02-0.624$ & $4.7-5.5$ & $10.9-11.4$ & $14.8-16.0$ \\
Rod 6 & $4.8-5.6$ & $6.3-8.3$ & $15.7-16.8$ & $20.3-21.6$ \\
\hline
\end{tabular}

Figures 4, 5, and 6 show the results of the FRAPCON analysis with the experimental data (the FRAPCON data is from the solid pellet cases in which both power and temperature were specified). The green is an overlay of the power history, which is provided to show what part thermal expansion played in rod elongation. The power axis has been scaled to make the overlay clearer.

In the case of Rod 2, the as-fabricated pellet-clad gap thickness for this rod was relatively large at $0.38 \mathrm{~mm}$. The early data showed a broad spread of elongation but generally represents the thermal expansion of the cladding. After 800 irradiation days, the clad elongates, likely due to pellet-clad mechanical contact with a large pellet-clad friction factor. FRAPCON does not appear to capture the mechanical contact. Note that for this large initial gap problem, when the pellet-clad interaction (PCI) occurs, the experiment shows that there is a significant friction component that causes the swelling fuel to pull the clad axially.

In the case of Rod 3, which had a relatively small as-fabricated pellet-clad gap (0.08 mm), FRAPCON predicts pellet-clad mechanical interaction, at the initial power ramp. This contact is predicted to exist throughout the irradiation period, such that the clad elongates throughout the experiment as the fuel pellets swell. However, the experimental data implies that, though the pellet-clad mechanical interaction occurs at the initial power ramp, the contact is limited in duration and the swelling of the fuel does not "pull" the cladding and increase the elongation.

In the case of Rod 6, which had a moderate pellet-clad gap $(0.23 \mathrm{~mm})$, FRAPCON shows clad elongation that is fairly constant with the indication that PCI might be beginning to occur at the end of the irradiation cycle. The experimental data shows some initial contact and relaxation with elongation beginning to occurring again at around 500 irradiation days, but this might coincide with the end of the irradiation as seen in FRAPCON (see the introduction of this section for transfer of elongation by BU to elongation by time issues).

\subsection{IFA-597}

\subsubsection{Experimental Background}

The IFA-597 experiments include data for three rodlets, labeled Rods 7, 8 and 9, which were all originally part of a single full-length fuel rod that was irradiated for approximately 12 years in the Ringhals 1 BWR. ${ }^{7}$ The rod was irradiated between 1980 and 1986 to a rod average BU of approximately $32 \mathrm{GWd} / \mathrm{MT}\left(\mathrm{UO}_{2}\right)$. The rod was then moved to a different bundle and irradiated from 1986 to 1992 to a final rod average BU of approximately $59 \mathrm{GWd} / \mathrm{MT}\left(\mathrm{UO}_{2}\right)$. The three rodlets were taken from the center of the rod where the average $\mathrm{BU}$ was estimated to be approximately $59 \mathrm{GWd} / \mathrm{MT}\left(\mathrm{UO}_{2}\right)$. The pellet rims 
for these rodlets were estimated to have a $\mathrm{BU}$ of $130 \mathrm{GWd} / \mathrm{MT}\left(\mathrm{UO}_{2}\right)$, which leads to the expectation of High-Burnup Structure (HBS) formation in the rim. Because of the irradiation of the fuel in multiple reactors, the Halden reactor portion of the irradiation is recorded as beginning at approximately the 66th time step, depending on the rod.

The fuel pellets in the top of Rods 8 and 9 were drilled and equipped with a thermocouple and pressure transducer. When Rod 7 was being drilled, the bit broke, and the thermocouple insertion was abandoned. Instead, the rod was equipped with a clad elongation detector. Though never specifically stated in the documentation, it appears that the original cladding was retained, and that end caps were attached straight to the old clad to close off the "new" experimental rods. The original fill gas was removed for fission gas analysis and replaced with fresh helium fill gas.

Rods 8 and 9 were loaded into the Halden reactor on July 8, 1995, and put through a few power ramps until the 29th, at which time Rod 9 failed and all the rods were removed from the reactor. In January of 1997, Rods 7 and 8 were placed in the reactor and irradiated until May of that year. They obtained approximately $2 \mathrm{GWd} / \mathrm{MT}\left(\mathrm{UO}_{2}\right)$ of further irradiation.

The experimental database contains the power history as a function of irradiation time for the three rods. This information includes BU, clad surface temperature, and LHGR at four points along the length of the rods. The database also contains data on temperature vs. power during ramp-ups for Rods 8 and 9, fission gas release (FGR) vs. BU for Rod 8, and clad elongation vs. BU for Rod 7. In addition, a post-irradiation examination (PIE) was conducted for Rod 8, which resulted in experimental data of the radial distribution of BU, porosity, and various fission products.

Because of the nature of the data provided, and the similar irradiation histories and profiles of the rods, Rod 8 is the only rod where a detailed FRAPCON run was conducted. The elongation data for Rod 7 was used in comparison with the results for Rod 8.

Table 4 provides the as-fabricated specifications for Rod 8 , which were the same for Rods 7 and 9 , except in fuel length, which varied by no more than $9 \mathrm{~mm}$. The specific source and boundary condition inputs for the FRAPCON simulation of Rod 8 are given in Appendix A.

The experimental data provided for these experiments contained many properties that were not compatible with a FRAPCON analysis. The most important were the number of time steps and unique axial power shapes, which (like IFA-432) exceeded the maximum limit set by FRAPCON. The following sections describe how these challenges were overcome.

Table 4. IFA-597 pellet and clad geometry specifications for $\operatorname{Rod} 8$

\begin{tabular}{lc}
\hline Dimension & \\
\hline Pellet OD, mm & 10.67 \\
Pellet Length, mm & 10.9 \\
Pellet Density, g/cc & 10.47 \\
Clad ID, mm & 10.65 \\
Clad OD, mm & 12.25 \\
Gap diameter, mm & 0.21 \\
Fuel length, mm & 415.8 \\
\hline
\end{tabular}




\subsection{POWER SHAPE PROFILING}

The initial step for reducing the number of time steps in the database was to remove any time steps with duration of zero, which for this experiment was only the first data point. Secondly, consecutive time steps were checked for differences of less than a day. It was determined, that in order to maximize the total number of steps to no more than 400 (the FRAPCON limit), the steps that were less than or equal to 0.01 days would be collapsed together into a single step. This resulted in a total of 386 time steps. The collapsed values were found as the average of the values in a given set of collapsing time steps.

The axial power profile was given for three equal length zones (top, middle, and bottom) and at the location of the thermocouple. The LHGR at each of these points was converted into a power peaking factor (unit-less). These factors were then weighted by the inverse of the cross-sectional area (because some regions included an annulus, which has less fuel), which normalized the peaking factors to the volumetric power generation $\left(\mathrm{W} / \mathrm{m}^{3}\right)$. The upper region, which contained the thermocouple, was weighted as if the entire region were composed of solid pellets, whereas the thermocouple location was weighted by accounting for the thermocouple hole. This was done because the length of the thermocouple hole to the total length of the region in which it resides was small.

Using the volumetric power generation defined at four specific points for each of the time steps, a set of 20 weighted power peaking factors must be developed and converted back to an un-weighted form. Therefore, for each time step, a third-order Legendre polynomial was fit to the four weighted power peaking factors. This fit followed the form shown in Eq. (3), where the $P_{n}$ terms denote nth-order Legendre polynomial. The shape terms $\left(a_{1}, a_{2}, a_{3}\right)$ were sorted as either positive, negative, or approximately zero $(<|0.01|)$, which results in 27 possible categories for the sequences of $a_{1}, a_{2}$, and $a_{3}$. However, there were many sets (of the 27) that did not have any such power shapes, so more possible shapes could be defined. Therefore, the groupings of positive and negative coefficients were further sorted into two groups, each based on whether or not a given value was in the top or bottom half of the range of the parameter for a given fit sequence (large or small, positive or negative value). This results in a net of 108 total possible combinations for a sequence of fits. For example, each coefficient can fall into one of five categories (large negative, small negative, approximately zero, small positive, large positive). The width of the approximately zero range $(<\mid$ width|) was adjusted such that the total number of combinations of fit parameters that resulted was equal to 20 (width $=0.01$ ). The fits falling in specific categories were then averaged together, including the zeroth-order coefficient, resulting in 20 sets of $\bar{a}_{0}, \bar{a}_{1}, \bar{a}_{2}, \bar{a}_{3}$.

$$
y=a_{0}+a_{1} P_{1}+a_{2} P_{2}+a_{3} P_{3}
$$

Figure 9 shows examples for the averaging of two sets of coefficients. The left image shows an example where the profiles of six time steps were grouped together. The bottom image shows an example where only two profiles fit into the sorting categories. In both cases, the line denotes the average value that was used for each $a_{1}, a_{2}, a_{3}$.

Using the average fit coefficients and the corresponding Legendre polynomials, a function of the axial power peaking factors is constructed. This function was evaluated at 18 axial points, including both ends of the rod. FRAPCON does a linear interpolation between the given values for the power, but this is a minor consideration because of the quantity of data points used in the input deck.

Figures 5, 6, 7, 8, and 9 show the fits of the axial power peaking at the locations where data was given in the database. Also shown are the power profiles generated with the fits. 

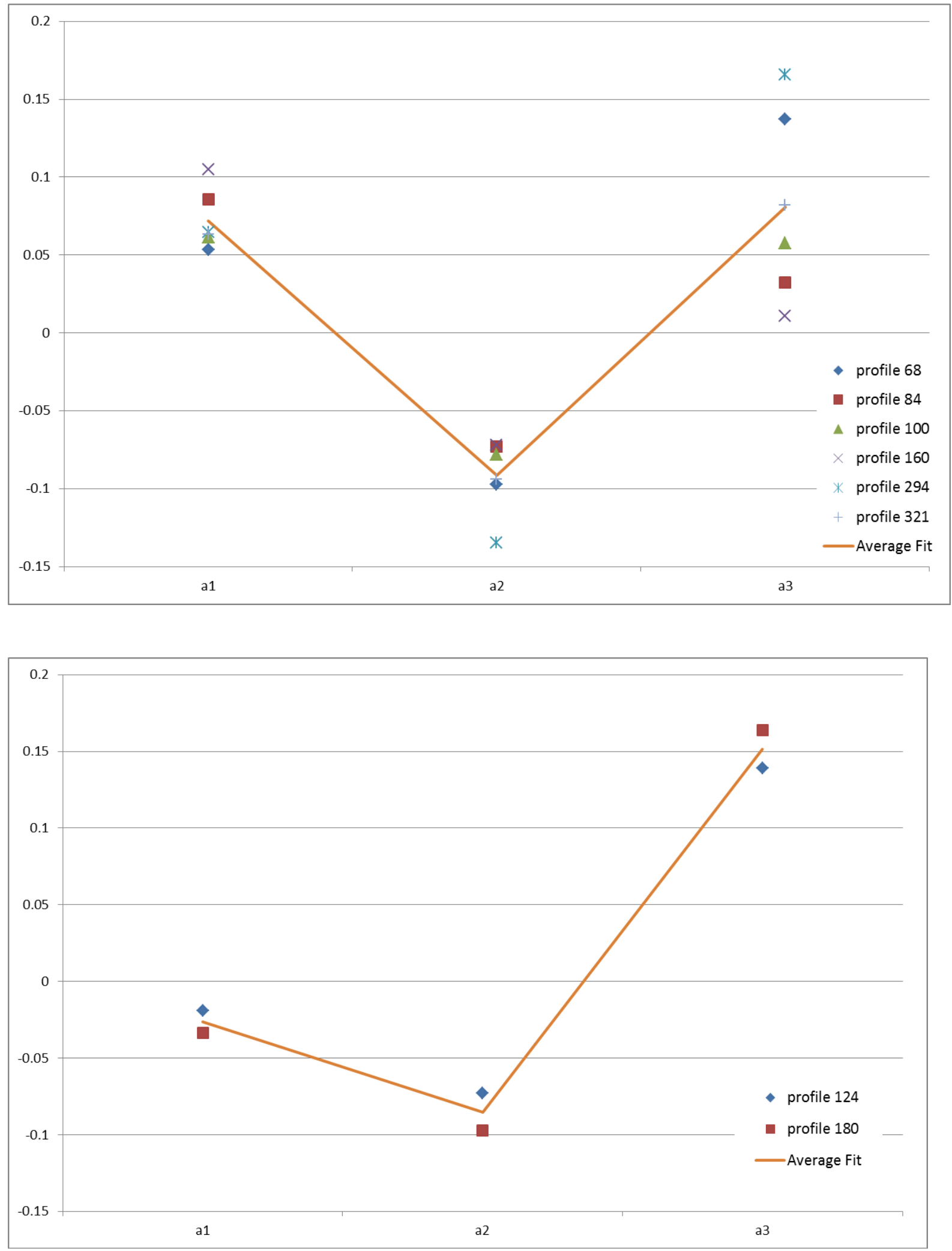

Fig. 4. Example fits of Legendre fit coefficients. 


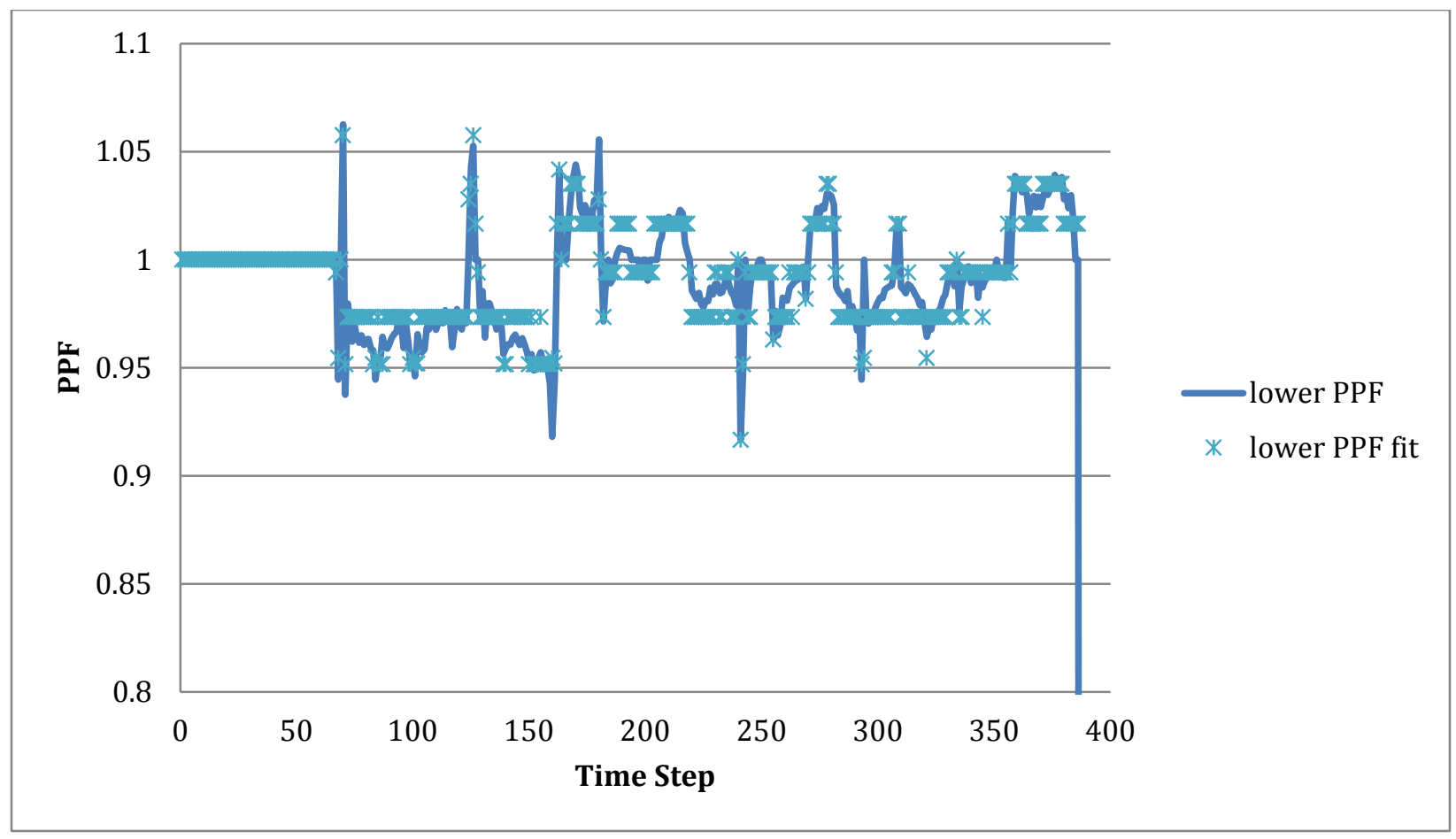

Fig. 5. IFA-597 Rod 8, lower region PPF fit.

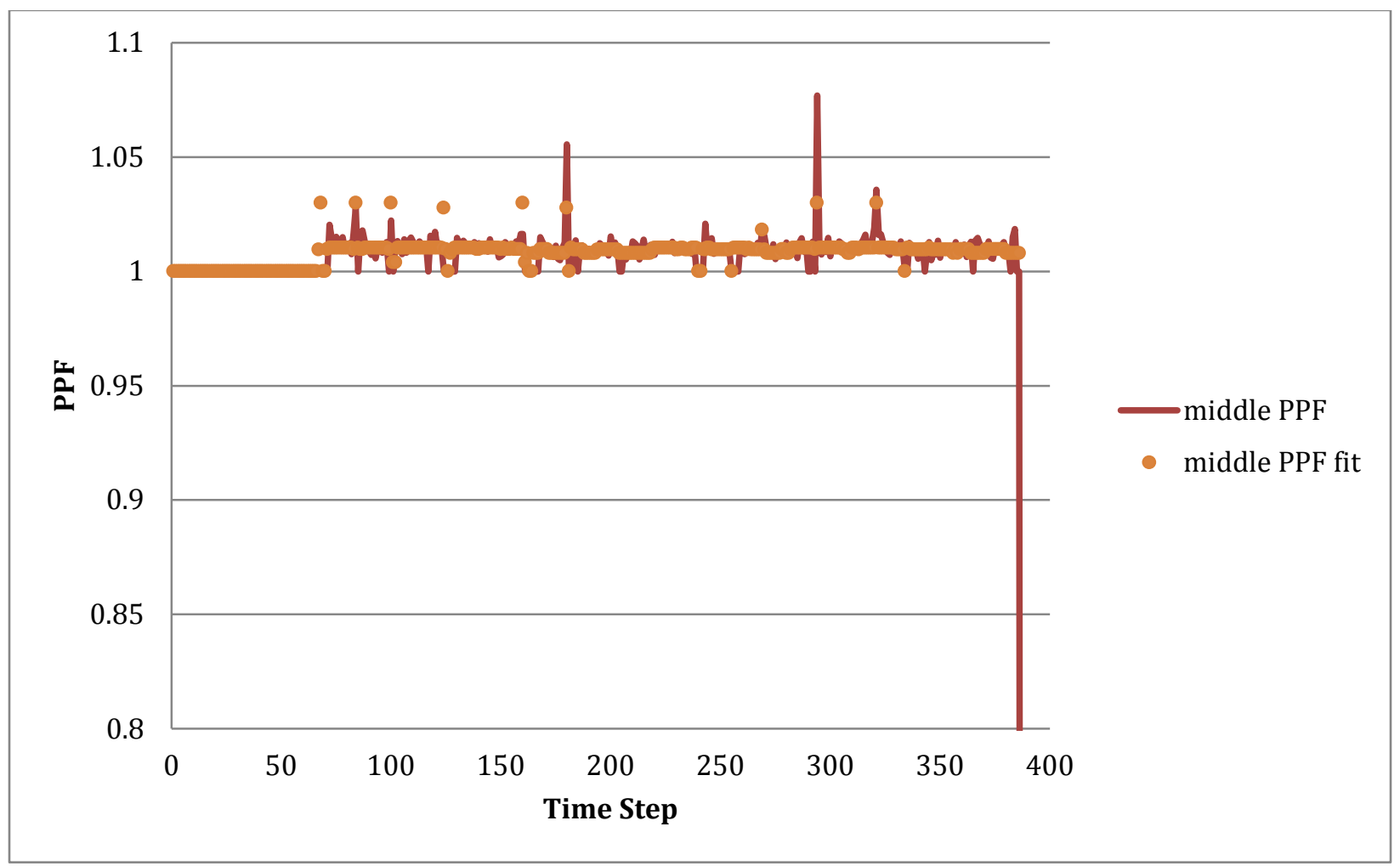

Fig. 6. IFA-597 Rod 8, middle region PPF fit. 


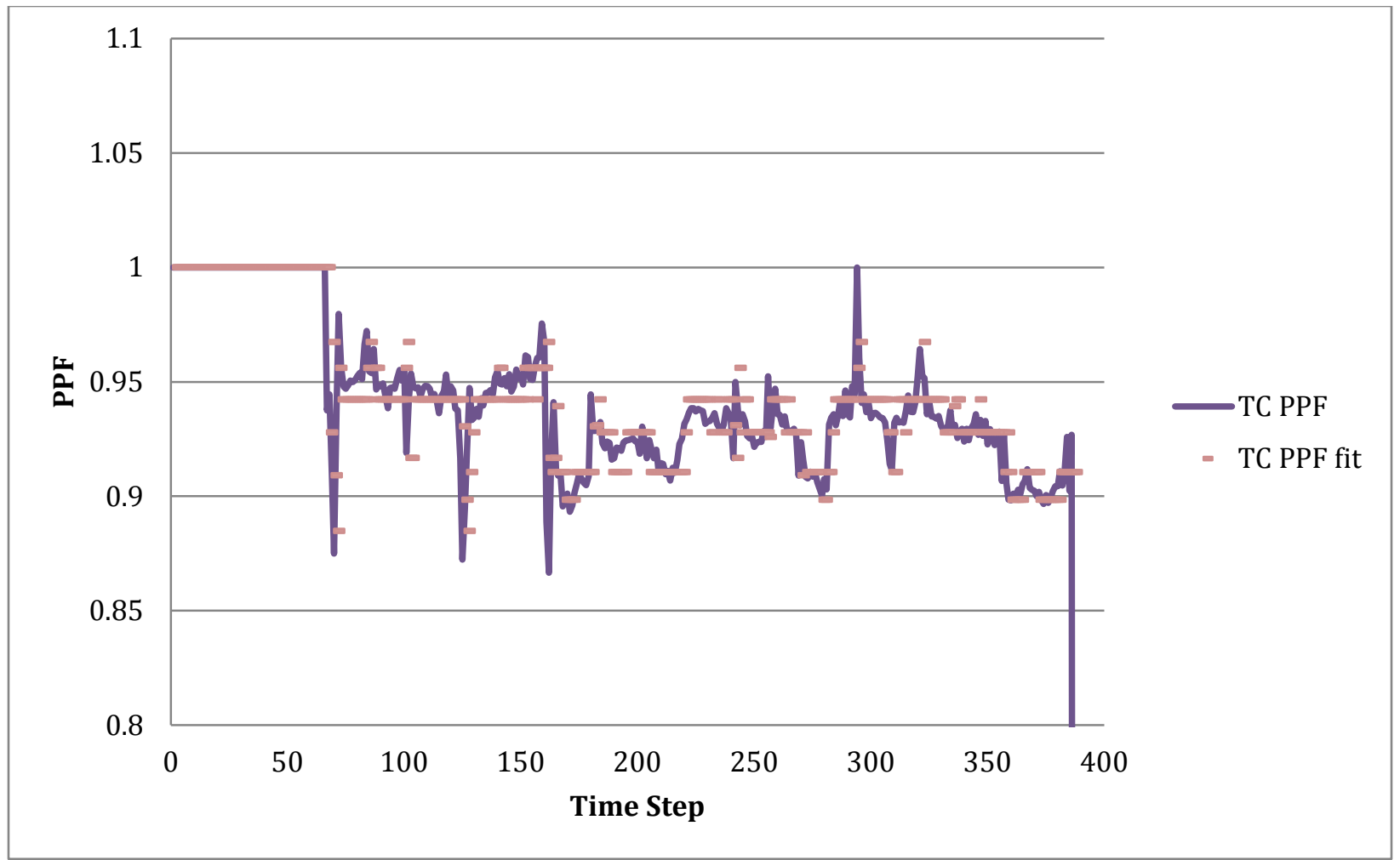

Fig. 7. IFA-597 Rod 8, at thermocouple PPF fit.

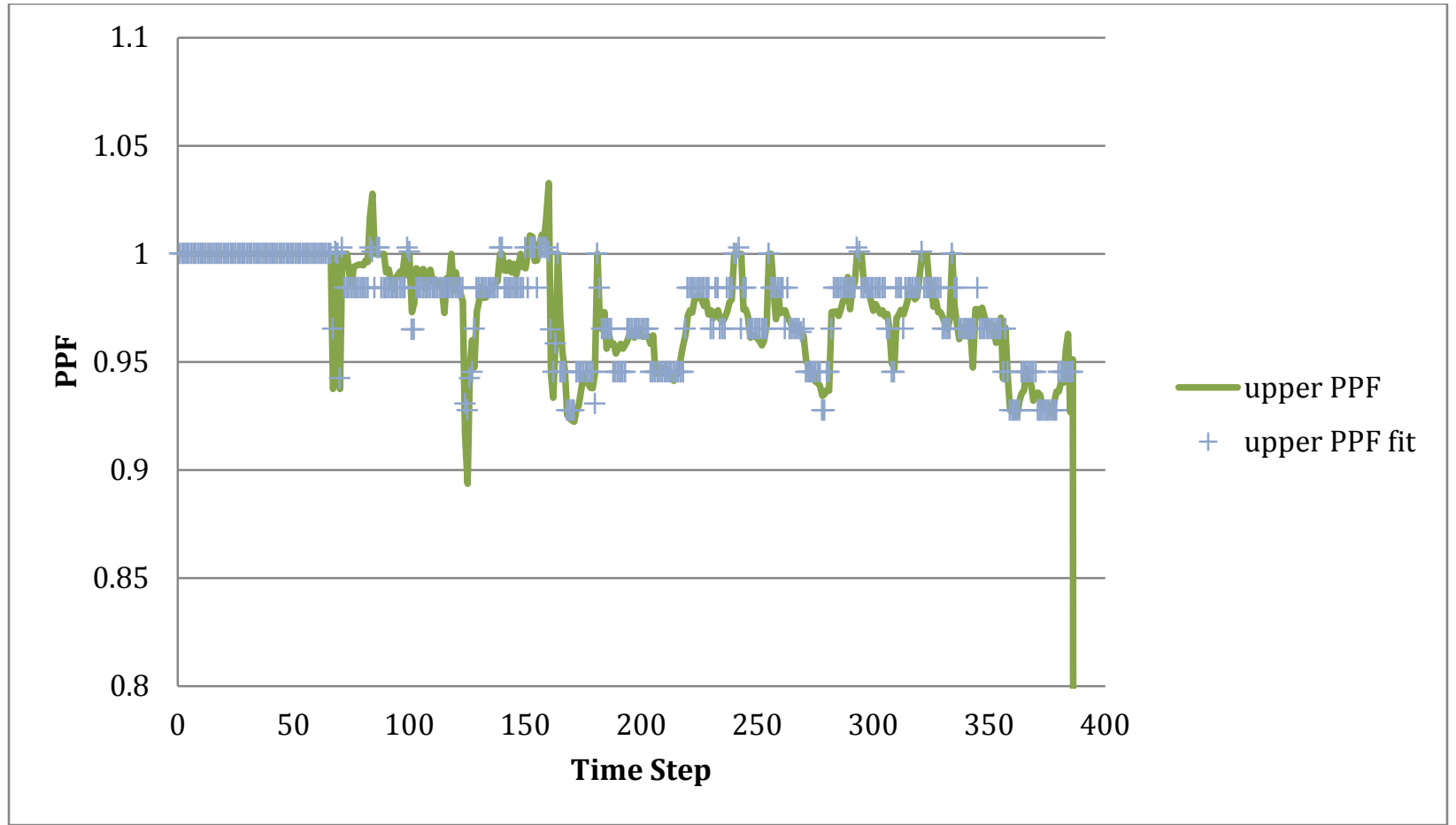

Fig. 8. IFA-597 Rod 8, upper region PPF fit. 


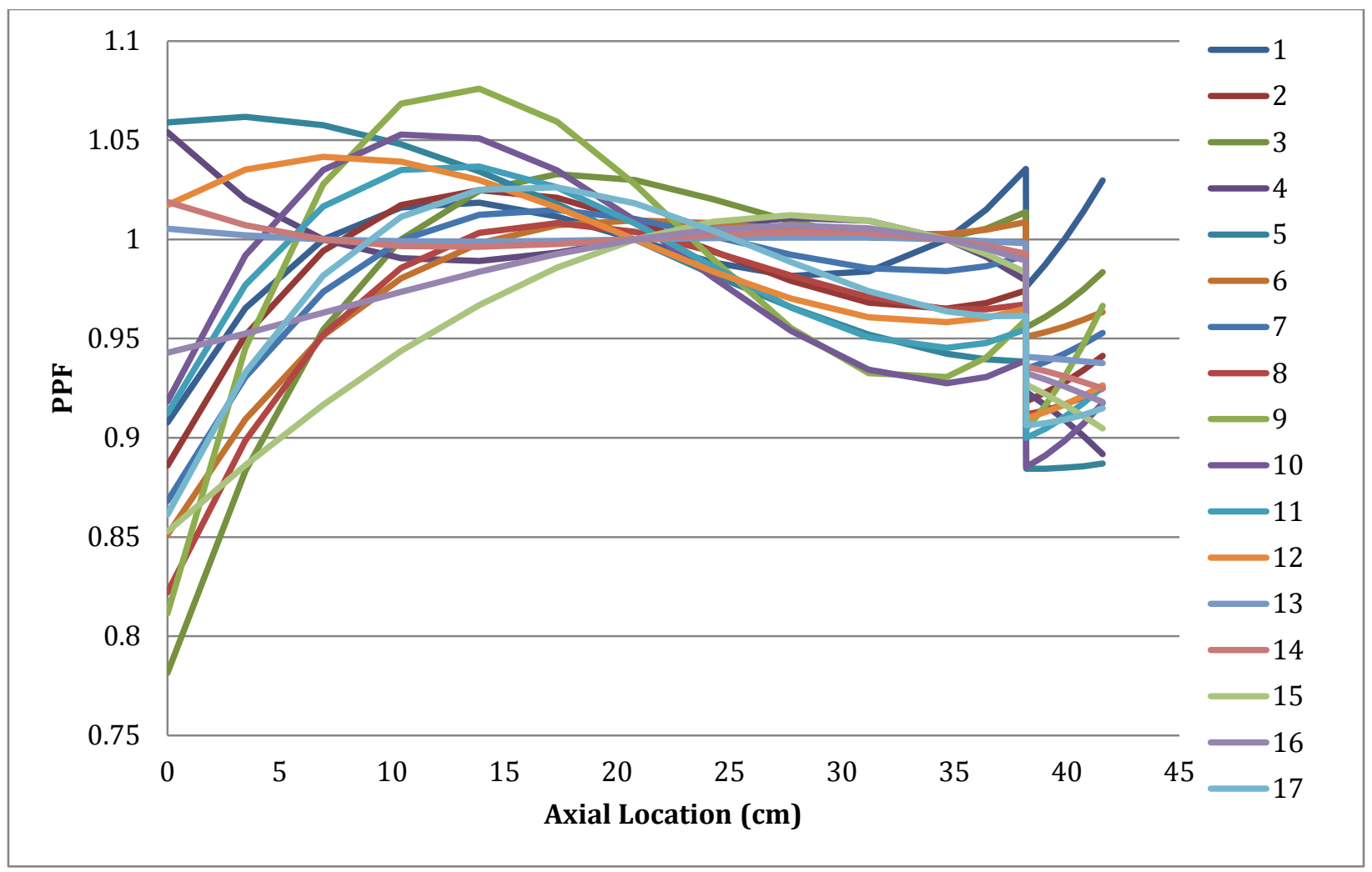

Fig. 9. IFA-597 Rod 8 axial power peaking profiles.

\subsection{CLAD TEMPERATURE SHAPE PROFILING}

The axial clad temperature profile was found in a similar manner as the power profile. Third-order Legendre polynomials were fit to the data for each time step and then sorted without regard to the $a_{0}$ term. In the case of the temperature inputs, the magnitude of the temperature is not separate from the shape of the temperature profile. However, the temperature was found to be nearly uniform along the length of the rod. The variations in temperatures ended up being averaged out for a majority of the rod position, with some of the fluctuation being maintained.

Figures 10,11, 12, 13, and 14 show the fits of the clad temperature at the four points given in the database, as well as the temperature profiles generated with the fits. 


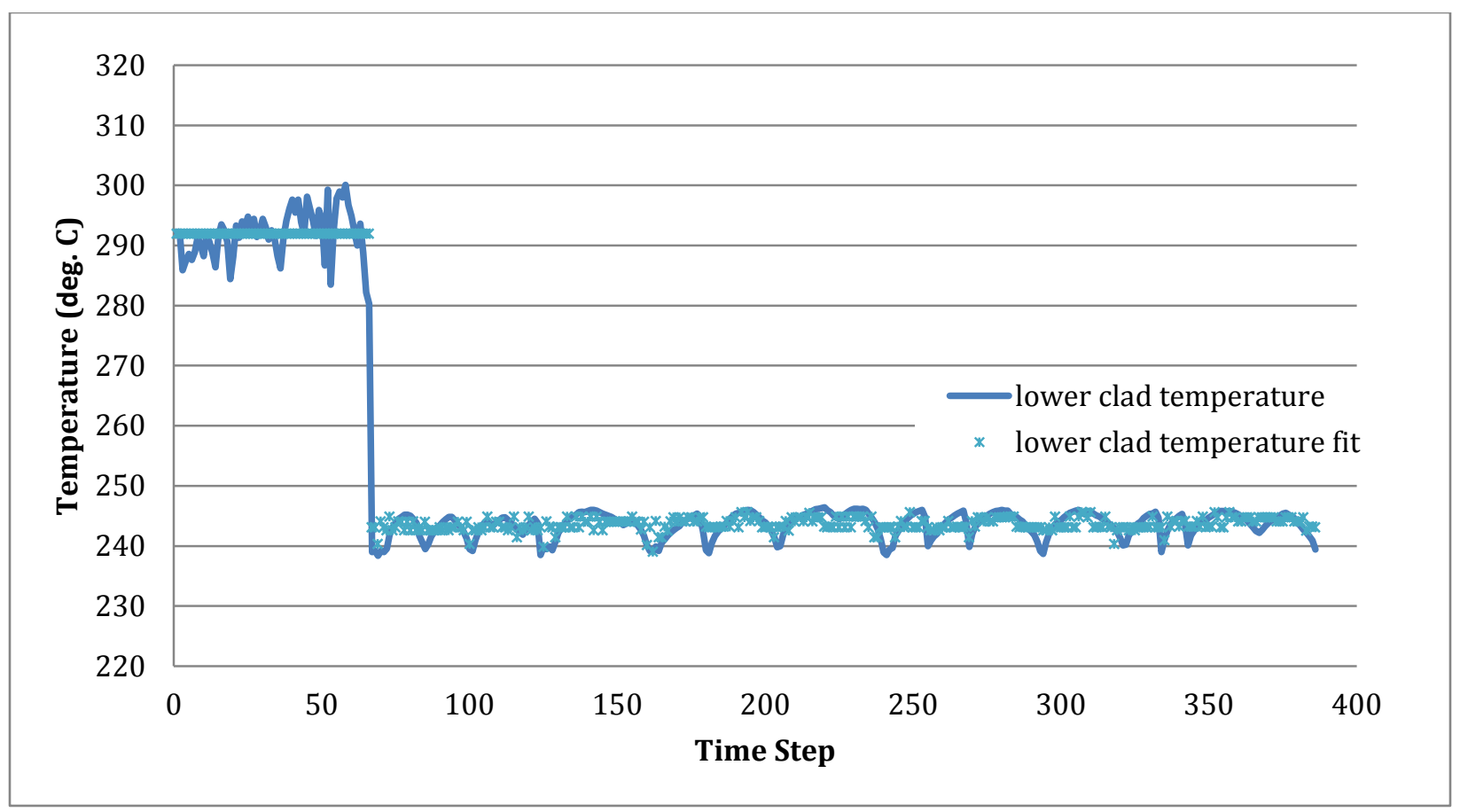

Fig. 10. IFA-597 Rod 8, lower region surface temperature fit.

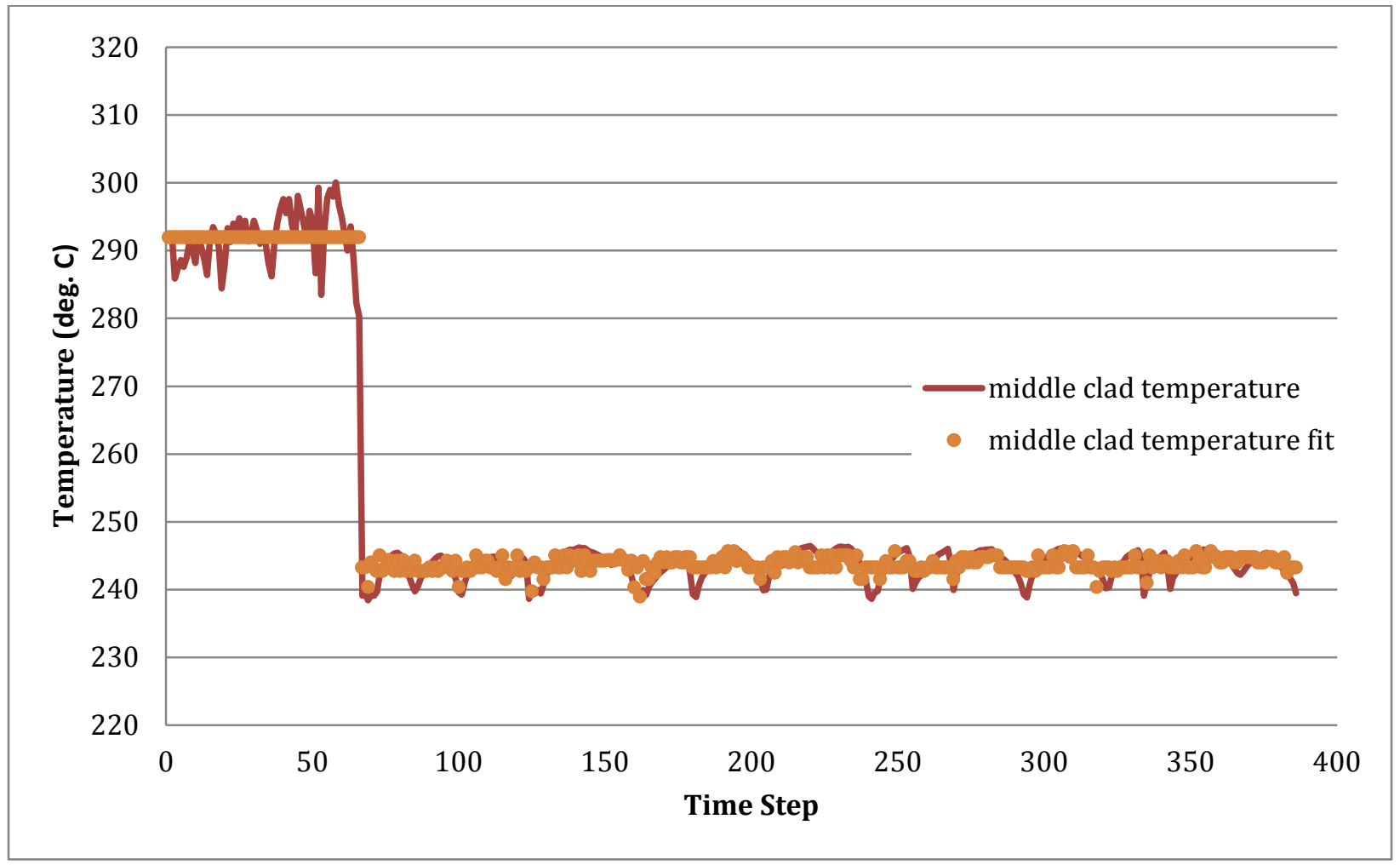

Fig. 11. IFA-597 Rod 8, middle region surface temperature fit. 


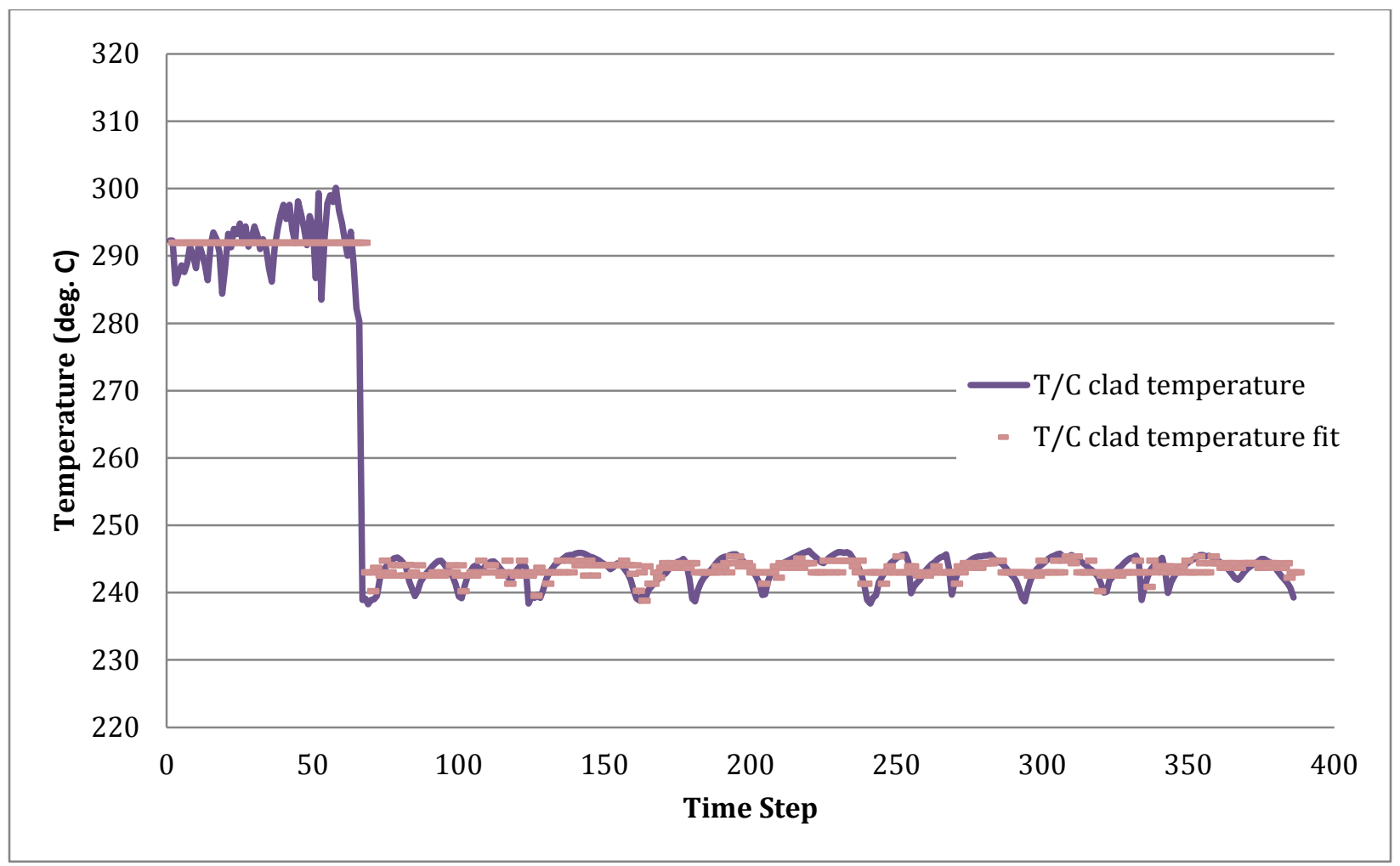

Fig. 12. IFA-597 Rod 8, at thermocouple surface temperature fit.

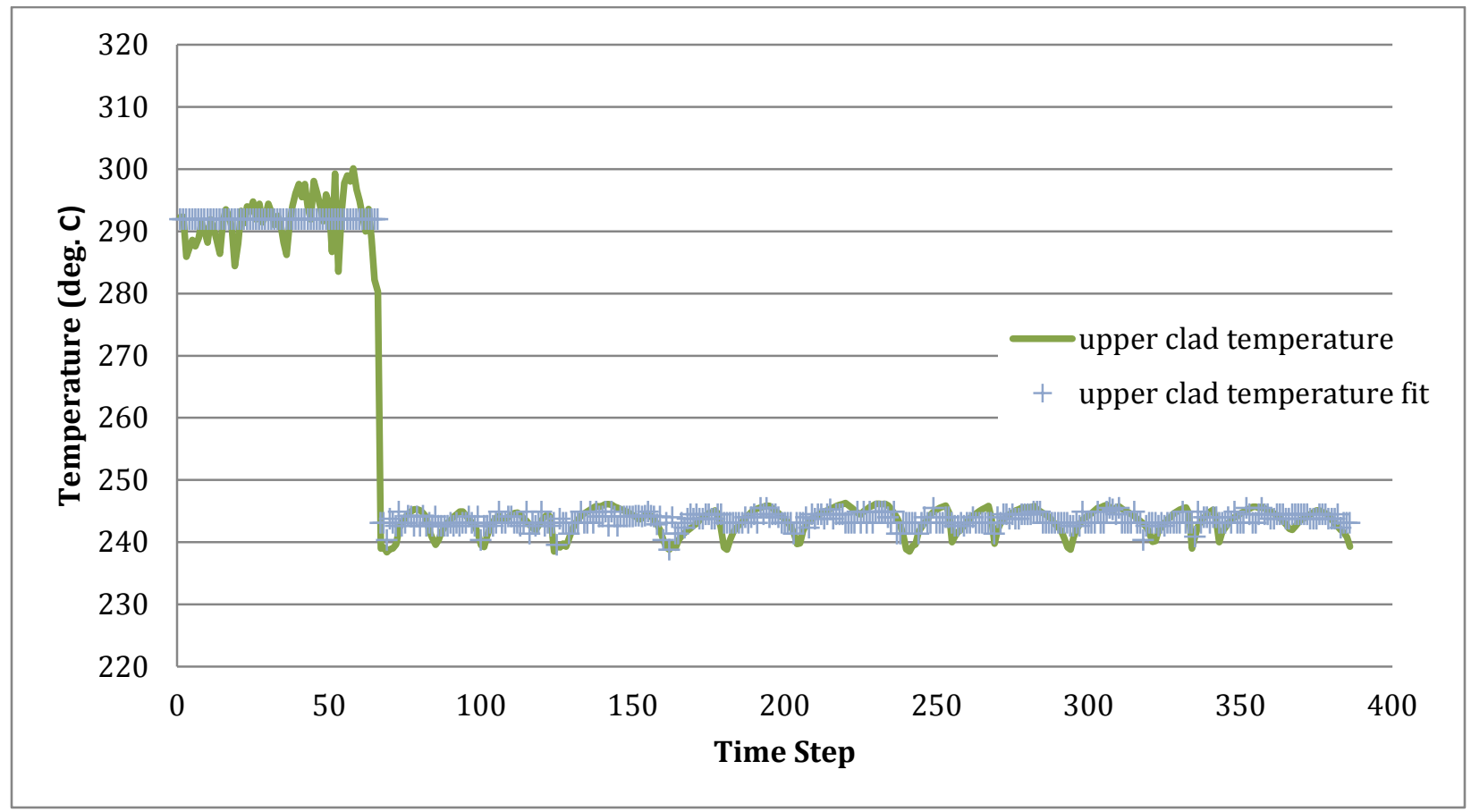

Fig. 13. IFA-597 Rod 8, upper region surface temperature fit. 


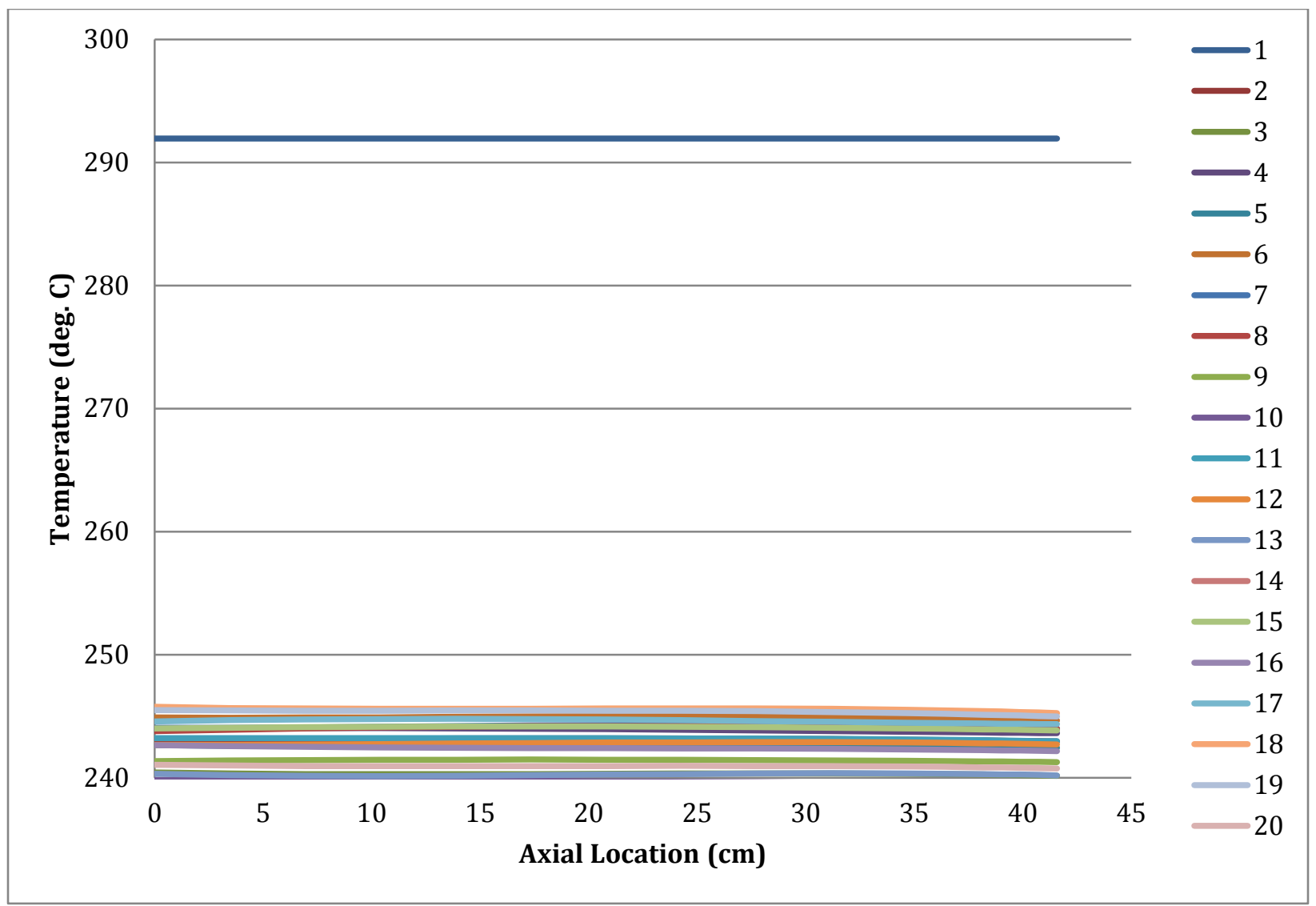

Fig. 14. IFA-597 Rod 8, axial surface temperature profiles.

\subsection{CENTERLINE TEMPERATURE CONSTRUCTION}

Unfortunately, although the experimental database provides a large amount of irradiation data, it neglects to give the temperature reading of the thermocouple at each time step. Therefore, the centerline temperature data has to be constructed from the tables giving centerline temperature as a function of LHGR and as a function of BU (Figure 15) via a similar to the elongation data for IFA-432.

Using the collapsed time steps, the BU of Rod 8 was calculated with the following Equation (4). The first 66 time steps in the database give information for the Ringhals portion of the irradiation. It was stated that the rod average BU before the Halden irradiation phase of the experiment was $\sim 59 \mathrm{GWd} / \mathrm{MT}\left(\mathrm{UO}_{2}\right)$. Therefore, a scaling factor of 1.011 was applied to Eq. (2) to make the BU 59 at time step 66. It should be noted that $\mathrm{BU}$ is provided at each time step, but with little detail. By calculating it, more information becomes available for the final fit.

Two data files provide centerline temperature as a function LHGR at the thermocouple at the beginning and end of the experiment. This corresponds with BUs of approximately 59 and $61.67 \mathrm{GWd} / \mathrm{MT}\left(\mathrm{UO}_{2}\right)$, respectively. The data was highly linear in nature, with $\mathrm{R}^{2}$ values greater than $99 \%$ when given a fit. 
where

$$
B U_{i}=\frac{\Delta t_{\text {step }} * A L H G R * L}{M_{f}} * \delta,
$$

$B U_{i} \quad$ is the $\mathrm{BU}$ for a particular irradiation step,

$\Delta t_{\text {step }} \quad$ is the duration of the irradiation period,

ALHGR is the average linear heat generation rate,

$L \quad$ is the length of the rod,

$M_{\mathrm{f}} \quad$ is the mass of the fuel in the rod, and

$\delta \quad$ is an adjustment factor (1.011) used to adjust the BU such that the BU at the beginning of irradiation in the Halden reactor was $59 \mathrm{GWd} / \mathrm{MT}\left(\mathrm{UO}_{2}\right)$.

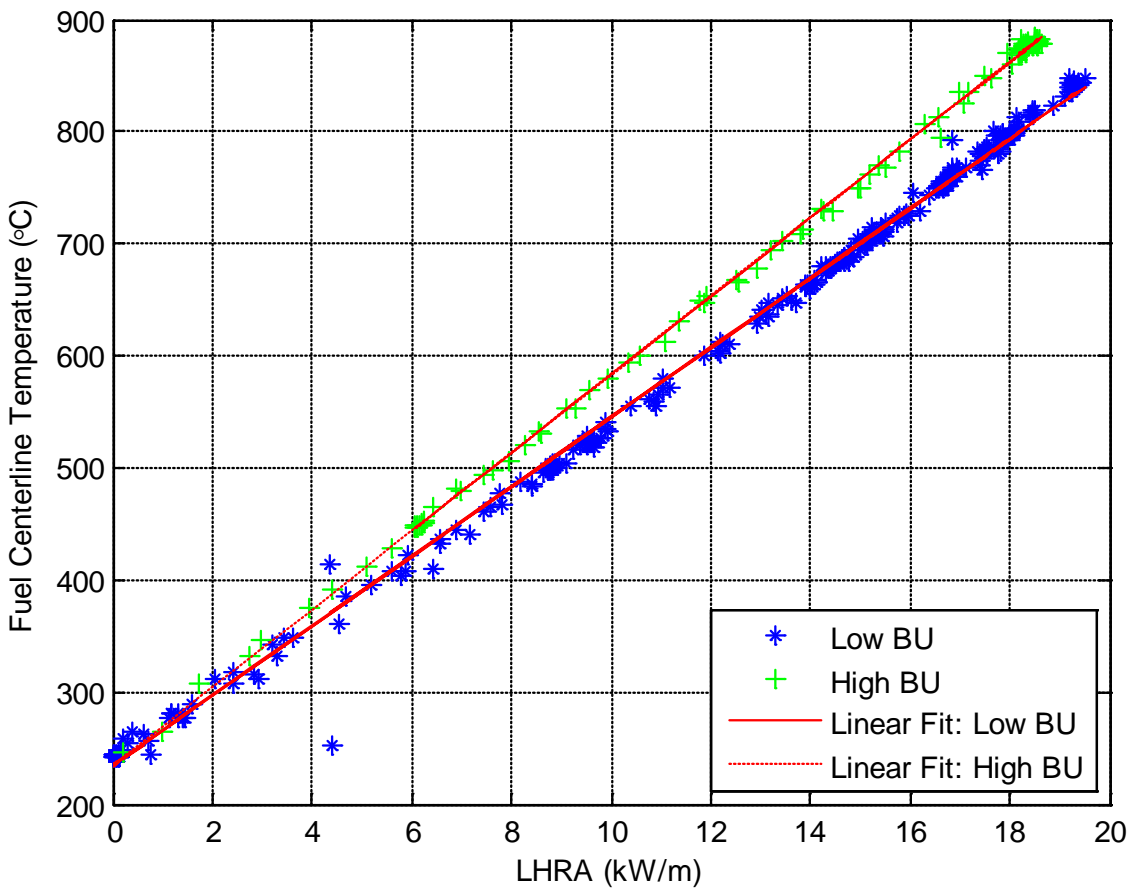

Fig. 15. IFA-597 Rod 8 centerline temperature as a function of LHGR and BU.

Given the ALHGR at a time step, the centerline temperature was calculated as if at the beginning of the experiment and at the end. A linear interpolation is then conducted based on the actual BU at the given time step.

\subsection{FRAPCON CENTERLINE RESULTS}

The data of interest from this experiment is for the time steps after 3000 days of irradiation. The experiment put the high BU fuel through multiple power ramps with little to no irradiation occurring between those ramp tests. This resulted in an experiment which may not qualify as steady-state "enough" for proper FRAPCON analysis.

Figures 16. and 17 show the irradiation period for Rod 8 between 3000 days and the end of the experiment. When FRAPCON is given only the axial power profile, it seems to over predict the centerline temperature at the ends of the power ramps. When FRAPCON is also given the clad axial temperature profile, it appears to under-predict the centerline temperature at the beginning of the power ramps. 
It should be reiterated, however, that the "experimental data” (i.e., the centerline temperature) was reconstructed by creating curve fits from data that was compiled from the irradiation histories. Therefore, an estimate of how exact FRAPCON came in replicating the experiment is indeterminable.

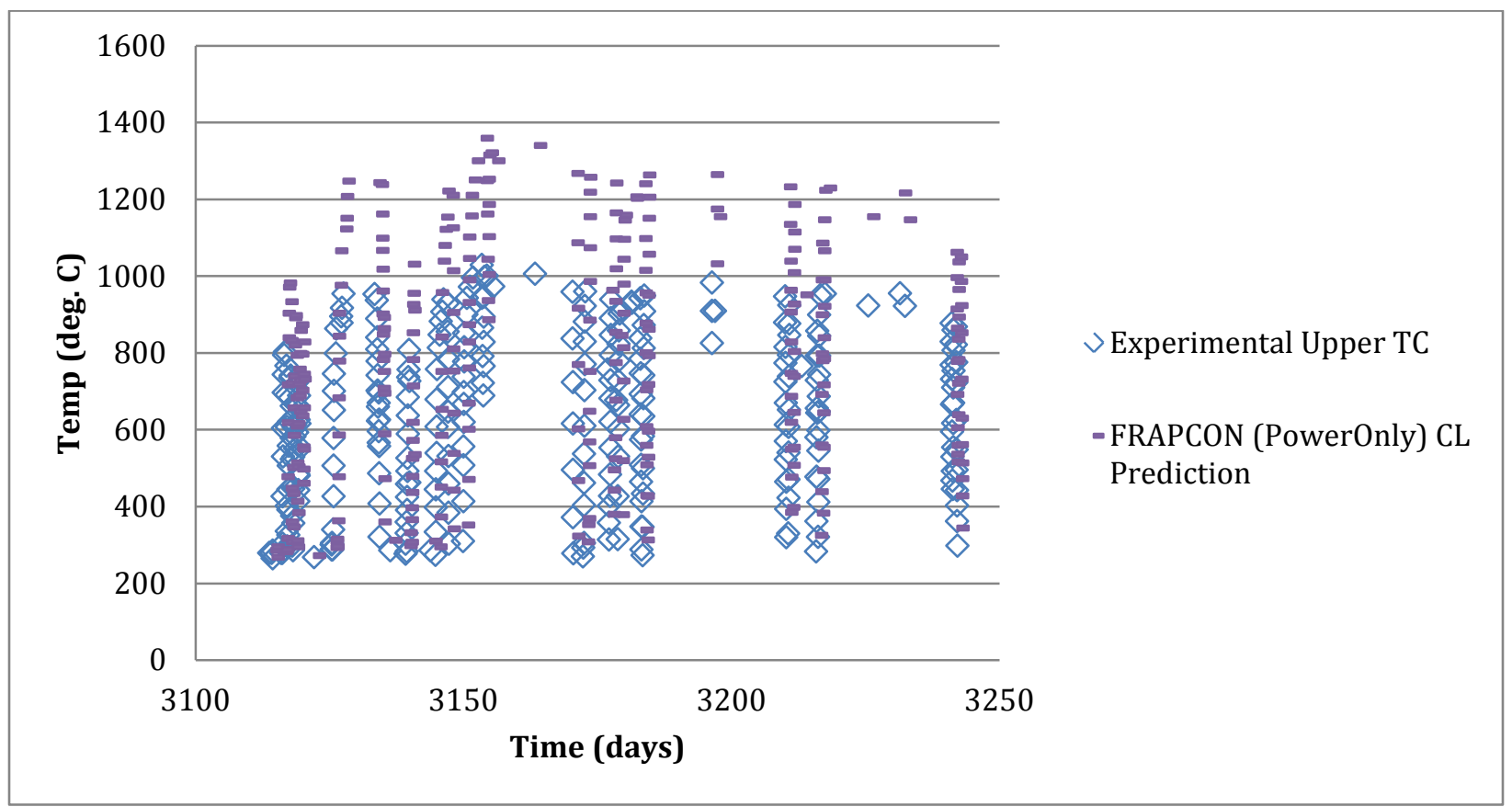

Fig. 16. IFA-597 Rod 8 centerline temperature comparison with constant surface temperature.

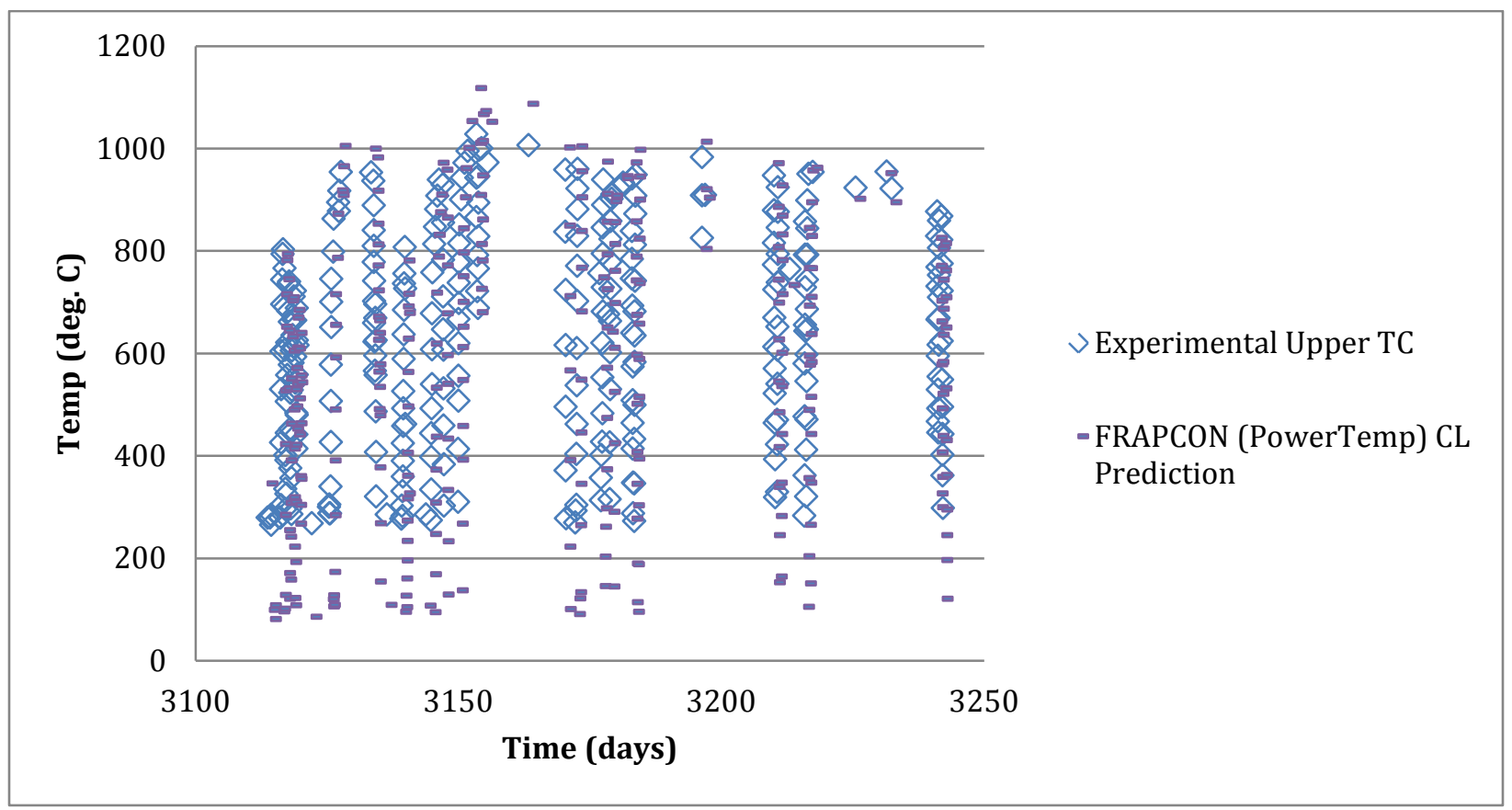

Fig. 17. IFA-597 Rod 8 centerline temperature comparison with specified surface temperature. 


\subsection{FRAPCON AXIAL CLAD ELONGATION}

Rod 7 was equipped with a clad elongation measurement device. The comparable irradiation histories of Rods 7 and 8 result in the ability to attribute the strain in Rod 7 as an approximate strain for Rod 8. The difference in the initial length of $8.5 \mathrm{~mm}$ between the two rods is not significant in the comparison of the elongation. Since the elongation data was given as a function of BU, it was correlated to each time step by that step's BU. This data, therefore, does not account for temperature effects on elongation. Figure 18 shows the FRAPCON elongation results for the entire irradiation history.

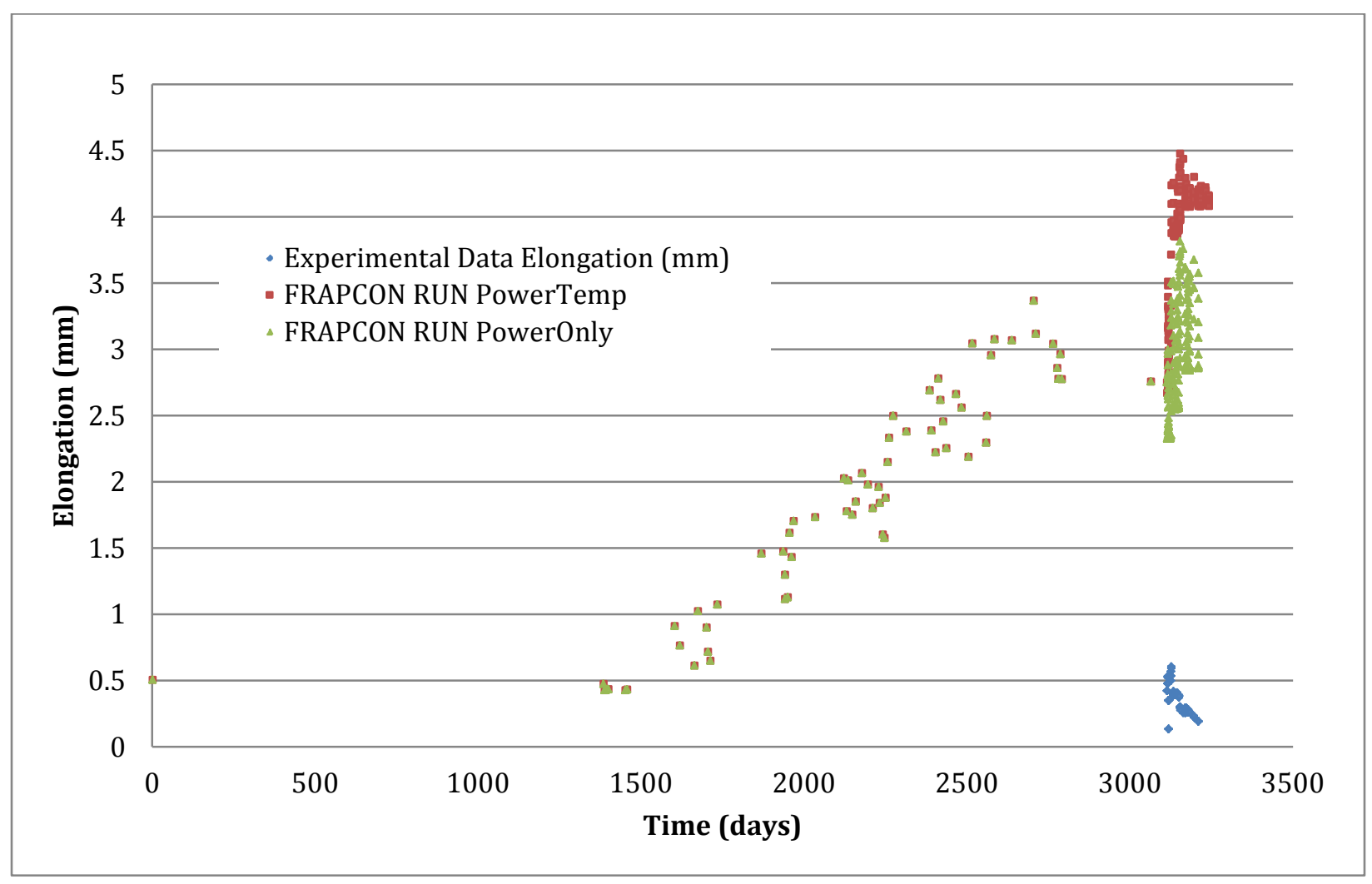

Fig. 18. IFA-597 Rod 8 elongation.

The elongation data for the experiment starts when the rods were under irradiation in the Halden reactor. Therefore, the zero point for the elongation measurements probably included the permanent elongation from the original 12 years of irradiation.

If the FRAPCON data is zeroed out using the largest elongation predicted during the original irradiation, then the following, shown in Fig. 19, results. The FRAPCON run in which the power and temperature distributions were specified seems to follow the general shape of the experimental data. Again, because of the large uncertainty in correlating the data, a detailed numerical comparison would yield unreliable results. 


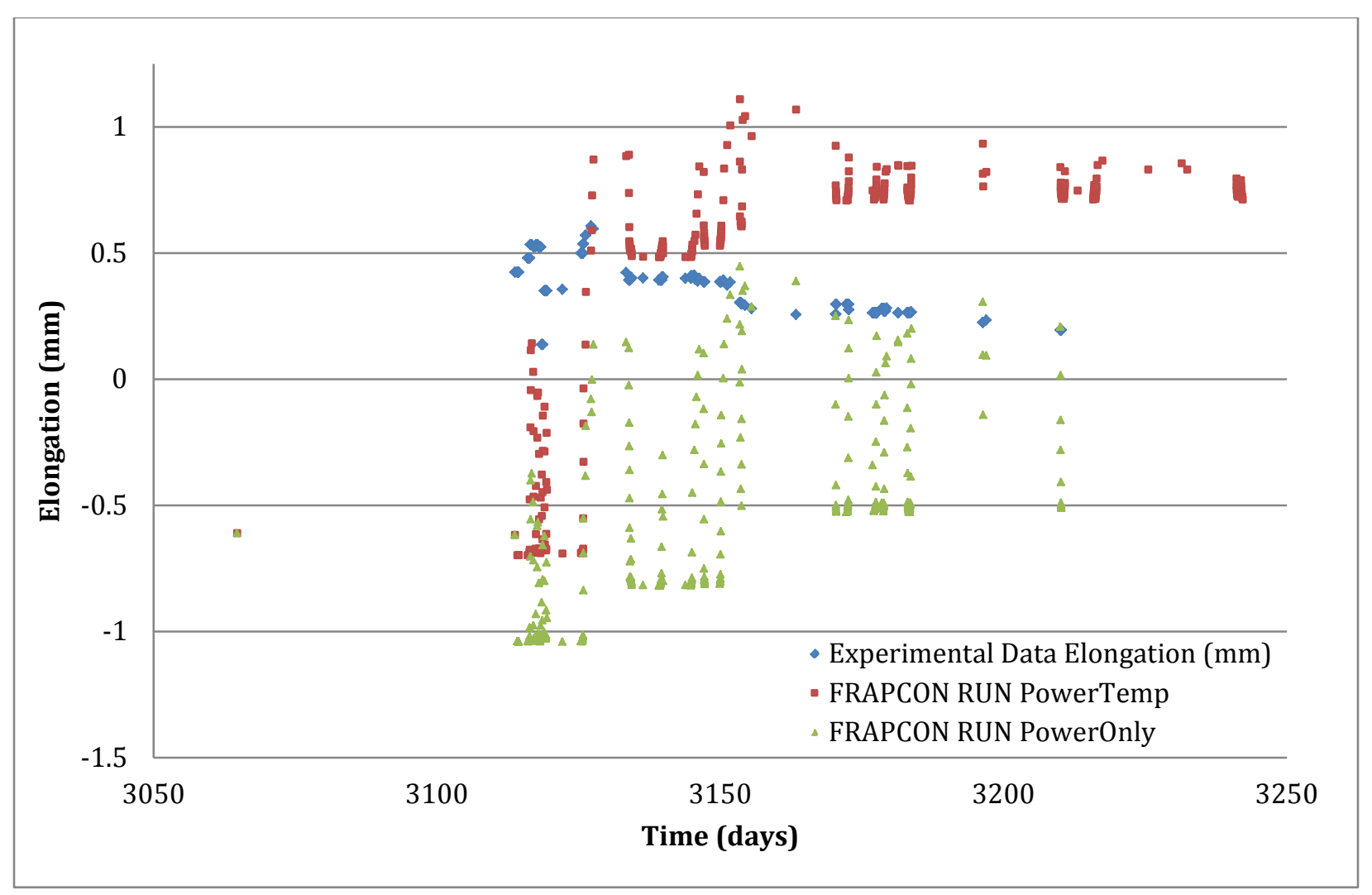

Fig. 19. IFA-597 Rod 8 elongation zeroed for Halden irradiation.

\subsection{FRAPCON FISSION GAS RELEASE}

Fission gas release was also tabulated as a function of BU for the experiment. As with the elongation data, the FGR data was correlated to a time step based on the BU at that time step. Because of this, no data is available preceding day 3130 . As can be seen in Fig. 20, both FRAPCON runs (with power specified only and power and temperature both specified) over predict the measured FGR, which is common with FRAPCON. The jumps in FGR at approximately days 3140 and 3150 are similar to the experiment in percent relative increase. 


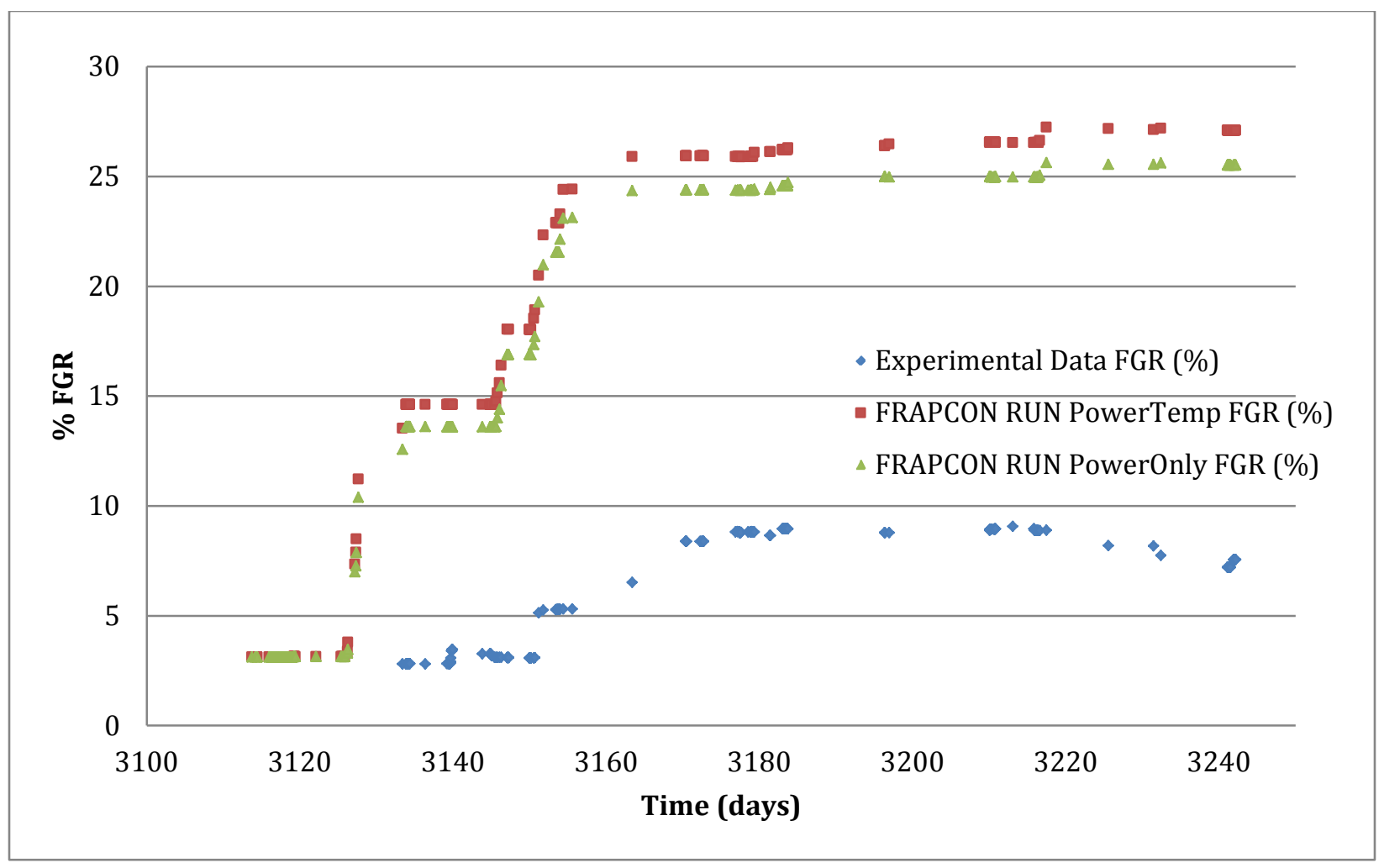

Fig. 20. IFA-597 Rod 8 percent fission gas release. 



\section{IFA-597MOX}

\subsection{EXPERIMENTAL BACKGROUND}

The purpose of the IFA-597mox experiments was to observe the fission gas release and thermal behavior of mixed oxide (MOX) fuel. ${ }^{8}$ Included in this experiment was the exploration of the potential differences in behavior as affected by the presence of an annulus in the pellets. Therefore, the database contains data for two rods, which were equipped with a thermocouple and pressure bellows transducer. The specific information provided included clad temperatures at four axial locations, the centerline temperature at the thermocouple, BU, and rod internal pressure, all as a function of irradiation time.

Rod 1 consisted of solid pellets with several annular pellets at the top of the rod providing space for the thermocouple. Rod 2 consisted of all annular pellets. The rods were irradiated in spurts from July 1997 to January 2002. The rods were run at a low enough power rating to preclude FGR by placing $\mathrm{UO}_{2}$ rods around them. At about $10 \mathrm{GWd} / \mathrm{MT}$ (MOX), the power rating was increased for the FGR studies. After an additional power uprating at about 22-27 GWd/MT (MOX), additional neighboring $\mathrm{UO}_{2}$ rods were added in order to reduce the specific power of the MOX rods. ${ }^{8}$

Table 5 provides the as-fabricated information on both rods in the database.

Table 5. IFA-579MOX pellet and clad geometry specifications ${ }^{8}$

\begin{tabular}{lcc}
\hline Dimension & Rod 1 & Rod 2 \\
\hline Fuel rod length, mm & 224 & 220 \\
Length of drilled section, mm & $\sim 43$ & 220 \\
Pellet inner radius, mm & $0.9 / 0.0$ & 0.9 \\
Pellet outer radius, mm & \multicolumn{2}{c}{4.025} \\
Pellet length, mm & \multicolumn{2}{c}{10.50} \\
Dishing depth, mm & \multicolumn{2}{c}{0.26} \\
Land width, mm & \multicolumn{2}{c}{5.30} \\
Chamfer height, mm & 0.15 \\
Chamfer width, mm & \multicolumn{2}{c}{0.30} \\
Cladding inner radius, mm & \multicolumn{2}{c}{4.11} \\
Cladding outer radius, mm & \multicolumn{2}{c}{4.75} \\
\hline
\end{tabular}

\subsection{POWER AND TEMPERATURE SHAPE PROFILING}

The axial power shape for both rods was relatively flat, with a drop in the upper portion. Therefore, a visual fit was applied in the same manner as described for the IFA-432 data. The axial positions given were at the end points of the rods, at the thermocouple, and at the midpoint of each rod.

The axial temperature profile was also relatively constant. This allowed for an easy visual fit following the same procedure as used for the IFA-432 rods. The following two plots (Figs. 21 and 22) show the power and temperature profiles for Rod 1 sorted and with their fits. 


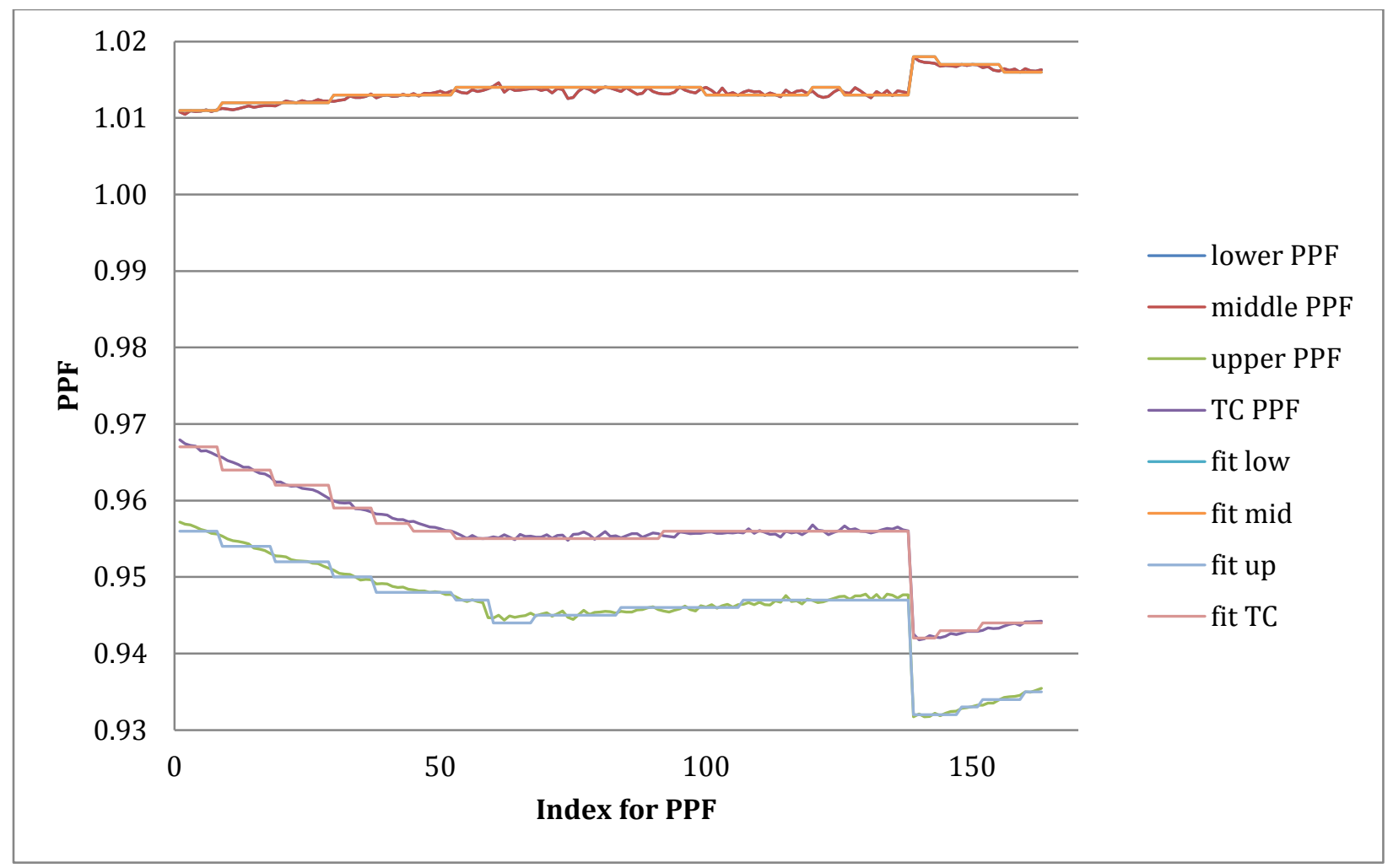

Fig. 21. IFA-597mox Rod 1 sorted PPFs with fits. 


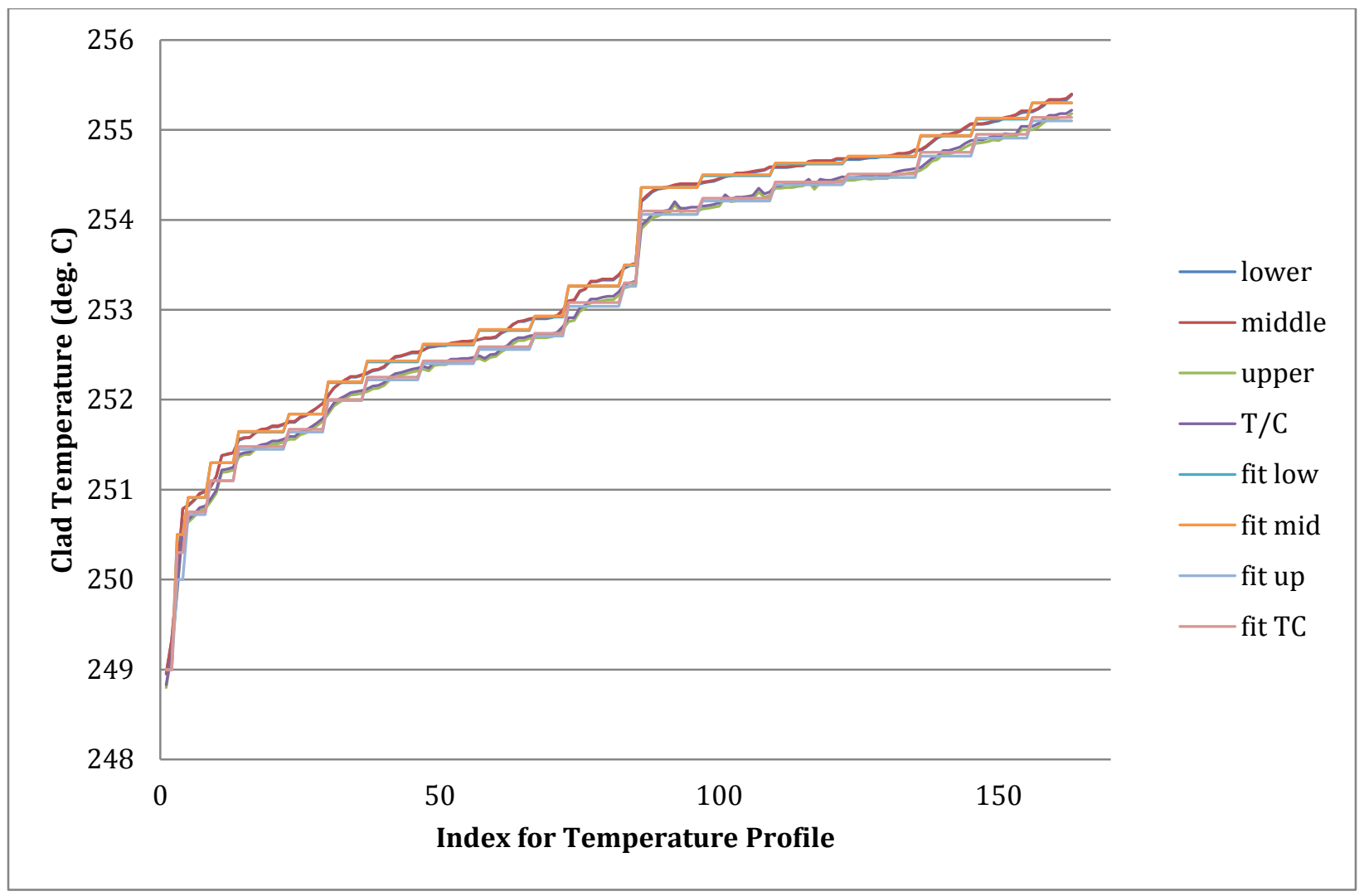

Fig. 22. IFA-597mox sorted temperature profiles with fits.

\subsection{FRAPCON CENTERLINE TEMPERATURE RESULTS}

For the FRAPCON input, Rod 2 was modeled as a fully annular rod. Rod 1 was modeled as entirely solid, because FRAPCON does not support specifying mixed pellet types. The centerline results are presented below.

For Rod 1, the best prediction of the centerline temperature occurs when only the axial power distribution is supplied to FRAPCON. Supplying the temperature distribution results in about a 20 degree increase in predicted temperature (Fig. 23).

For Rod 2, the best prediction for the centerline temperature is found when both axial power and temperature profiles are specified. Again, there is about a 20 degree difference in the results when axial temperature is not specified (Fig. 24).

Of particular interest is the closeness to which the FRAPCON data matches the experimental data. For MOX fuels, FRAPCON uses one of two models for thermal conductivity. The first is a modified version of an expression developed by the Nuclear Fuels Industries for $\mathrm{UO}_{2}$ fuels. Some fitting terms are used to adjust the correlation for MOX fuel. ${ }^{3}$ The origin of the fitting terms is not specified.

The second model for the MOX thermal conductivity that can be used is one that was derived directly from these experiments and, therefore, is not applicable for validation. 


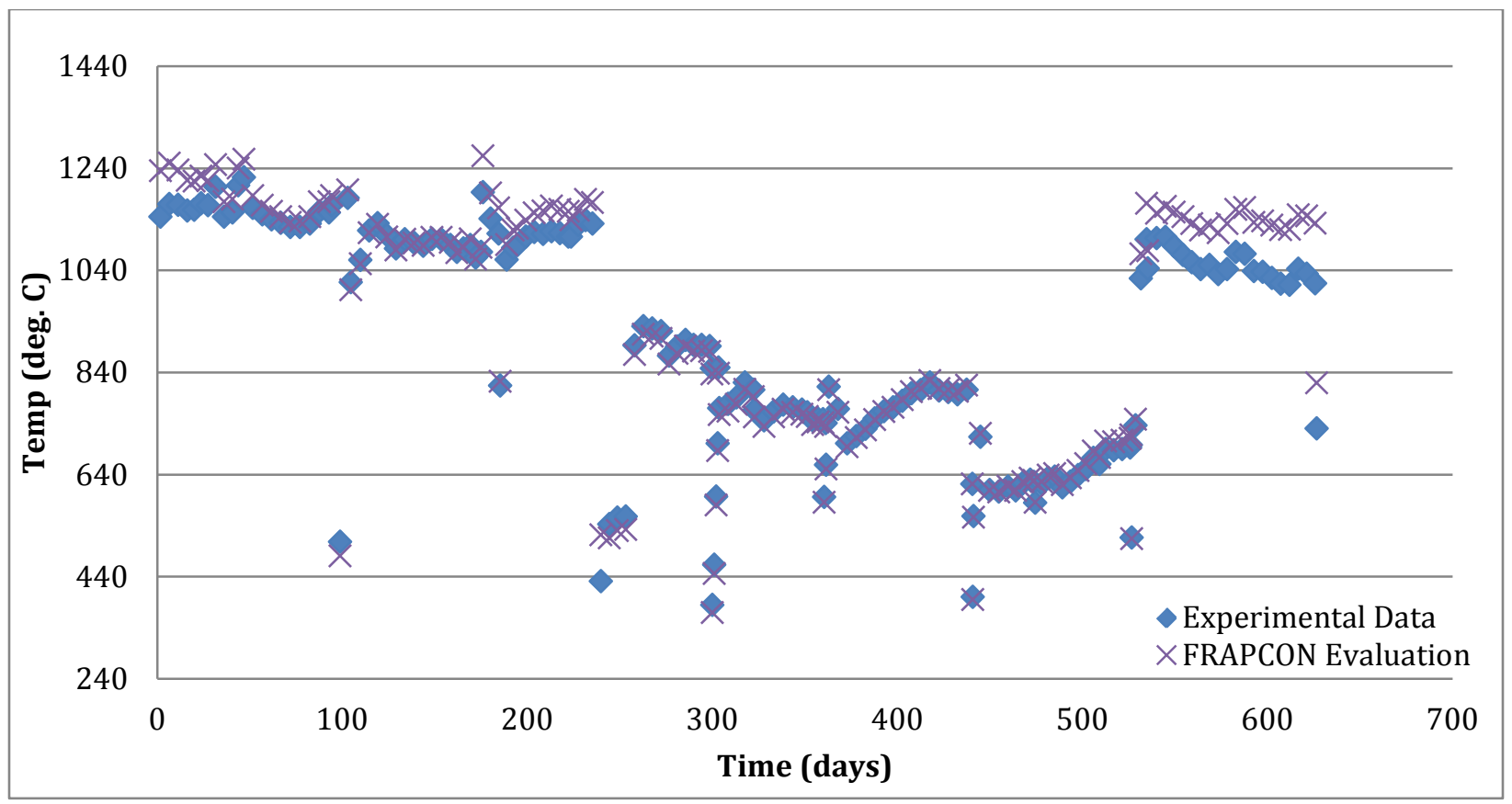

Fig. 23. IFA-597mox Rod 1 centerline temperature comparison (PowerOnly).

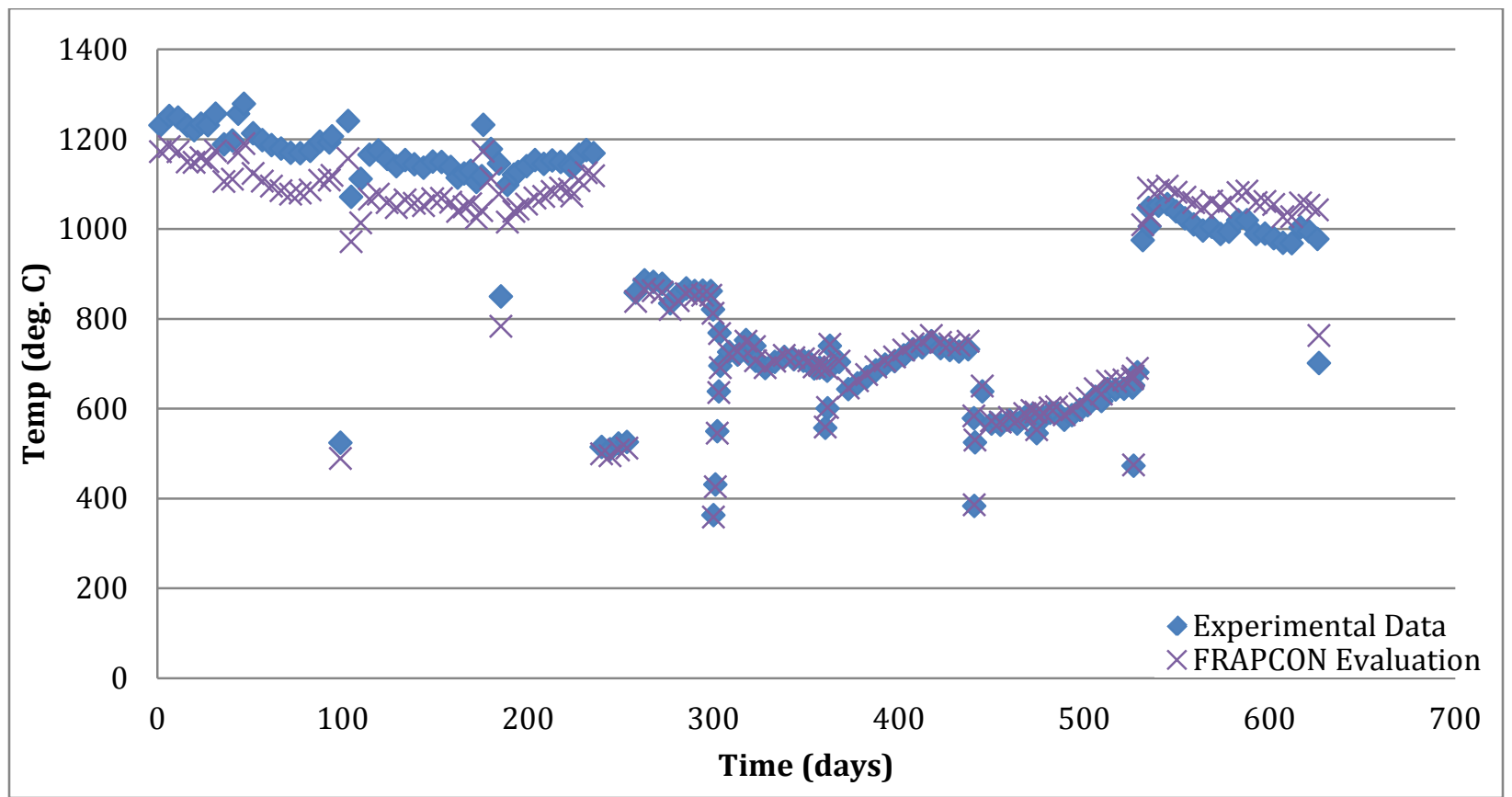

Fig. 24. IFA-597mox Rod 2 centerline temperature comparison (PowerTemp). 
Figures 25 and 26 show predicted rod internal pressure compared to the measured data.

The data follows the same trend as shown from the centerline temperature predictions. For the solid rod, the FRAPCON prediction where only the axial power distribution was supplied better follows the experimental data, while the reverse case is true for the hollow rod.

A comparison of these results with the case in which the Halden correlation for MOX thermal conductivity was used can be viewed in Appendix C.

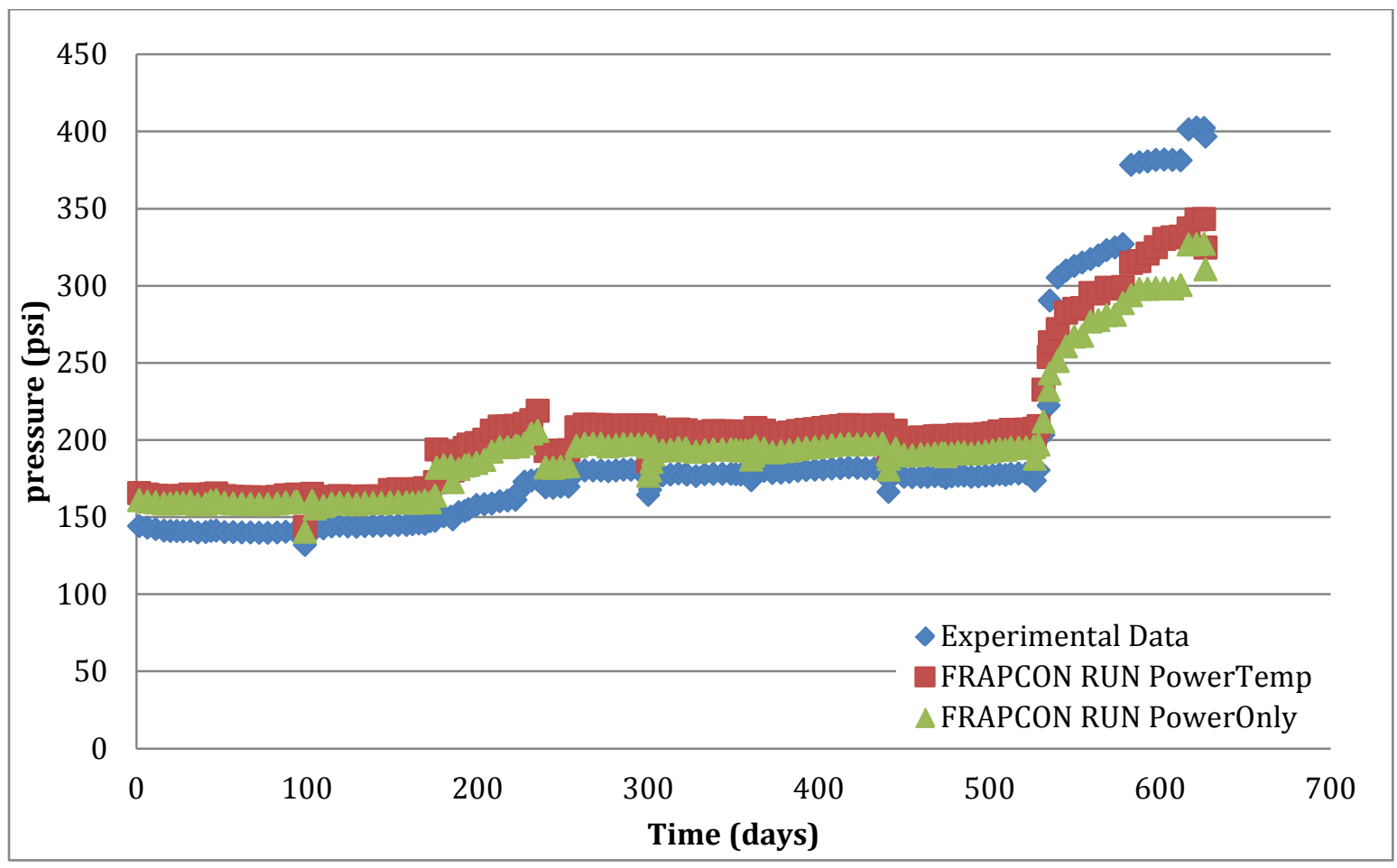

Fig. 25. IFA-597mox Rod 1 plenum pressure. 


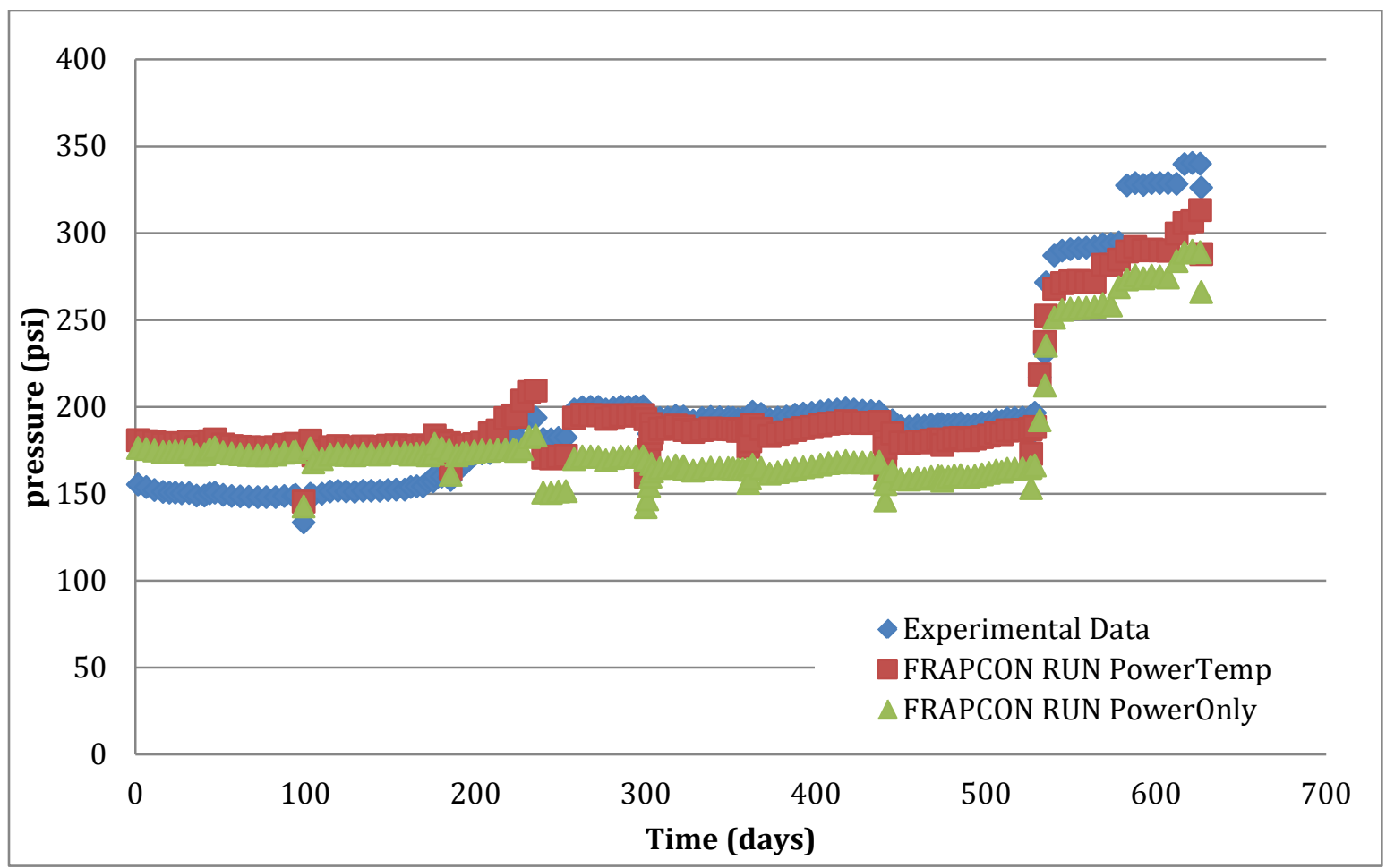

Fig. 26. IFA-597mox Rod 2 plenum pressure. 


\section{CONCLUSIONS}

This report shows that the IFA-432, 597, and 597mox experimental datasets provide a well-rounded set of information with regards to nuclear fuel performance code validation. The experiments provide for centerline temperature, clad temperature, clad axial elongation, radial BU, fission gas release, and internal rod pressure. This data can be reproduced using FRAPCON with various degrees of accuracy depending on the experiment.

For the five rods of the IFA-432 database, FRAPCON predicts centerline temperatures that differ from the experimental values on average by, 13, 43, 15, and 6 percent, respectively, when simulated as solid with only the power specified. Specifying clad outer temperatures increase the average percent difference by approximately 1 percent. The annular pellet simulations resulted in a decrease in the percent difference for the rods, from anywhere between 1.4 percent for rod 5 to 10.2 percent for rod 3 .

When rod 8 of the IFA-597 database was modeled with only the power specified, the average percent difference between the predicted centerline temperature and the experimental data was about 21 percent. When modeled with the clad temperature also specified, the average percent difference became -17 percent.

FRAPCON best predicted the mox rods with average percent differences of 1.8 and -5 percent for rods 1 and 2, respectively. With clad temperature also specified, the average percent difference was 4.2 and -1.4 percent.

There are some modeling and validation issues with some of the data provided in the NEA databases. The IFA-597 experiment is particularly difficult to model due to the 12-year irradiation time of the rods before the Halden experimental irradiation. Additionally, the data varies strongly with time, violating the steadystate assumption of FRAPCON for some time steps. The elongation data for the IFA-432 experiments is not provided in a format ideal for a step-by -step comparison. Therefore, only a qualitative analysis of elongation behavior can be made between the experimental data and modeling codes.

One of the goals of the analyses performed is to provide additional information not available in the experimental databases, for the purposes of validating advanced fuel performance codes currently under development, as well as to provide a reasonable window for which results should be obtained with these codes. 



\section{REFERENCES}

1. The Public Domain Database on Nuclear Fuel Performance Experiments for the Purpose of Code Development and Validation (September 7, 2009), retrieved December 9, 2011 from OECD-NEA: http://www.oecd-nea.org/science/fuel/ifpelst.html.

2. Nuclear Energy Agency - Organization for Economic Co-Operation and Development (2009), Nuclear Fuel Behavior in Loss-of-coolant Accident (LOCA) Conditions, retrieved December 9, 2011, from OECD-NEA: www.oecd-nea.org/nsd/reports/2009/nea6846_LOCA.pdf.

3. K. J. Geelhood, W. G. Luscher, and C. E. Beyer, FRAPCON-3.4: A Computer Code for the Calculation of Steady-State Thermal-Mechanical Behavior of Oxide Fuel Rods for High Burnup, Pacific Northwest National Laboratory, Richland (2010).

4. F. Owre, Introduction to the Halden Reactor Project. Retrieved June 21, 2012, from US NRC, http://www.nrc.gov/public-involve/conference-symposia/ric/past/2009/slides/presentations/thu-8301000-ongoing-research-oecd-halden/presentation-format/owre-slides-01.pdf (March 10-12, 2009).

5. J. A. Turnbull, Database for Fuel Performance Modeling, OECD-NEA (1995).

7. J. A. Turnbull, Summary for Halden IFA-597, OECD-NEA (2002).

8. H. Koike, The MOX Fuel Behaviour Test IFA-597.4/.5/.6/.7; Summary of In-Pile Fuel Temperature and Gas Release Data. OECD Halden Reactor Project (2003). 



\section{APPENDIX A: FRAPCON INPUT PARAMETERS}

Appendix A contains the values assigned to the input variables for the FRAPCON cases. 


\section{IFA-432}

Table A.1. FRAPCON input parameters for IFA-432 Rods 1 and 2

\begin{tabular}{|c|c|c|c|c|c|}
\hline \multicolumn{3}{|c|}{ IFA-432 Rod 1} & \multicolumn{3}{|c|}{ IFA-432 Rod 2} \\
\hline Variable & Value & Units & Variable & Value & Units \\
\hline dco & 0.5031 & inches & dco & 0.5031 & inches \\
\hline thkcld & 0.0370 & inches & thkcld & 0.0370 & inches \\
\hline thkgap & 0.0045 & inches & thkgap & 0.0075 & inches \\
\hline totl & 1.8960 & feet & totl & 1.8734 & feet \\
\hline $\mathrm{cpl}$ & 2.0000 & inches & cpl & 2.0000 & inches \\
\hline dspg & 0.3500 & inches & dspg & 0.3500 & inches \\
\hline dspgw & 0.0300 & inches & dspgw & 0.0300 & inches \\
\hline vs & 5.0000 & - & vs & 5.0000 & - \\
\hline hplt & 0.5118 & inches & hplt & 0.5118 & inches \\
\hline rc & 0.0345 & inches & rc & 0.0345 & inches \\
\hline enrch & 10.0 & $\%$ u235 of U & enrch & 10.0 & $\%$ u235 of U \\
\hline den & 95.0730 & $\%$ TD & den & 95.0730 & $\% \mathrm{TD}$ \\
\hline roughf & 8.50E-05 & inches & roughf & $8.50 \mathrm{E}-05$ & inches \\
\hline rsntr & 75 & $\mathrm{~kg} / \mathrm{m}^{\wedge} 3$ & rsntr & 75 & $\mathrm{~kg} / \mathrm{m}^{\wedge} 3$ \\
\hline tsint & 3092 & $\mathrm{~F}$ & tsint & 3092 & $\mathrm{~F}$ \\
\hline $\mathrm{icm}$ & 2 & - & icm & 2 & - \\
\hline zr2vintage & 0 & - & zr2vinage & 0 & - \\
\hline roughc & 2.50E-05 & inches & roughc & $2.50 \mathrm{E}-05$ & inches \\
\hline fgpav & 14.7 & psi & fgpav & 14.7 & psi \\
\hline idxgas & 1 & - & idxgas & 1 & - \\
\hline iplant & -4 & - & iplant & -4 & - \\
\hline nsp & 0 & - & nsp & 0 & - \\
\hline p2(IT) & 500 & psi & p2(IT) & 500 & psi \\
\hline $\operatorname{tw}(\mathrm{IT})$ & 464 & $\mathrm{~F}$ & $\operatorname{tw}(\mathrm{IT})$ & 464 & $\mathrm{~F}$ \\
\hline go(IT) & 0 & $\mathrm{lb} / \mathrm{hr}-\mathrm{ft} \wedge 2$ & go(IT) & 0 & $\mathrm{lb} / \mathrm{hr}-\mathrm{ft} \wedge 2$ \\
\hline pitch & 0.56 & inches & pitch & 0.56 & inches \\
\hline icor & 2 & - & icor & 0 & - \\
\hline crdt & 0 & mils & crdt & 0 & mils \\
\hline crdtr & 0 & $\mathrm{mils} / \mathrm{hr}$ & crdtr & 0 & mils/hr \\
\hline flux $(\mathrm{J})$ & $5.00 \mathrm{E}+15$ & & flux $(J)$ & $5.00 \mathrm{E}+15$ & \\
\hline im & 256 & - & im & 319 & - \\
\hline $\mathrm{nr}$ & 25 & - & $\mathrm{nr}$ & 25 & - \\
\hline ngasr & 45 & - & ngasr & 45 & - \\
\hline ngasmod & 2 & - & ngasmod & 2 & - \\
\hline na & 18 & - & na & 18 & - \\
\hline nunits & 1 & - & nunits & 1 & - \\
\hline
\end{tabular}


Table A.2. FRAPCON input parameters for IFA-432 Rods 3 and 5

\begin{tabular}{|c|c|c|}
\hline \multicolumn{3}{|c|}{ IFA-432 Rod 3} \\
\hline Variable & Value & Units \\
\hline dco & 0.5031 & inches \\
\hline thkcld & 0.0370 & inches \\
\hline thkgap & 0.0016 & inches \\
\hline totl & 1.8707 & feet \\
\hline cpl & 2.0000 & inches \\
\hline dspg & 0.3500 & inches \\
\hline dspgw & 0.0300 & inches \\
\hline vs & 5.0000 & - \\
\hline hplt & 0.5118 & inches \\
\hline $\mathrm{rc}$ & 0.0345 & inches \\
\hline dishsd & 0.2136 & inches \\
\hline enrch & 10.0 & $\%$ u235 of U \\
\hline den & 95.0730 & \% TD \\
\hline roughf & 8.50E-05 & inches \\
\hline rsntr & 75 & $\mathrm{~kg} / \mathrm{m}^{\wedge} 3$ \\
\hline tsint & 3092 & $\mathrm{~F}$ \\
\hline icm & 2 & - \\
\hline zr2vinage & 0 & - \\
\hline roughc & $2.50 \mathrm{E}-05$ & inches \\
\hline fgpav & 14.7 & psi \\
\hline idxgas & 1 & - \\
\hline iplant & -4 & - \\
\hline nsp & 0 & - \\
\hline p2(IT) & 500 & psi \\
\hline $\operatorname{tw}(\mathrm{IT})$ & 464 & $\mathrm{~F}$ \\
\hline go(IT) & 0 & $\mathrm{lb} / \mathrm{hr}-\mathrm{ft} \wedge 2$ \\
\hline pitch & 0.56 & inches \\
\hline icor & 0 & - \\
\hline crdt & 0 & mils \\
\hline crdtr & 0 & mils/hr \\
\hline flux $(J)$ & $5.00 \mathrm{E}+15$ & \\
\hline im & 349 & - \\
\hline $\mathrm{nr}$ & 25 & - \\
\hline ngasr & 45 & - \\
\hline ngasmod & 2 & - \\
\hline na & 18 & - \\
\hline nunits & 1 & - \\
\hline
\end{tabular}

\begin{tabular}{|c|c|c|}
\hline \multicolumn{3}{|c|}{ IFA-432 Rod 5} \\
\hline Variable & Value & Units \\
\hline dco & 0.5031 & inches \\
\hline thkcld & 0.0370 & inches \\
\hline thkgap & 0.0045 & inches \\
\hline totl & 1.8986 & feet \\
\hline cpl & 2.0000 & inches \\
\hline dspg & 0.3500 & inches \\
\hline dspgw & 0.0300 & inches \\
\hline vs & 5.0000 & - \\
\hline hplt & 0.5118 & inches \\
\hline rc & 0.0345 & inches \\
\hline dishsd & 0.2100 & inches \\
\hline enrch & 10.0 & $\%$ u235 of U \\
\hline den & 92.0620 & \% TD \\
\hline roughf & 8.50E-05 & inches \\
\hline rsntr & 75 & $\mathrm{~kg} / \mathrm{m}^{\wedge} 3$ \\
\hline tsint & 3092 & $\mathrm{~F}$ \\
\hline icm & 2 & - \\
\hline zr2vinage & 0 & - \\
\hline roughc & 2.50E-05 & inches \\
\hline fgpav & 14.7 & psi \\
\hline idxgas & 1 & - \\
\hline iplant & -4 & - \\
\hline nsp & 0 & - \\
\hline p2(IT) & 500 & psi \\
\hline $\operatorname{tw}(\mathrm{IT})$ & 464 & F \\
\hline go(IT) & 0 & $\mathrm{lb} / \mathrm{hr}-\mathrm{ft} \wedge 2$ \\
\hline pitch & 0.56 & inches \\
\hline icor & 0 & - \\
\hline crdt & 0 & mils \\
\hline crdtr & 0 & mils/hr \\
\hline flux $(J)$ & $5.00 \mathrm{E}+15$ & \\
\hline im & 334 & \\
\hline $\mathrm{nr}$ & 25 & - \\
\hline ngasr & 45 & - \\
\hline ngasmod & 2 & - \\
\hline na & 18 & - \\
\hline nunits & 1 & - \\
\hline
\end{tabular}


Table A.3. FRAPCON input parameters for IFA-432 Rod 6

\begin{tabular}{|c|c|c|}
\hline \multicolumn{3}{|c|}{ IFA-432 Rod 6} \\
\hline Variable & Value & Units \\
\hline dco & 0.5031 & inches \\
\hline thkcld & 0.0370 & inches \\
\hline thkgap & 0.0045 & inches \\
\hline totl & 1.8904 & feet \\
\hline cpl & 2.0000 & inches \\
\hline dspg & 0.3500 & inches \\
\hline dspgw & 0.0300 & inches \\
\hline vs & 5.0000 & - \\
\hline hplt & 0.5118 & inches \\
\hline rc & 0.0345 & inches \\
\hline dishsd & 0.2100 & inches \\
\hline enrch & 10.0000 & $\%$ u235 of U \\
\hline den & 95.0730 & \% TD \\
\hline roughf & 8.50E-05 & inches \\
\hline rsntr & 75 & $\mathrm{~kg} / \mathrm{m}^{\wedge} 3$ \\
\hline tsint & 3092 & $\mathrm{~F}$ \\
\hline icm & 2 & - \\
\hline zr2vinage & 0 & - \\
\hline roughc & $2.50 \mathrm{E}-05$ & inches \\
\hline fgpav & 14.7 & psi \\
\hline idxgas & 1 & - \\
\hline iplant & -4 & - \\
\hline nsp & 0 & - \\
\hline p2(IT) & 500 & psi \\
\hline $\operatorname{tw}(\mathrm{IT})$ & 464 & $\mathrm{~F}$ \\
\hline go(IT) & 0 & $\mathrm{lb} / \mathrm{hr}-\mathrm{ft} \wedge 2$ \\
\hline pitch & 0.56 & inches \\
\hline icor & 0 & - \\
\hline crdt & 0 & mils \\
\hline crdtr & 0 & mils/hr \\
\hline flux(J) & $5.00 \mathrm{E}+15$ & \\
\hline $\mathrm{im}$ & 244 & - \\
\hline $\mathrm{nr}$ & 25 & - \\
\hline ngasr & 45 & - \\
\hline ngasmod & 2 & - \\
\hline na & 18 & - \\
\hline nunits & 1 & - \\
\hline
\end{tabular}


IFA-597

Table A.4. FRAPCON input parameters for IFA-597 Rod 8

\begin{tabular}{|c|c|c|}
\hline \multicolumn{3}{|c|}{ IFA-597 Rod 8} \\
\hline Variable & Value & Units \\
\hline dco & 0.4823 & inches \\
\hline thkcld & 0.0315 & inches \\
\hline thkgap & 0.0041 & inches \\
\hline totl & 1.3642 & feet \\
\hline cpl & 2 & inches \\
\hline dspg & 0.4 & inches \\
\hline dspgw & 0.003 & inches \\
\hline vs & 20 & - \\
\hline hplt & 0.4291 & inches \\
\hline rc & 0 & inches \\
\hline hdish & 0.0039 & inches \\
\hline dishsd & 0.2055 & inches \\
\hline enrch & 3.347 & $\%$ u235 of U \\
\hline den & 95.5 & \% TD \\
\hline roughf & 8.50E-05 & inches \\
\hline rsntr & 75 & $\mathrm{~kg} / \mathrm{m}^{\wedge} 3$ \\
\hline tsint & 3092 & $\mathrm{~F}$ \\
\hline icm & 2 & - \\
\hline zr2vintage & 0 & - \\
\hline roughc & $4.50 \mathrm{E}-05$ & inches \\
\hline fgpav & 14.5038 & psi \\
\hline idxgas & 1 & - \\
\hline iplant & -4 & - \\
\hline nsp & 1 & - \\
\hline p2(IT) & & psi \\
\hline $\operatorname{tw}(\mathrm{IT})$ & 449.6 & $\mathrm{~F}$ \\
\hline go(IT) & & $\mathrm{lb} / \mathrm{hr}-\mathrm{ft} \wedge 2$ \\
\hline pitch & 0.56 & inches \\
\hline icor & 0 & - \\
\hline crdt & 0 & mils \\
\hline crdtr & 0 & mils/hr \\
\hline flux $(J)$ & $1.78 \mathrm{E}+16$ & \\
\hline im & 386 & - \\
\hline $\mathrm{nr}$ & 25 & - \\
\hline ngasr & 45 & - \\
\hline ngasmod & 2 & - \\
\hline na & 18 & - \\
\hline nunits & 1 & - \\
\hline
\end{tabular}


Table A.5. FRAPCON input parameters for IFA-597mox Rods 1 and 2

\begin{tabular}{|c|c|c|}
\hline \multicolumn{3}{|c|}{ IFA-597mox Rod 1} \\
\hline Variable & Value & Units \\
\hline dco & 0.3740 & inches \\
\hline thkcld & 0.0252 & inches \\
\hline thkgap & 0.0033 & inches \\
\hline totl & 0.7349 & feet \\
\hline cpl & 1.6154 & inches \\
\hline dspg & 0.3150 & inches \\
\hline dspgw & 0.0394 & inches \\
\hline vs & 17.1613 & - \\
\hline hplt & 0.4134 & inches \\
\hline rc & 0.0000 & inches \\
\hline hdish & 0.0102 & inches \\
\hline dishsd & 0.0541 & inches \\
\hline enrch & 0.2520 & $\%$ u235 of U \\
\hline imox & 1 & - \\
\hline moxtype & 1 & - \\
\hline comp & 7.4240 & wt. \% \\
\hline enrpu39 & 65.9474 & wt. \% \\
\hline enrpu40 & 23.8951 & wt. \% \\
\hline enrpu41 & 6.6311 & wt. \% \\
\hline enrpu42 & 3.5265 & wt. \% \\
\hline fotmtl & 1.9990 & - \\
\hline den & 95.5 & $\% \mathrm{TD}$ \\
\hline roughf & 5.51E-05 & inches \\
\hline rsntr & 48.772 & $\mathrm{~kg} / \mathrm{m}^{\wedge} 3$ \\
\hline tsint & 3092 & $\mathrm{~F}$ \\
\hline icm & 4 & - \\
\hline cldwks & 0.5 & - \\
\hline roughc & 5.91E-06 & inches \\
\hline fgpav & 72.5189 & psi \\
\hline idxgas & 1 & - \\
\hline iplant & -4 & - \\
\hline nsp & 0 & - \\
\hline p2(IT) & 487.3268 & psi \\
\hline $\operatorname{tw}(\mathrm{IT})$ & 464 & $\mathrm{~F}$ \\
\hline go(IT) & 0 & $\mathrm{lb} / \mathrm{hr}-\mathrm{ft} \wedge 2$ \\
\hline pitch & 0.56 & inches \\
\hline flux $(J)$ & $1.50 \mathrm{E}+15$ & - \\
\hline im & 163 & \\
\hline $\mathrm{nr}$ & 25 & - \\
\hline ngasr & 45 & - \\
\hline na & 18 & - \\
\hline nunits & 1 & - \\
\hline
\end{tabular}

\begin{tabular}{|c|c|c|}
\hline \multicolumn{3}{|c|}{ IFA-597mox Rod 2} \\
\hline Variable & Value & Units \\
\hline dco & 0.3740 & inches \\
\hline thkcld & 0.0252 & inches \\
\hline thkgap & 0.0033 & inches \\
\hline totl & 0.7218 & feet \\
\hline cpl & 1.6154 & inches \\
\hline dspg & 0.3150 & inches \\
\hline dspgw & 0.0394 & inches \\
\hline vs & 25.1921 & - \\
\hline hplt & 0.4134 & inches \\
\hline rc & 0.0354 & inches \\
\hline hdish & 0.0102 & inches \\
\hline dishsd & 0.0541 & inches \\
\hline enrch & 0.2520 & $\%$ u235 of U \\
\hline imox & 1 & - \\
\hline moxtype & 1 & - \\
\hline comp & 7.4240 & wt. \% \\
\hline enrpu39 & 65.9474 & wt. \% \\
\hline enrpu40 & 23.8951 & wt. \% \\
\hline enrpu41 & 6.6311 & wt. \% \\
\hline enrpu42 & 3.5265 & wt. \% \\
\hline fotmtl & 1.9990 & - \\
\hline den & 95.5 & $\% \mathrm{TD}$ \\
\hline roughf & 5.51E-05 & inches \\
\hline rsntr & 48.772 & $\mathrm{~kg} / \mathrm{m}^{\wedge} 3$ \\
\hline tsint & 3092 & $\mathrm{~F}$ \\
\hline icm & 4 & - \\
\hline cldwks & 0.5 & - \\
\hline roughc & 5.91E-06 & inches \\
\hline fgpav & 72.5189 & psi \\
\hline idxgas & 1 & - \\
\hline iplant & -4 & - \\
\hline nsp & 0 & - \\
\hline p2(IT) & 487.3268 & psi \\
\hline $\operatorname{tw}(\mathrm{IT})$ & 464 & F \\
\hline go(IT) & 0 & $\mathrm{lb} / \mathrm{hr}-\mathrm{ft} \wedge 2$ \\
\hline pitch & 0.56 & inches \\
\hline flux $(J)$ & $1.50 \mathrm{E}+15$ & - \\
\hline $\mathrm{im}$ & 163 & \\
\hline $\mathrm{nr}$ & 25 & - \\
\hline ngasr & 45 & - \\
\hline na & 18 & - \\
\hline nunits & 1 & - \\
\hline
\end{tabular}




\section{APPENDIX B: FRAPCON RESULTS FOR IFA-432}

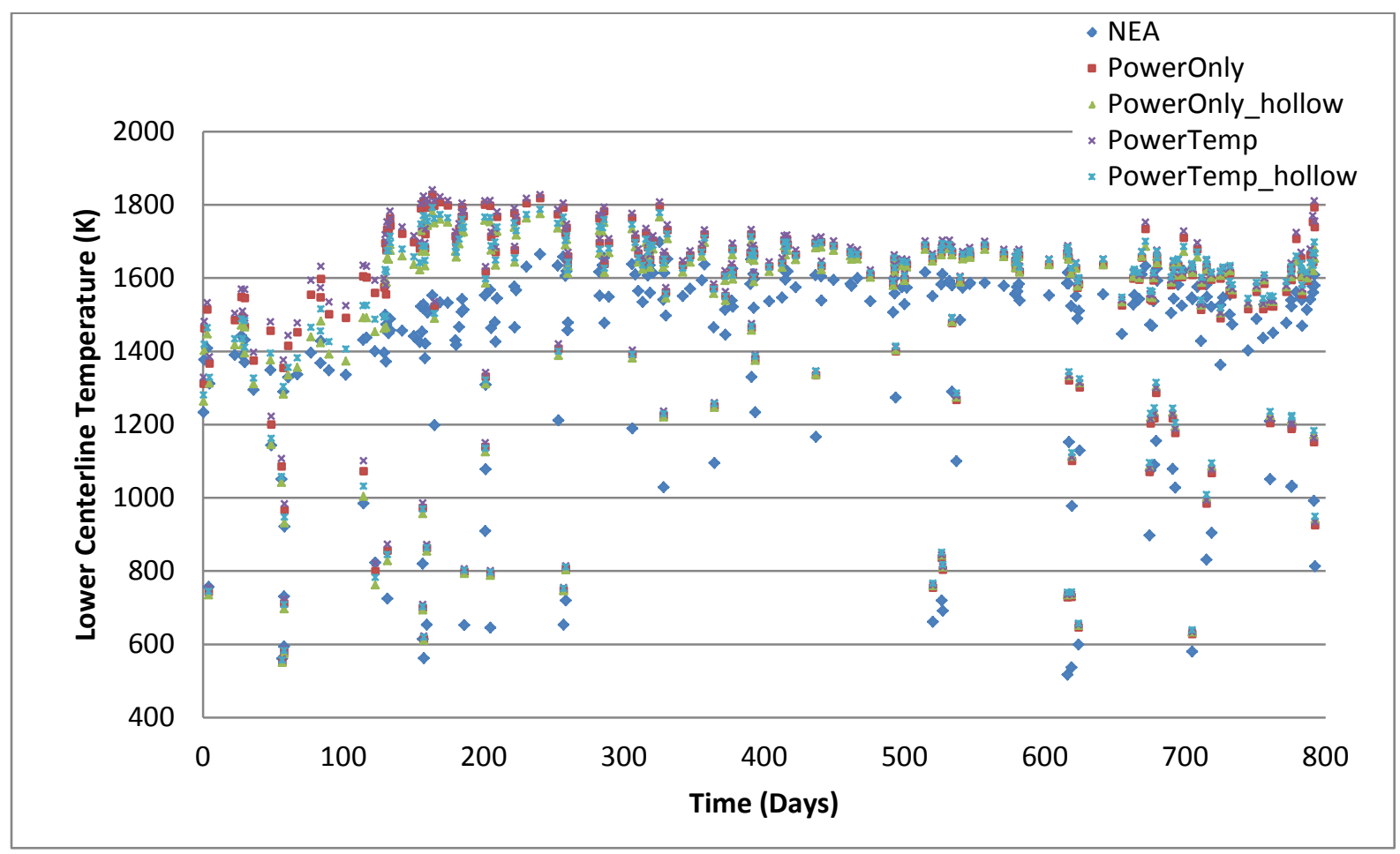

Fig. B.1. IFA-432 Rod 1 FRAPCON centerline temperature results.

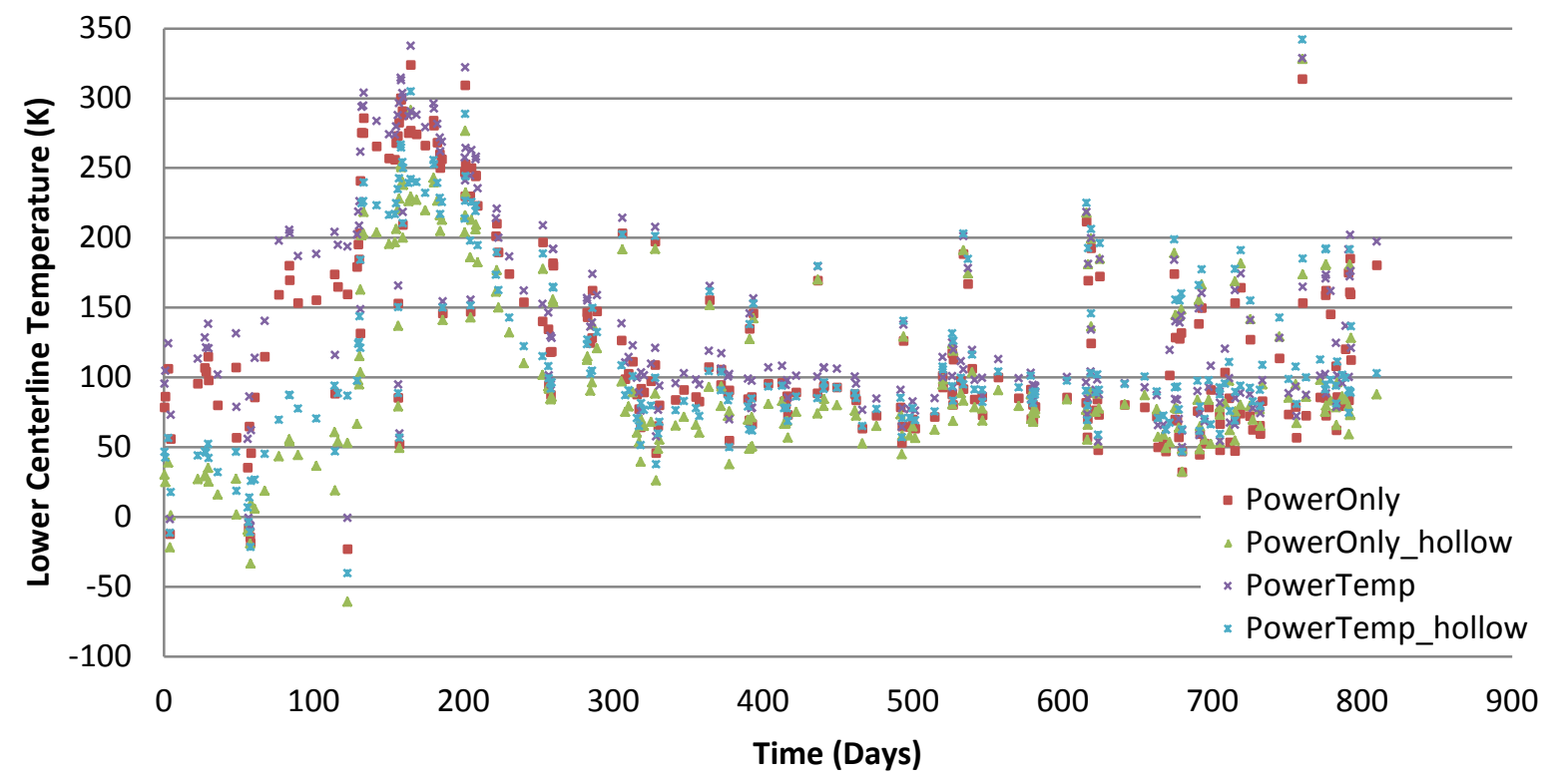

Fig. B.2. IFA-432 Rod 1 FRAPCON centerline temperature error. 


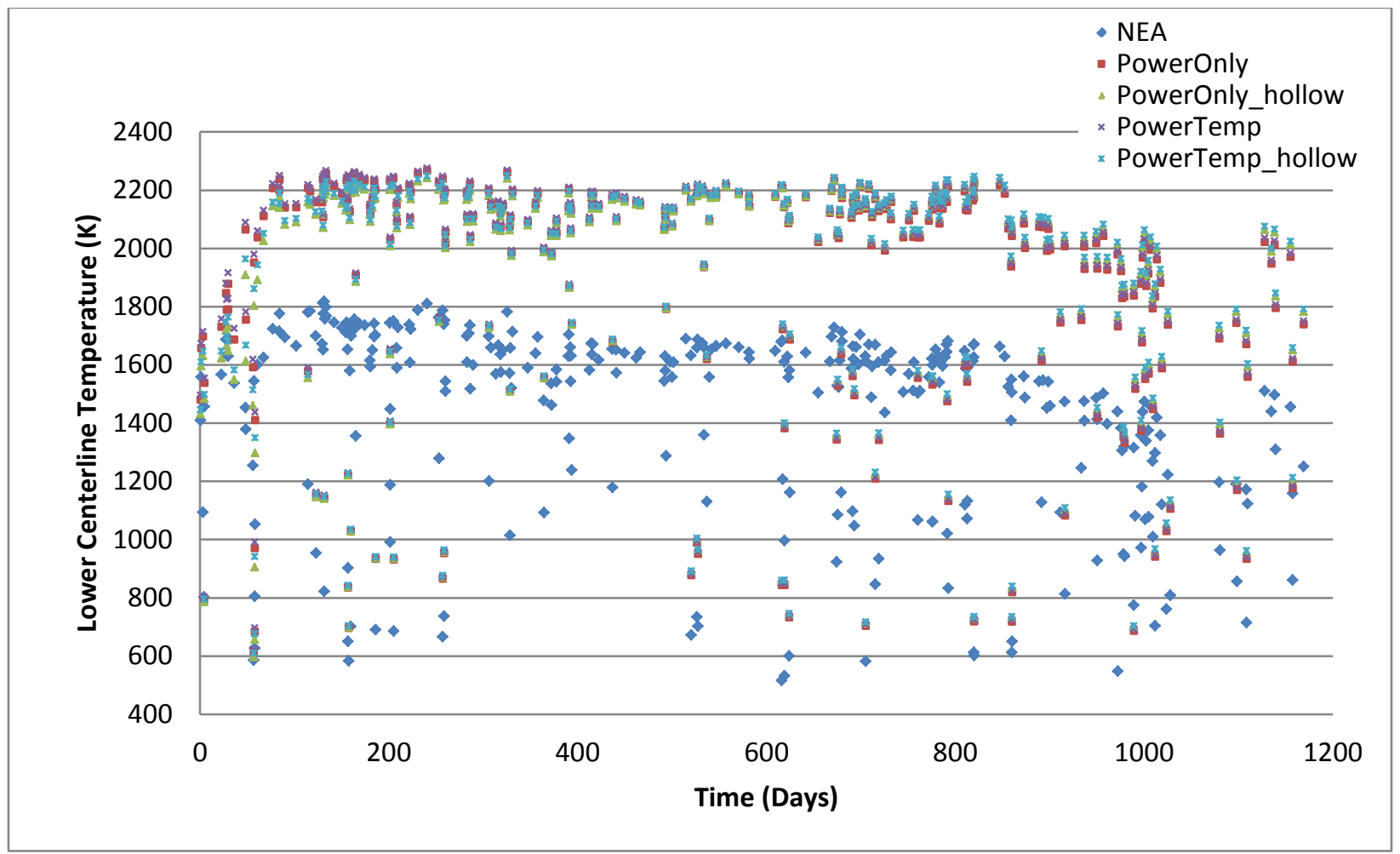

Fig. B.3. IFA-432 Rod 2 FRAPCON centerline temperature results.

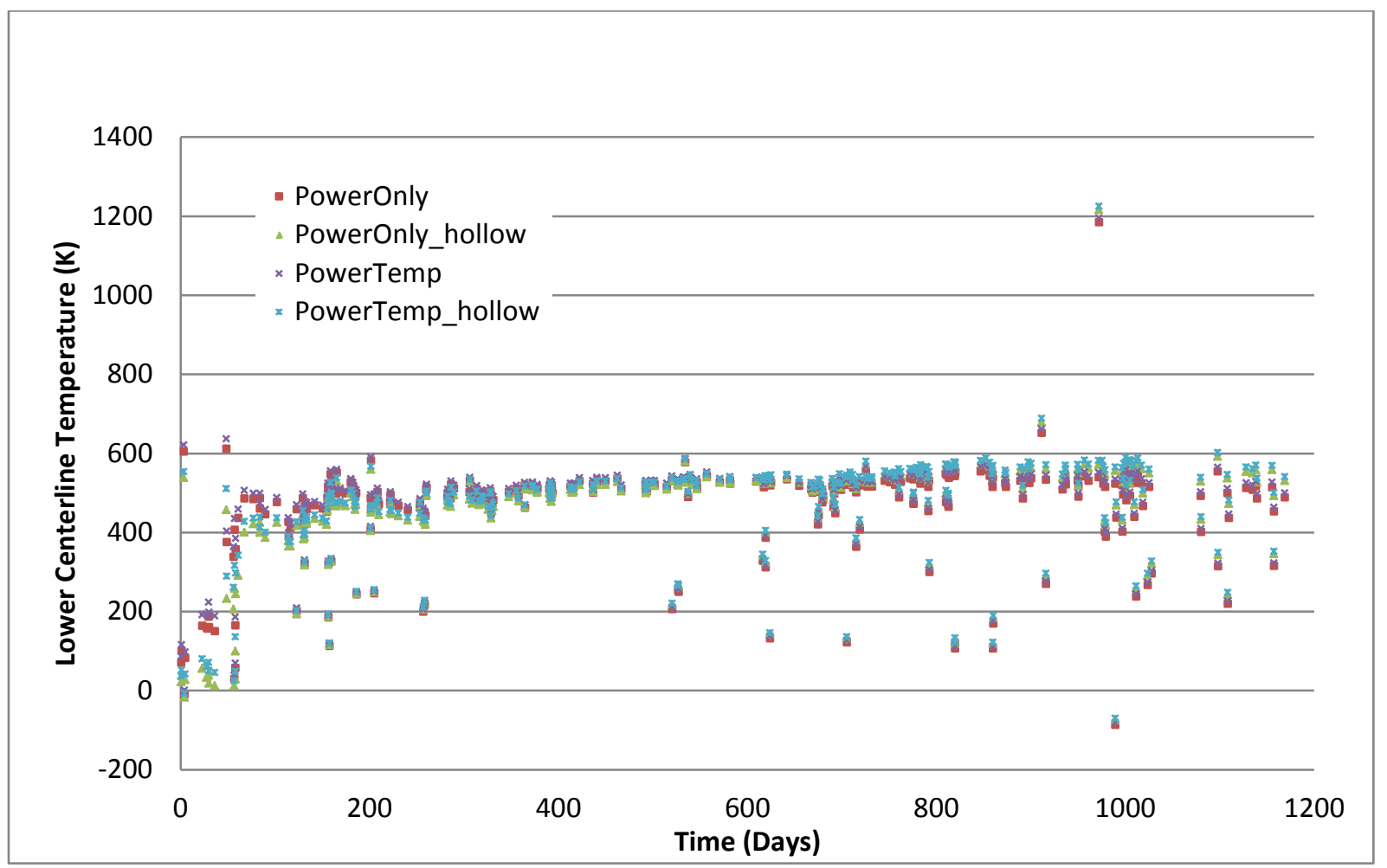

Fig. B.4. IFA-432 Rod 2 FRAPCON centerline temperature error. 


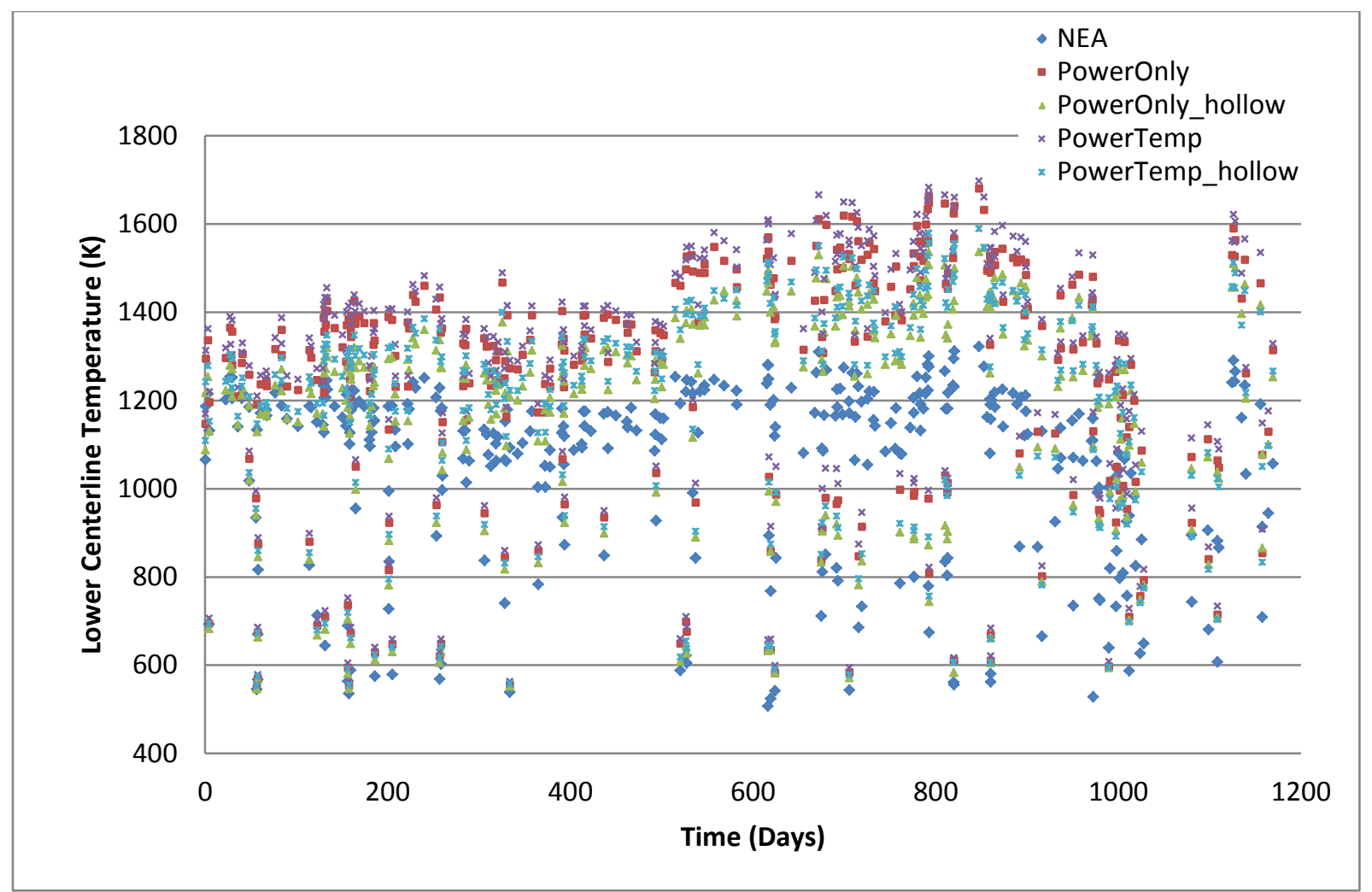

Fig. B.5. IFA-432 Rod 3 FRAPCON centerline temperature results.

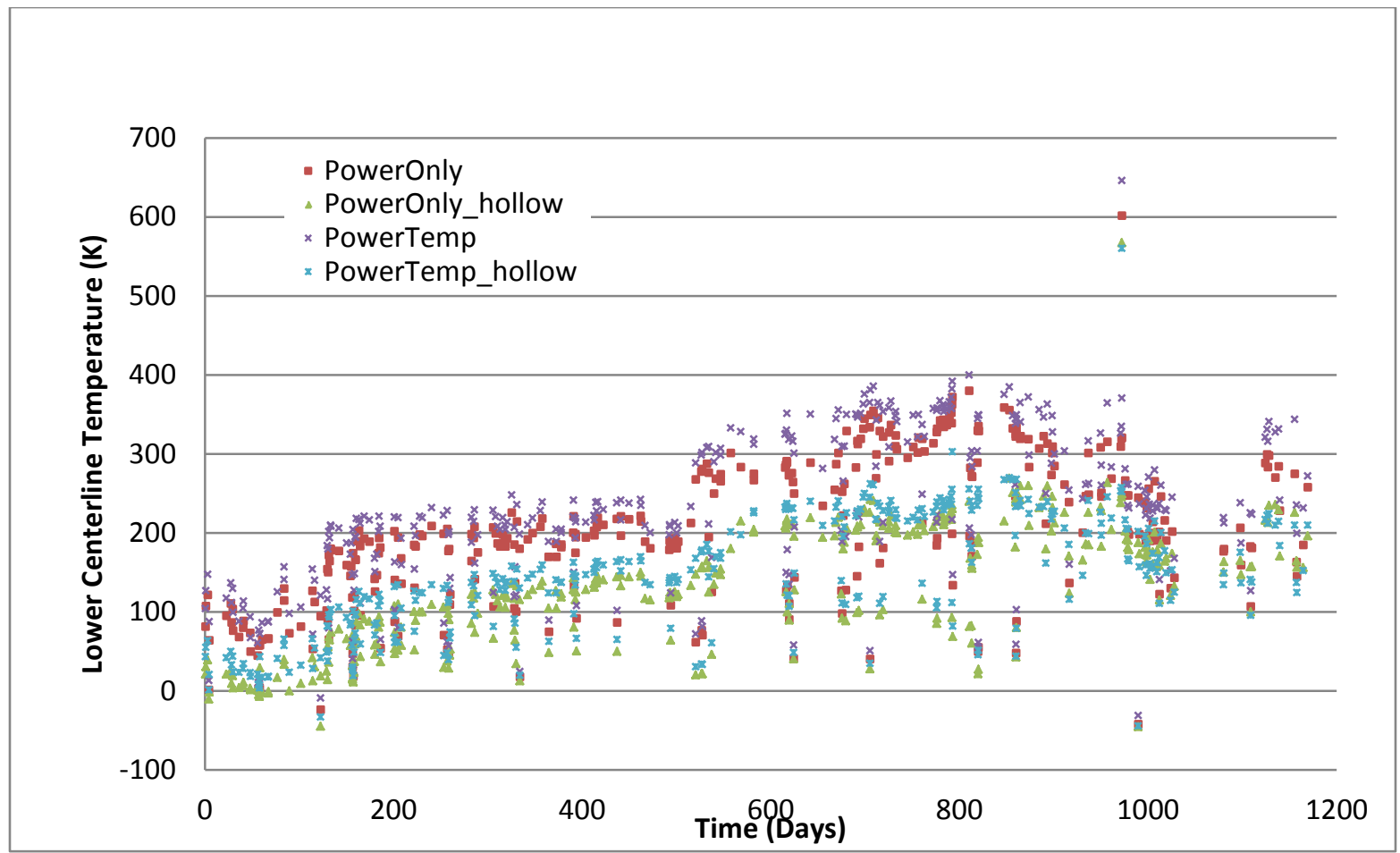

Fig. B.6. IFA-432 Rod 3 FRAPCON centerline temperature error. 


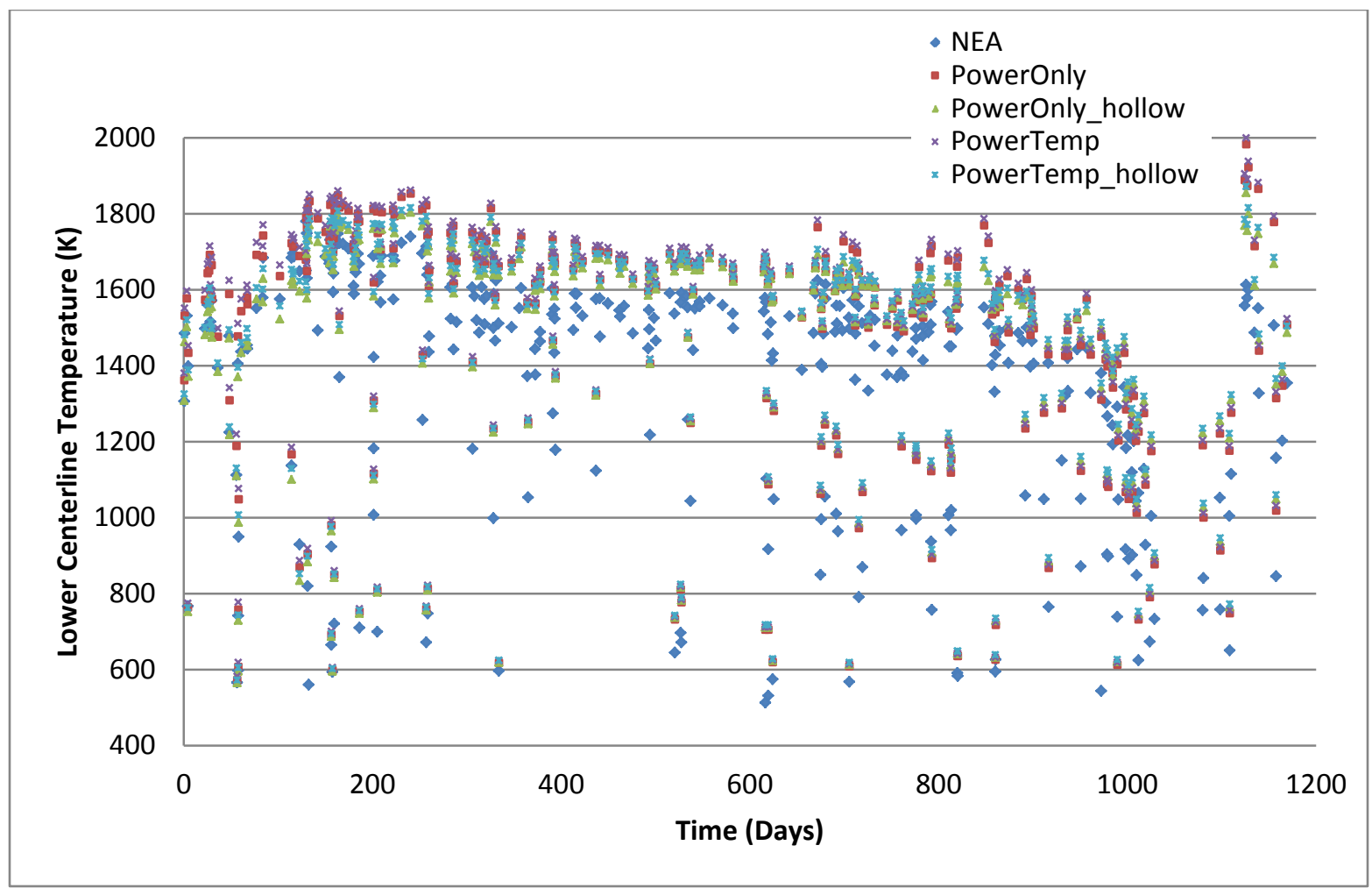

Fig. B.7. IFA-432 Rod 5 FRAPCON centerline temperature results.

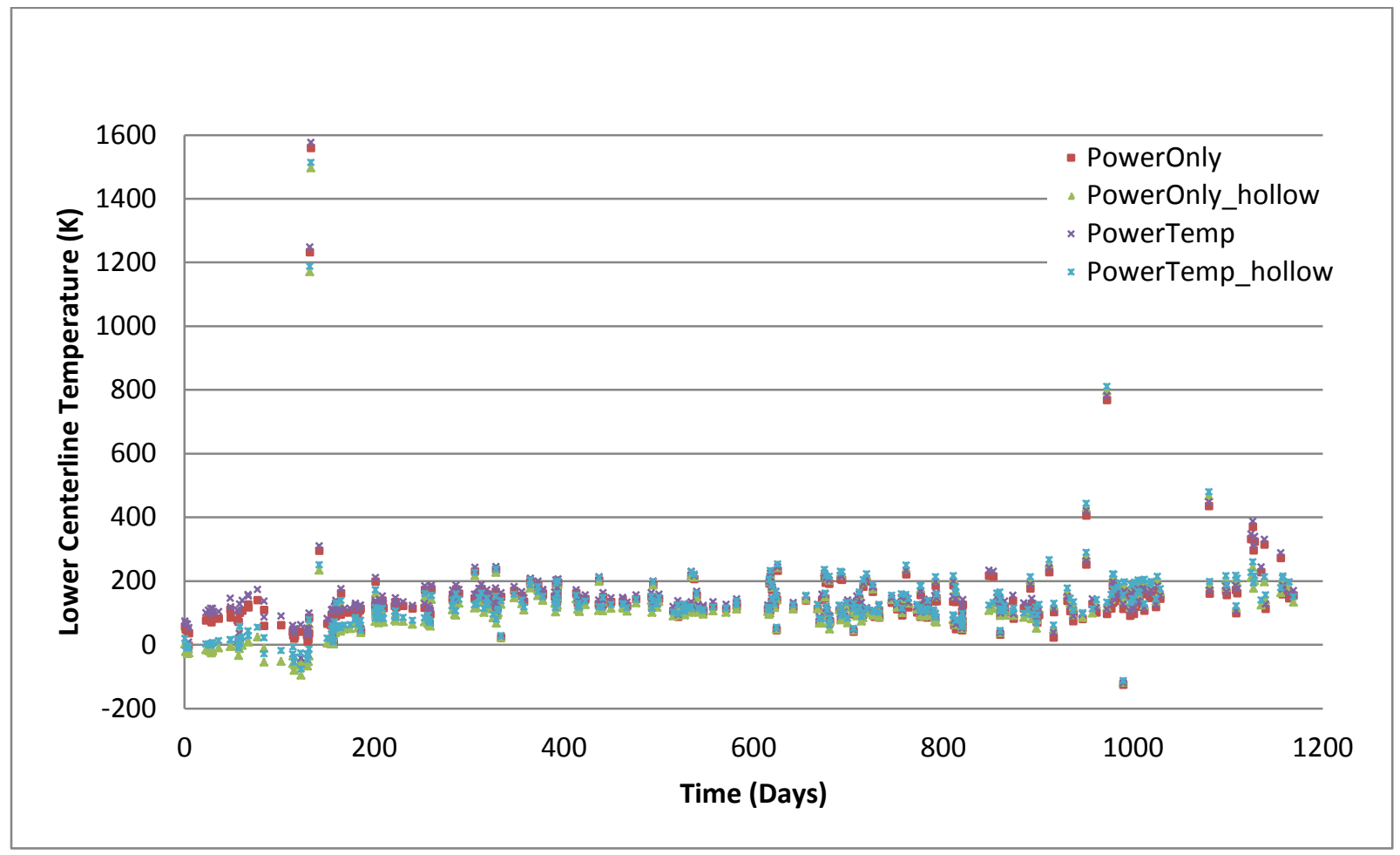

Fig. B.8. IFA-432 Rod 5 FRAPCON centerline temperature error. 


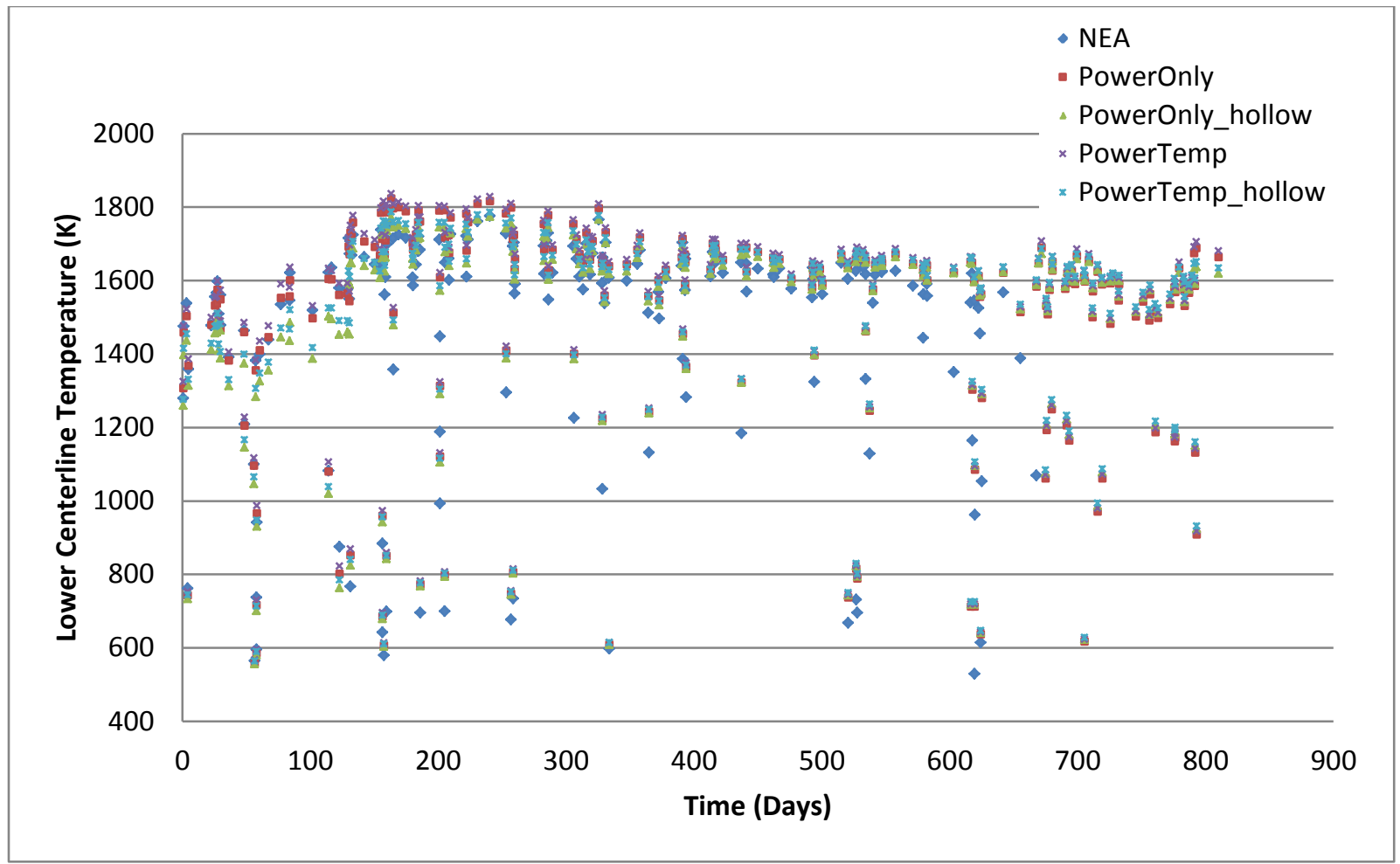

Fig. B.9. IFA-432 Rod 6 FRAPCON centerline temperature results.

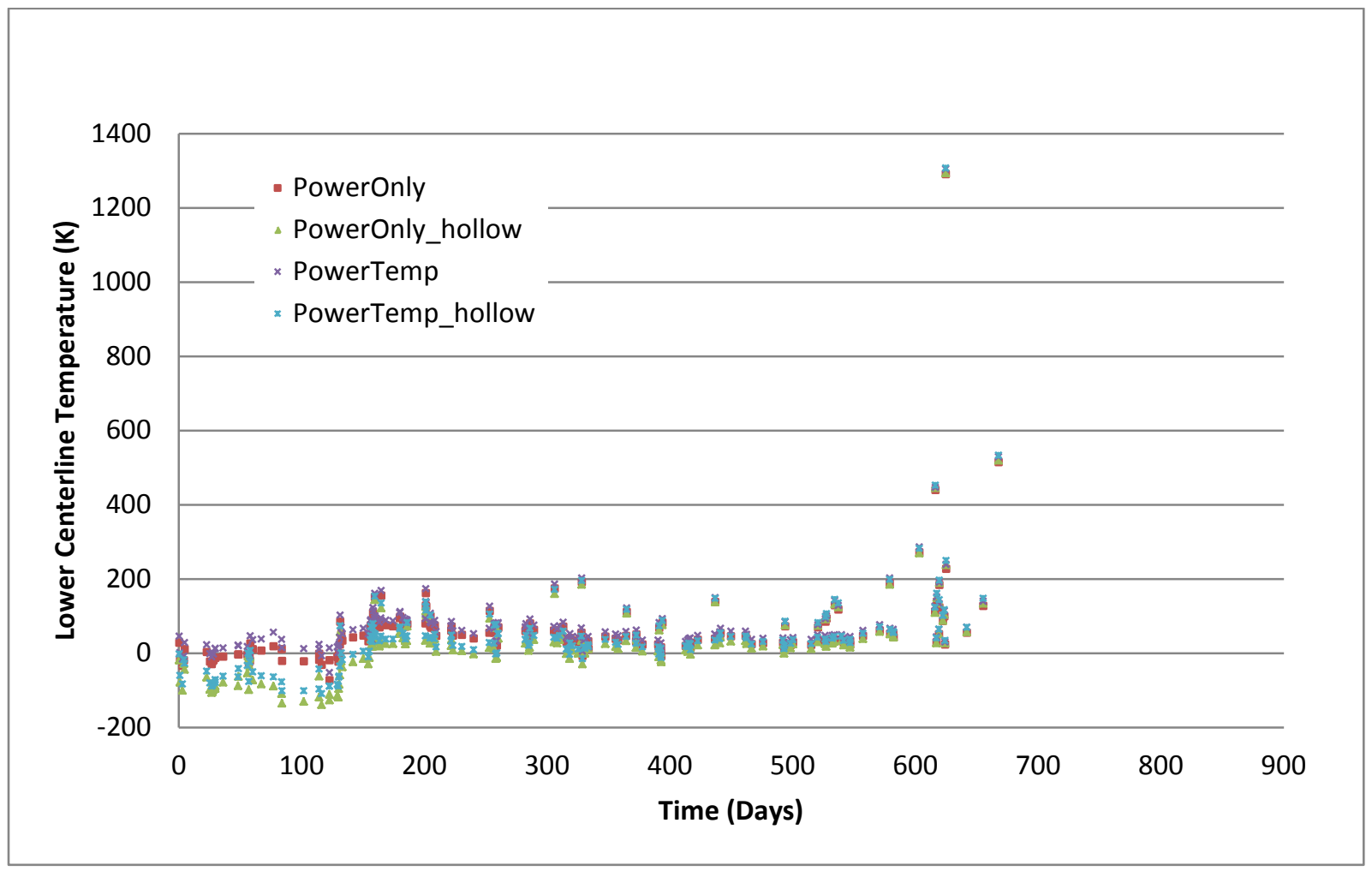

Fig. B.10. IFA-432 Rod 6 FRAPCON centerline temperature results. 



\section{APPENDIX C: FRAPCON RESULTS FOR IFA-597mox}

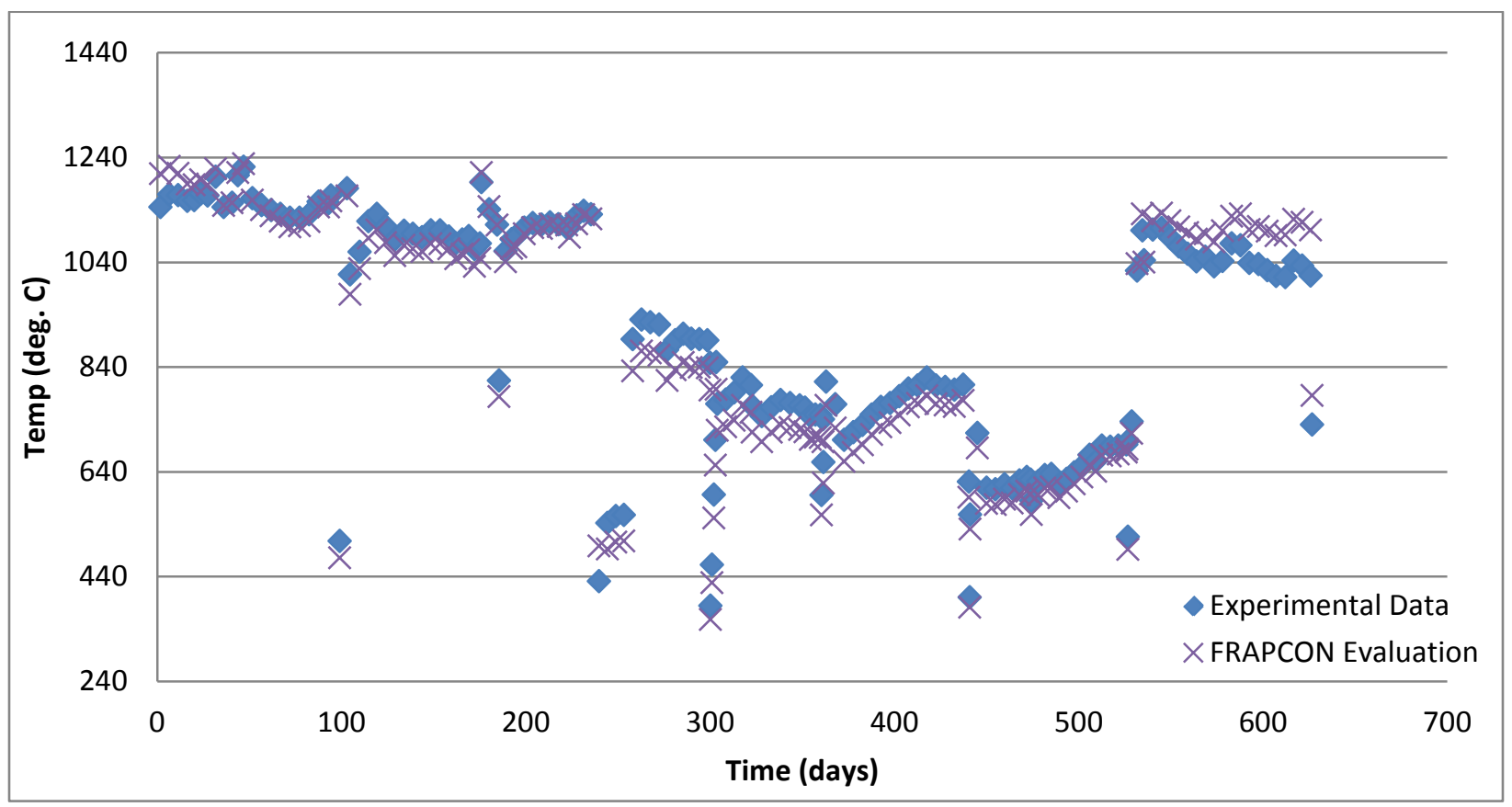

Fig. C.1. IFA-597mox Rod 1 centerline temperature comparison using Halden correlation (PowerOnly).

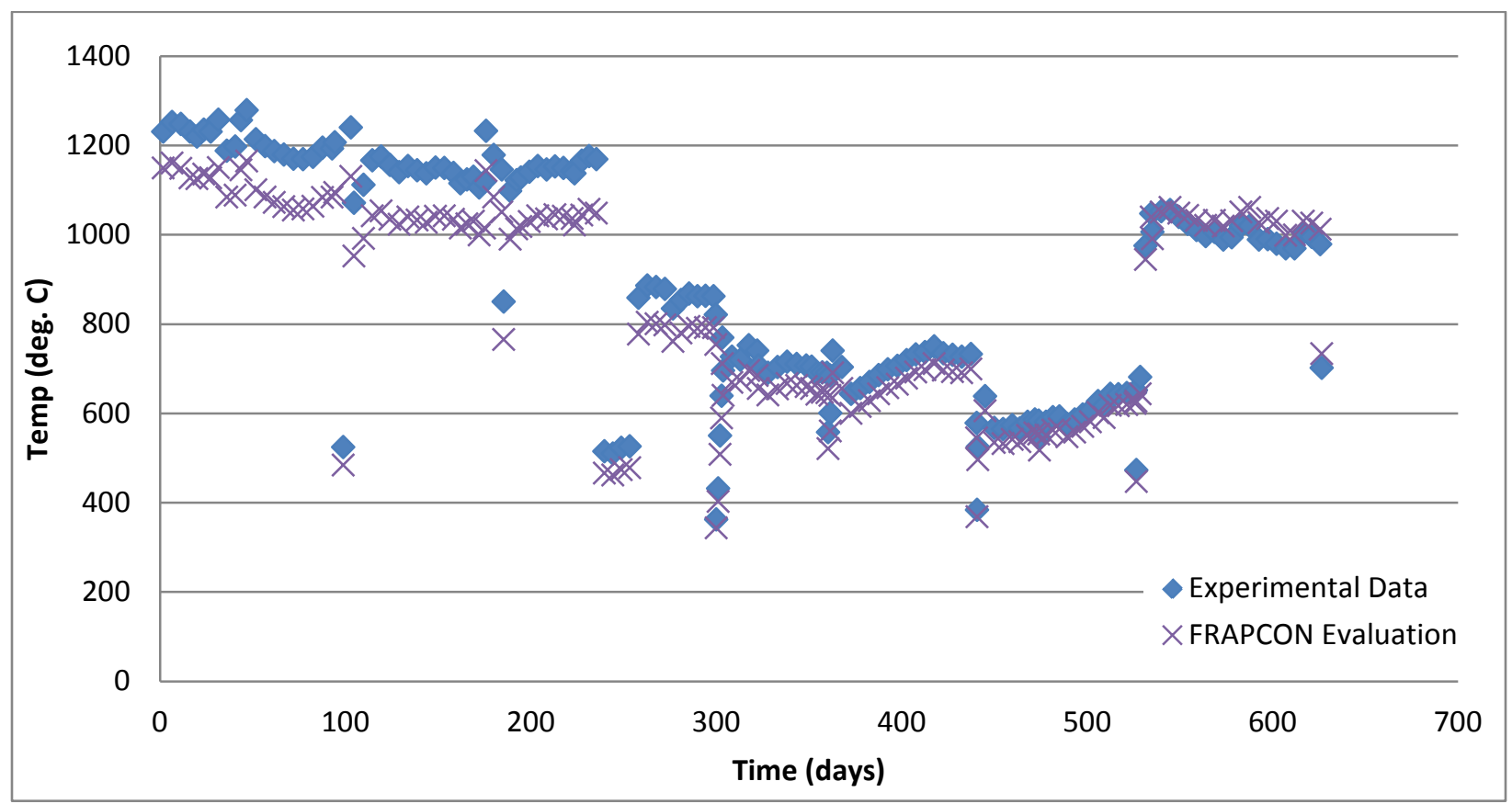

Fig. C.2. IFA-597mox Rod 2 centerline temperature comparison using Halden correlation (PowerTemp). 


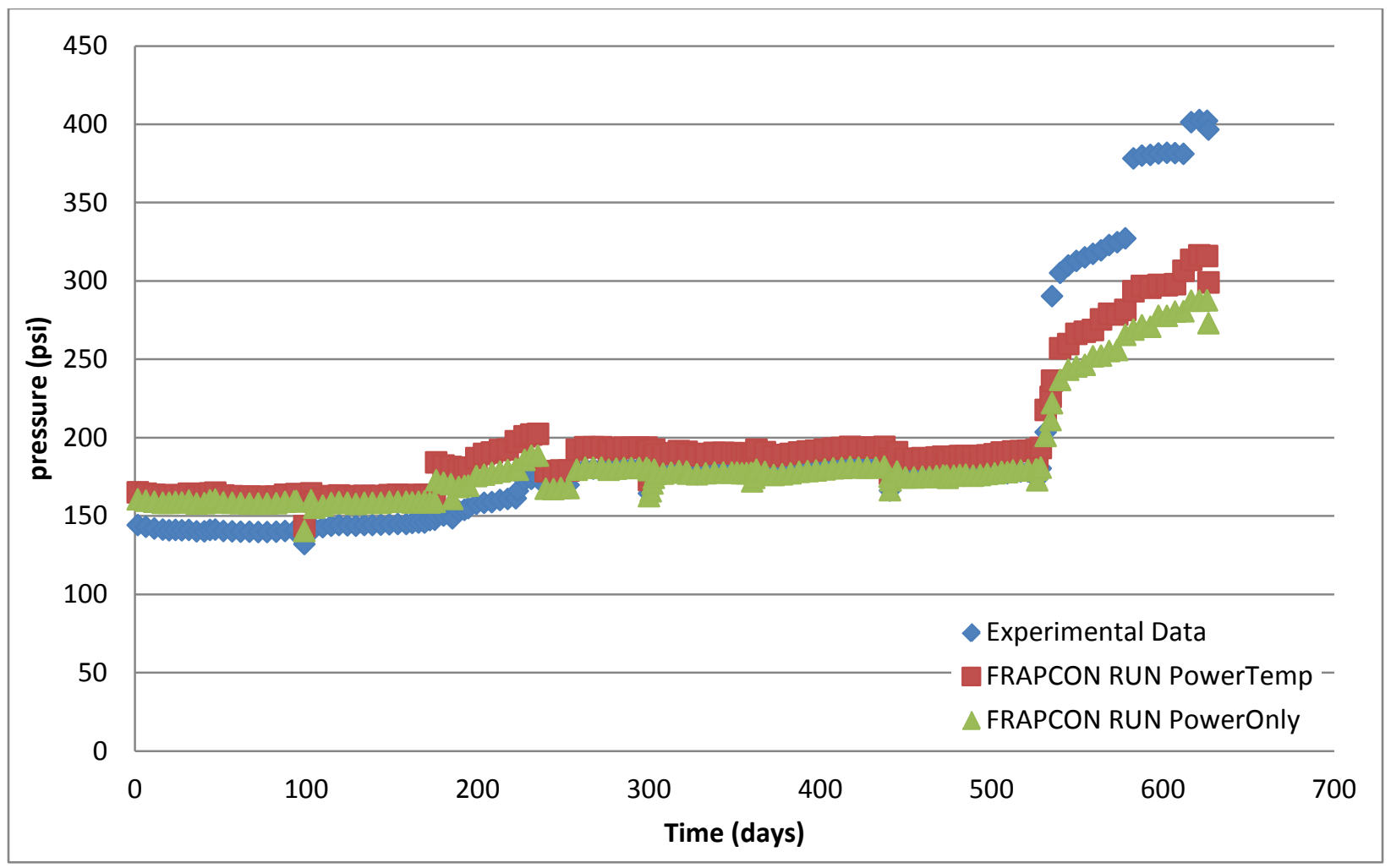

Fig. C.3. IFA-597mox Rod 1 plenum pressure comparison using Halden correlation.

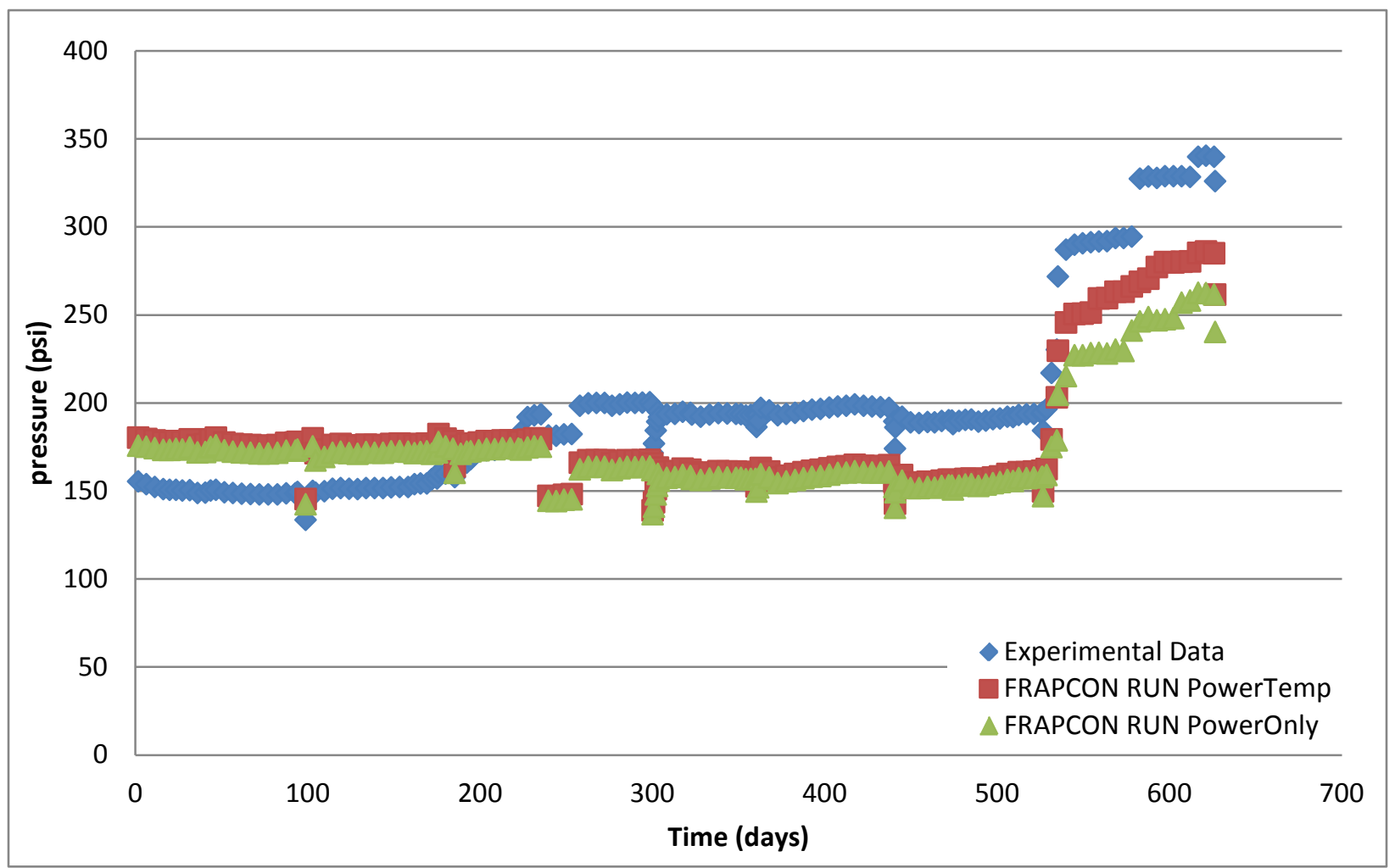

Fig. C.4. IFA-597mox Rod 2 plenum pressure comparison using Halden correlation. 


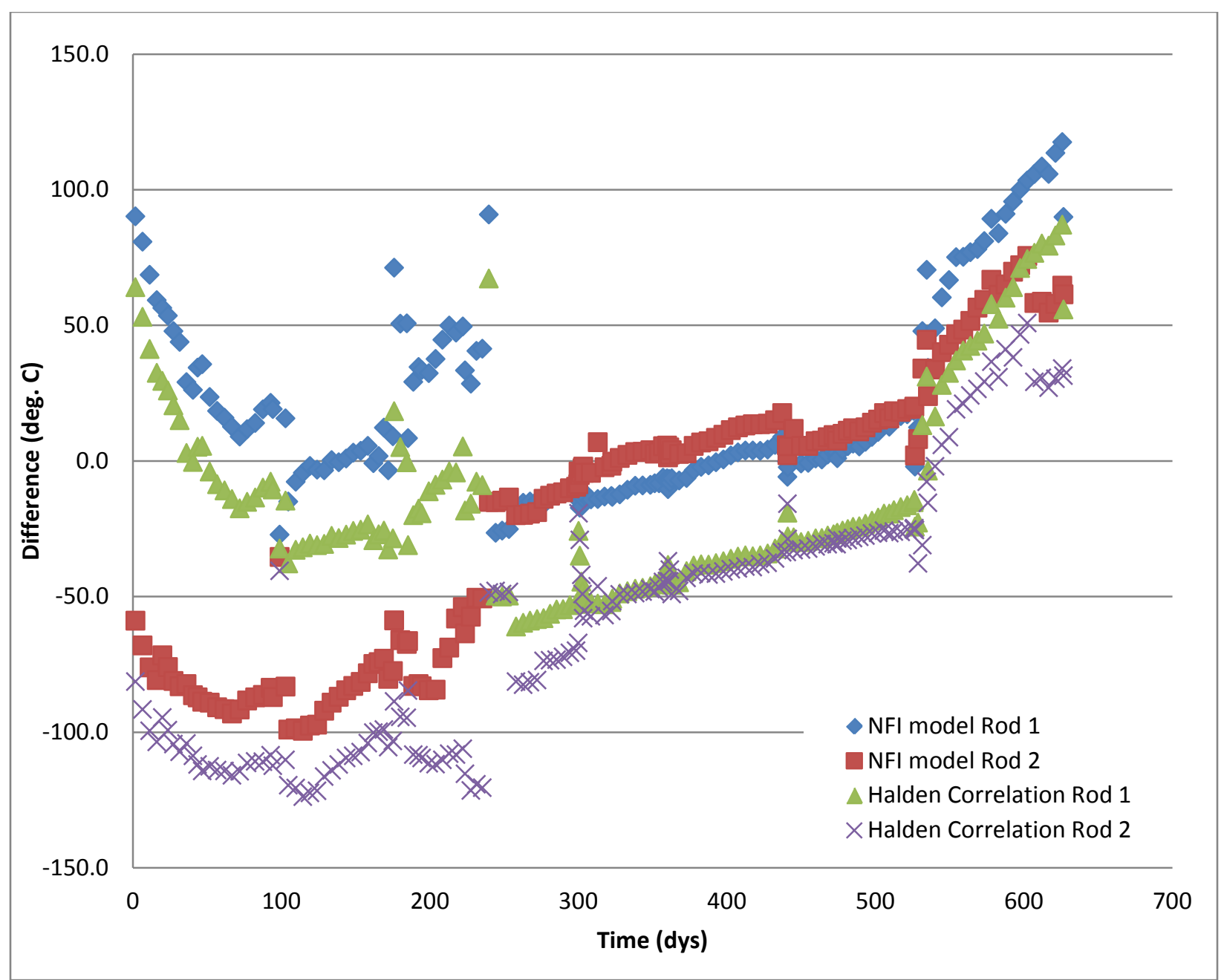

Fig. C.5. Differences between experimental and predicted centerline temperatures for IFA-597mox, Rods 1 and 2, given two different conductivity models. 